\title{
IntechOpen
}

\author{
IntechOpen Book Series
}

Biochemistry, Volume 5

\section{Oral Health by Using Probiotic Products}

Edited by Razzagh Mahmoudi 



\section{Oral Health by Using Probiotic Products}

Edited by Razzagh Mahmoudi 

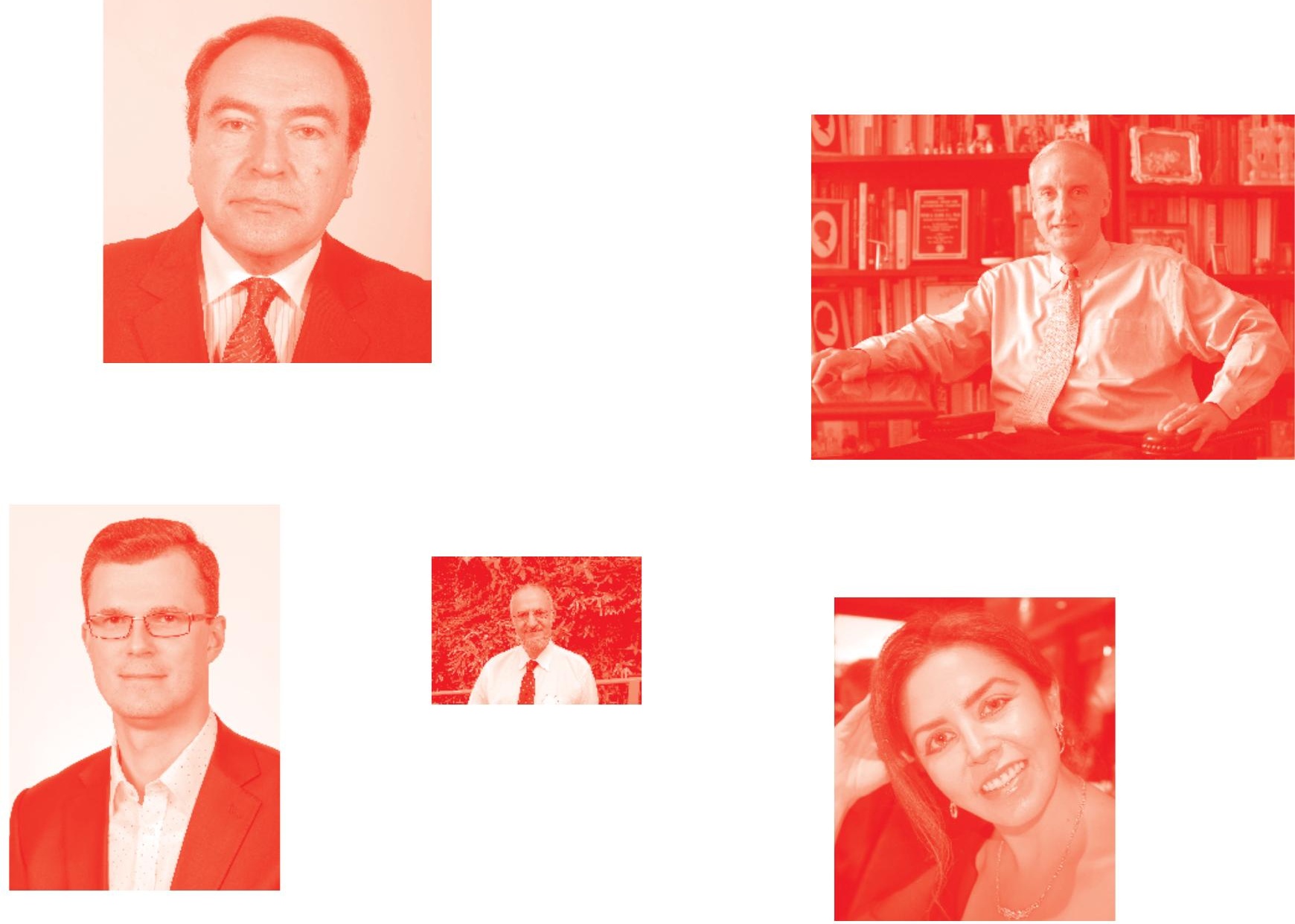

Supporting open minds since 2005
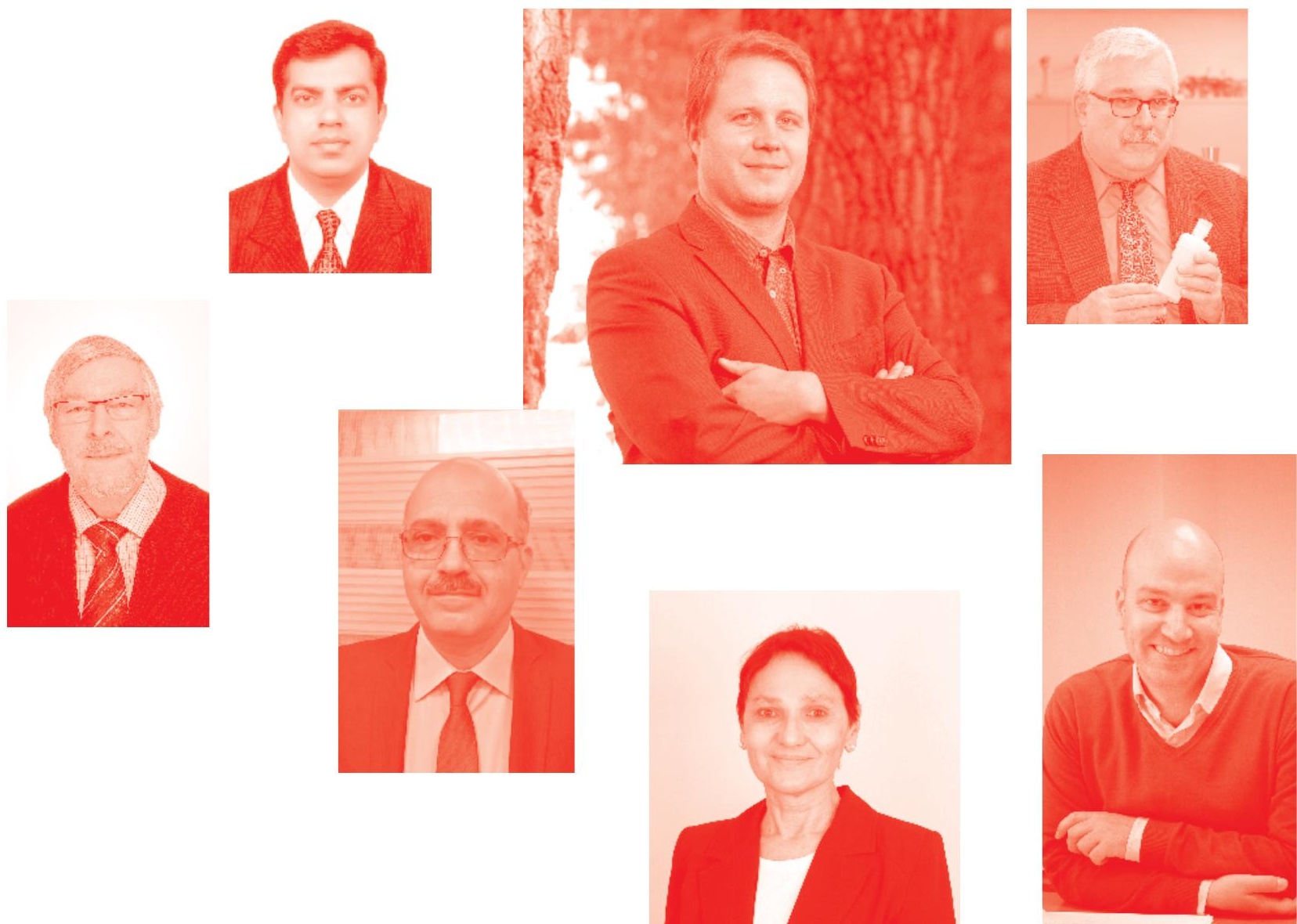
Oral Health by Using Probiotic Products

http: //dx. doi. org/10.5772/intechopen. 78421

Edited by Razzagh Mahmoudi

Part of IntechOpen Book Series: Biochemistry, Volume 5

Book Series Editor: Miroslav Blumenberg

\section{Contributors}

Nabila Gulzar, Iqra Muqaddas, Saima Rafiq, Muhammad Nadeem, Cheng, Sha Jiang, Jiaying Hu, Razzagh Mahmoudi, Vladimir Mikhailovitch Lakhtin, Mikhail Lakhtin, Vladimir Aleshkin, Stanislav Afanasiev, Silvana Cisternas, Alejandra Cruz, Carolina Díaz, Ricardo Muñoz, Marcia Rivas, Paula Carrasco

() The Editor(s) and the Author(s) 2019

The rights of the editor(s) and the author(s) have been asserted in accordance with the Copyright, Designs and Patents Act 1988. All rights to the book as a whole are reserved by INTECHOPEN LIMITED. The book as a whole (compilation) cannot be reproduced, distributed or used for commercial or non-commercial purposes without INTECHOPEN LIMITED's written permission. Enquiries concerning the use of the book should be directed to INTECHOPEN LIMITED rights and permissions department (permissions@intechopen.com).

Violations are liable to prosecution under the governing Copyright Law .

\section{(cc) BY}

Individual chapters of this publication are distributed under the terms of the Creative Commons Attribution 3.๑ Unported License which permits commercial use, distribution and reproduction of the individual chapters, provided the original author(s) and source publication are appropriately acknowledged. If so indicated, certain images may not be included under the Creative Commons license. In such cases users will need to obtain permission from the license holder to reproduce the material. More details and guidelines concerning content reuse and adaptation can be found at http : //www . intechopen . com/copyright-policy. html.

\section{Notice}

Statements and opinions expressed in the chapters are these of the individual contributors and not necessarily those of the editors or publisher. No responsibility is accepted for the accuracy of information contained in the published chapters. The publisher assumes no responsibility for any damage or injury to persons or property arising out of the use of any materials, instructions, methods or ideas contained in the book.

First published in London, United Kingdom, 2019 by IntechOpen

IntechOpen is the global imprint of INTECHOPEN LIMITED, registered in England and Wales , registration number: 11086078 , 7th floor, 10 Lower Thames Street, London,

EC3R 6AF, United Kingdom

Printed in Croatia

British Library Cataloguing-in-Publication Data

A catalogue record for this book is available from the British Library

Additional hard and PDF copies can be obtained from orders@intechopen .com

Oral Health by Using Probiotic Products

Edited by Razzagh Mahmoudi

p. $\mathrm{cm}$.

Print ISBN 978-1-83968-139-4

Online ISBN 978-1-83968-140-0

eBook (PDF) ISBN 978-1-83968-141-7

ISSN 2632-@983 


\section{We are IntechOpen, \\ the world's leading publisher of Open Access books}

\section{Built by scientists, for scientists}

\section{$4,500+$}

Open access books available

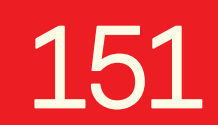

Countries delivered to

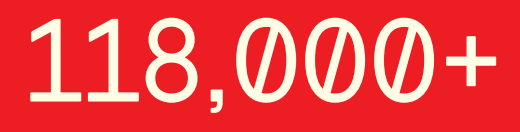

International authors and editors
$130 \mathrm{M}+$

Downloads

Our authors are among the

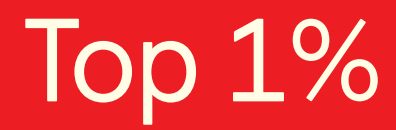

most cited scientists

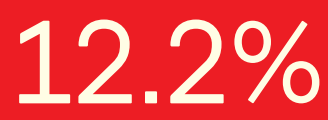

Contributors from top 500 universities

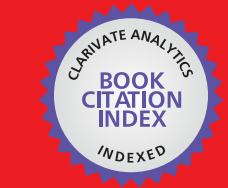

WEB OF SCIENCE ${ }^{\text {MM }}$

Selection of our books indexed in the Book Citation Index in Web of Science ${ }^{\mathrm{TM}}$ Core Collection (BKCI)

\section{Interested in publishing with us? \\ Contact book.department@intechopen.com}

Numbers displayed above are based on latest data collected.

For more information visit www.intechopen.com 



\section{IntechOpen Book Series Biochemistry Volume 5}

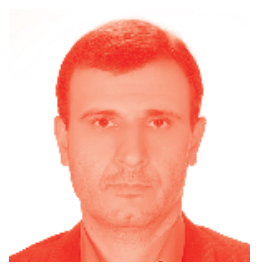

Razzagh Mahmoudi, DVM, PhD, is an associate professor of food hygiene and safety at the Department of Food Safety and Hygiene, Qazvin University of Medical Sciences, Iran. He was Educational Deputy of the Faculty of Public Health from 2010 to 2019 (member of the Founding Board at the Medical Microbiology Research Center, Qazvin University of Medical Sciences, Iran). He is an editorial board member of about five international journals. His specializations are in molecular food microbiology, functional foods, probiotics and prebiotics, medicinal plants, food chemistry, dairy and meat technology, food, and human nutrition. His research field includes molecular food microbiology, natural preservatives from medicinal plants and biological sources, production of new functional foods, application of natural preservatives in dairy and meat products, and innovative pharmacological and nutritional research in new drug production and food production. He has published around 180 papers (ISI, Scopus, PubMed, CAB, CAS, ISC, etc.), one book chapter, and 80 abstracts in national and international congresses.

\section{Editor of Volume 5: Razzagh Mahmoudi}

Qazvin University of Medical Sciences, Qazvin, Iran

Book Series Editor: Miroslav Blumenberg

NYU Langone Medical Center, New York, USA

\section{Scope of the Series}

Biochemistry, the study of chemical transformations occurring within living organisms, impacts all of life sciences, from molecular crystallography and genetics, to ecology, medicine and population biology. Biochemistry studies macromolecules proteins, nucleic acids, carbohydrates and lipids -their building blocks, structures, functions and interactions. Much of biochemistry is devoted to enzymes, proteins that catalyze chemical reactions, enzyme structures, mechanisms of action and their roles within cells. Biochemistry also studies small signaling molecules, coenzymes, inhibitors, vitamins and hormones, which play roles in the life process. Biochemical experimentation, besides coopting the methods of classical chemistry, e.g., chromatography, adopted new techniques, e.g., X-ray diffraction, electron microscopy, NMR, radioisotopes, and developed sophisticated microbial genetic tools, e.g., auxotroph mutants and their revertants, fermentation etc. More recently, biochemistry embraced the 'big data' omics systems. 
Initial biochemical studies have been exclusively analytic: dissecting, purifying and examining individual components of a biological system; in exemplary words of Efraim Racker, (1913 -1991) “Don't waste clean thinking on dirty enzymes." Today however, biochemistry is becoming more agglomerative and comprehensive, setting out to integrate and describe fully a particular biological system. The 'big data' metabolomics can define the complement of small molecules, e.g., in a soil or biofilm sample; proteomics can distinguish all the proteins comprising e.g., serum; metagenomics can identify all the genes in a complex environment e.g., bovine rumen. This Biochemistry Series will address both the current research on biomolecules, and the emerging trends with great promise. 


\section{Contents}

$\begin{array}{ll}\text { Preface } & \text { XIII }\end{array}$

$\begin{array}{ll}\text { Chapter } 1 & 1\end{array}$

Introductory Chapter: Oral Health by Using Probiotic Products

by Razzagh Mahmoudi, Sara Moosazad, Katayoon Aghaei

Chapter 2

Therapeutic Potential of Probiotics and Prebiotics

by Nabila Gulzar, Iqra Muqaddas Saleem, Saima Rafiq and Muhammad Nadeem

Chapter 3

Gut-Brain Axis: Probiotic, Bacillus subtilis, Prevents Aggression via the Modification of the Central Serotonergic System

by Heng-Wei Cheng, Sha Jiang and Jiaying Hu

Chapter 4

Oral Health by Using Probiotic Products

by Razzagh Mahmoudi, Sara Moosazad and Katayoon Aghaei

Chapter 5

Metabolite Multiprobiotic Formulas for Microbial Health

by Mikhail V. Lakhtin, Vladimir M. Lakhtin, Vladimir A. Aleshkin

and Stanislav S. Afanasiev

Chapter 6

Gut Microbiota and Obesity: Prebiotic and Probiotic Effects

by Silvana Cisternas León, Paula Carrasco Vergara, Alejandra Cruz Neira, Ricardo Muñoz Maldonado, Carolina Díaz Araneda and Marcia Rivas Zuñiga 



\section{Preface}

In this book, the importance of using probiotics and probiotic foods in oral and oral health has been studied. The contents of the book include oral health and effective factors, probiotic microarmonts, probiotic foods, probiotics and dental caries, probiotics, and oral fungal infections. The most suitable probiotic strains that can be used in food and that are appropriate for the prevention of oral and dental problems are also discussed.

Razzagh Mahmoudi

Qazvin University of Medical Sciences,

Qazvin, Iran 



\title{
Chapter 1
}

\section{Introductory Chapter: Oral Health by Using Probiotic Products}

\author{
Razzagh Mahmoudi, Sara Moosazad, Katayoon Aghaei
}

\section{Oral health}

Oral health is one of the most important health issues and tooth decay raises a great deal of concern about that and with widespread public concern about the use of industrial drugs to reduce dental caries, nature-based treatments are highly welcomed. The second organ that has a diverse microbial community is the mouth, which contains more than 700 species of bacteria. Disruption of the natural microbial flora of the mouth through the consumption of various nutrients can have consequences for our health, such as oral and throat cancer, tooth loss, and periodontal disease [1].

\section{Probiotic products}

Many publications said using probiotic products can be a factor in improving the health of the digestive system, reproductive organs, and oral hygiene.

Probiotic bacteria should have the ability to adhere to and colonize surfaces in the oral cavity, have a good shelf life, and be nontoxic. Two main groups probiotic bacteria are Lactobacillus and Bifidobacterium. The Lactobacillus, as a member of oral microbial flora, can play an important role in the microcosm balance of the oral cavity. B. bifidum, B. longum, and B. infantis are the probiotic species of Bifidobacterium.

Today, with the increasing awareness of people about the beneficial effects of probiotic bacteria, consumption of functional foods is increasing. Functional foods are such food that promotes health [2,3].

Functional foods must have three items:

1. they have a different effect from a nutrition standpoint;

2. they reduce the risk of pathological illnesses; and

3. they benefit the community and the consumer [4].

New food products are converted into probiotic foods by adding probiotic bacteria. These foods include a variety of different types such as cheese, ice cream, milk-based dessert, baby milk, and mayonnaise. The main thing is the texture of these foods [5].

The fourth mechanism of how probiotic bacteria work in the mouth include:

1. competition between probiotic bacteria and pathogenic bacteria in adhesion to mucus and teeth, which in this way prevents the pathogenic bacteria from attaching; 
2. they can produce factors such as peroxide and bacteriocin, which act as antibacterial agents against oral pathogens; and

3. with the presence of probiotic bacteria, oral conditions change and the growth medium of pathogenic bacteria do not occur, such as the reduction of $\mathrm{pH}$ or alteration of the structural protein of salivary glands $[6,7]$.

4. Probiotics can have beneficial effects on dental health by stimulating nonspecific immunity and regulating cellular and humoral immune responses.

\section{Conclusion}

Probiotics are becoming more common due to concerns about oral and dental diseases and increased consumer interest in natural remedies. Based on the research and the effect of probiotics in reducing the number of pathogenic bacteria in these organs, they can be used in foods.

\section{Author details}

Razzagh Mahmoudi $^{1 *}$, Sara Moosazad ${ }^{2}$ and Katayoon Aghaei ${ }^{2}$

1 Medical Microbiology Research Center, Qazvin University of Medical Sciences, Qazvin, Iran

2 Food Hygiene and Safety, Faculty of Public Health, Qazvin University of Medical Sciences, Qazvin, Iran

*Address all correspondence to: r.mahmodi@yahoo.com

\section{IntechOpen}

(C) 2019 The Author(s). Licensee IntechOpen. This chapter is distributed under the terms of the Creative Commons Attribution License (http://creativecommons.org/licenses/ by/3.0), which permits unrestricted use, distribution, and reproduction in any medium, provided the original work is properly cited. (cc) BY 


\section{References}

[1] Kilian M, Chapple I, Hannig M, Marsh P, Meuric V, Pedersen A, et al. The oral microbiome-An update for oral healthcare professionals. British Dental Journal. 2016;221(10):657

[2] Najmeh A, Shiva M. The role of probiotic on oral health. Journal of Isfahan Dental School. 2011;7(2):187-199

[3] Tandon V, Arora V, Yadav V, Singh V, Punia H, Agrawal S, et al. Concept of probiotics in dentistry. International Journal of Dental and Medical Research. 2015;1(6):206-209

[4] Coman MM, Cecchini C, Verdenelli MC, Silvi S, Orpianesi C, Cresci A. Functional foods as carriers for SYNBIO $®$, a probiotic bacteria combination. International Journal of Food Microbiology. 2012;157(3):346-352

[5] Soccol CR, Vandenberghe LPS, Spier MR, Medeiros ABP, Yamaguishi CT, Lindner JDD, et al. The potential of probiotics: A review. Food Technology and Biotechnology. 2010;48(4):413-434

[6] Comelli EM, Guggenheim B, Stingele F, Neeser JR. Selection of dairy bacterial strains as probiotics for oral health. European Journal of Oral Sciences. 2002;110(3):218-224

[7] Lewis S, Freedman A. The use of biotherapeutic agents in the prevention and treatment of gastrointestinal disease. Alimentary Pharmacology \& Therapeutics. 1998;12(9):807-822 



\title{
Chapter 2
}

\section{Therapeutic Potential of Probiotics and Prebiotics}

\author{
Nabila Gulzar, Iqra Muqaddas Saleem, Saima Rafiq \\ and Muhammad Nadeem
}

\begin{abstract}
Advancement in technology is continued as the time is passed. The biological active ingredients technology is the challenging issues for both the researchers and manufacturers. In last decade, much research has been happened about the potential health benefits of pro and prebiotic ingredients. Probiotics are the live microorganisms when given in adequate amount confer health benefits but the prebiotics are indigestible ingredients that enhance the activity of one or more probiotics in the colon. The therapeutic potential of these two biological active ingredients is the outcome of emerging field of biotechnology. A number of studies indicating therapeutic potential of probiotics regarding gastrointestinal health, cancer, constipation, immunomodulation, Helicobacter pylori, liver disease and urogenital infection have been documented. Similarly, prebiotics also improved helpful for many communicable and non-communicable diseases. It can be seen that advancement in the biotechnology field offer great choice to deliver a marvelous health advantages. Although the market for probiotic and prebiotic food and supplements has been increased in this new era but still need to develop food and supplements containing these two active ingredients with the cooperation of legal bodies of the country.
\end{abstract}

Keywords: therapeutic, probiotics, prebiotics

\section{Introduction}

This chapter criticizes and presents the role of different probiotics and prebiotics in the prevention of various ailments and improvement of consumer's health. Scientist worked and explored the action of beneficial live microorganisms and non-digestible food components for the improvement of human health. The chapter highlights various sources and mode of action of probiotics and prebiotics. Disease prevention and health intriguing aspects of these therapeutic components is also addressed in this chapter.

\section{Probiotics}

The term probiotics was characterized by Parker [1] as life forms and some substances which are responsible for the equalization of the intestinal microorganisms. Fuller [2] defined probiotics as feed supplements in the form of live microorganisms which valuably influences the host creature by enhancing the microbial balance in the intestines. Subsequently, Moriarty [3] recommended that the meaning 
of probiotics be reached out to microbial water added substances. Administering probiotics in water has been appeared to enhance water quality by decreasing the centralizations of nitrogen and phosphorus [4]. Probiotics directed in water or eating routine likewise may hinder the development of pathogenic microorganisms, contribute stomach related proteins to expand feed usage, give other development advancing components, and restoring the immune response of the living beings.

Hill et al. [5] updated the probiotics as live microorganisms when given in adequate amount confer health benefits.

\subsection{Probiotics: selection criteria}

For the living organisms to be termed as probiotics the given criteria should be fulfilled:

1. It must get separated from the same species from its expected host.

2. It ought to have an clear favorable impact on its host.

3. It should not produce any symptoms of disease.

4. It ought to have the capacity to survive the conditions gastrointestinal tract and can easily be passed through it.

5. During storage, greater number of practical microscopic organisms must have the capacity to endure extended lengths of time $[6,7]$.

\subsection{Probiotics: mechanism of action}

Mechanisms for the advantages of probiotics are not completely understood. However, generally it includes [8].

- Adherence and colonization of the gut.

- Suppression of development or epithelial authoritative/intrusion by pathogenic microscopic organisms and generation of antimicrobial substances.

- Improvement of intestinal hindrance work.

- Controlled exchange of dietary antigens.

- Stimulation of host mucosal and systematic immunity [9].

\subsection{Standardization of probiotics}

In Europe health claims of probiotics are assessed by the "European Food Safety Authority" (EFSA). For the selection guidance of probiotics European Commission published probiotics health claims [10] this meant that probiotics are not considered as nutrition claim but it is a health claim. It is further clarified that this general health claim is not mention for any body functions because the health claim of probiotics and strain specific. Consequently, probiotics term is banned with regard to advertising and labelling as food supplement in Europe. 
In USA probiotic companies face legal encounters. In the research of probiotics, there are also FDA's restrictions for human trials. The study with regard to human trial must be filed as "Investigative New Drug," which appears redundant and costly obligation.

In Canada, the government has also issued regulatory documents for the use probiotics in food. Canada has a list of 17 probiotic species that can make nonspecific health claims, but no strain-specific probiotic claims have been approved [11].

In 2012, the Chinese Food and Drug Administration (CFDA) issued "Requirements on and a Guide to the Naming of Health Foods" and this year, provision for health food registration and filing was released. Currently, there are 27 health food categories based on health effects recognized in China, including enhancing immunity, the maintenance and relief of constipation, and modulating the intestinal bacteria. The health claim of any probiotics are governed an approval process involving technical review of safety, scientific substantiation of the health effect (based on animal and/or human studies), quality control, quantitative assessment and assessment of the product formulation [12].

\subsection{Commonly used probiotics}

A portion of the widely utilized probiotic microorganisms are Lactobacillus rhamnosus, Lactobacillus reuteri, bifidobacteria and certain strains of Lactobacillus casei, Lactobacillus acidophilus-groups, Bacillus coagulans, Escherichia coli strain Nissle 1917, certain enterococci, particularly Enterococcus faecium (SF68), and the yeast Saccharomyces boulardii. Bacterial spore formers, for the most part of the class Bacillus influence the scene. The given probiotics are being used in variety of food products such as fermented milks either independently or in mixes. With the new research endeavors new genera and strains of probiotics are being developed.

Probiotic can either include a single stain or a blend of at least two strains. For example, VSL3 is a probiotic that comprises of blend of eight different strains. The effects of probiotics are strain specific and cannot be summed up. A one strain may display diverse advantages when utilized exclusively and in mix. The benefits arising from the use of probiotics vary according to patient group. Constrained studies showed the adequacy of use of multiple probiotic strains [13].

FAO and WHO have mutually introduced advanced rules with a specific end goal to establish the systematic outlook for a successful Probiotic assessment probiotics in nourishments to support the health cases and other advantages. The standard rules on probiotics developed by FAO/WHO could be used worldwide for assessing probiotics in nourishment that can lead to the supporting of health claims. According to the rules following activities must be fulfilled:

\section{Identification of strain.}

2. Functional portrayal of the strains and safety properties.

3. Proving the medical advantages in human examinations.

4. Labeling of the adequacy claims and the shelf life of the substance must be honest and should not be deceiving.

\subsection{Therapeutic potential of probiotics}

The probiotics have most imperative and recorded helpful impacts that incorporate the prevention from various diseases including diarrhea, increasing the 
effectiveness of antibacterial activity, reduction in the symptoms of constipation, changes in the conjugation of bile and salts. Moreover, they are also involved in nutrient formation and in enhancing their utilization by the body; a few probiotics are thought to have anti-oxidant action as entire cells or lysates. Probiotics have additionally exhibited their intrinsic impacts in reducing manifestations of allergy, cancer AIDS, various infections of respiratory system and urinary tract. There are different random reports on their advantageous impacts on autism, fatigue, type 2 diabetes, aging, fatigue, obesity and osteoporosis [14].

\subsubsection{Diarrhea}

The Diarrhea is defined by World health Organization as three to four watery stools in the period of 24 hours. Over the period of more than 20 years several examinations have been done on the microorganisms by several in vitro studies, animal models and some other suitable clinical investigations have confirmed the role of probiotics in reducing the severity of various type of diarrhea [15] Saccharomyces boulardii is the only yeast probiotic that is used for treating the diarrhea.

\subsubsection{Acute infantile diarrhea}

Rotavirus is the major cause of acute infantile diarrhea and is the most concentrated gastrointestinal condition and it requires quick oral rehydration as an essential treatment. Along with the oral rehydration therapy Probiotics are thought to have beneficial effects. Although further data is needed to confirm the investigations however 10 billion CFU is the minimum potent dose in kids within the 48 hours [16]. A trial was conducted on C. difficile-related colitis and results showed that $S$. boulardii reduce the onset of infection in the patients who had more than one consecutive $C$. defficile disease. S. boulardii is yeast which produces proteases that inhibit the $C$. defficile toxins and also blocks its receptors in the intestines. The yeast $S$. boulardii discharges a protease that separates $C$. difficile poisons and hinders the poison intestinal receptors. The Probiotic additionally found to activate particular antitoxin A which is an immunoglobulin that attacks the factor involved in increasing the risk of diarrhea $[17,18]$.

\subsubsection{Antibiotic associated diarrhea}

Disruption of the natural micro flora is due to the use of anti-microbial medications, i.e., antibiotics frequently prompts diarrhea. The principle component by which antimicrobials cause loose bowels is through weakened protection against pathogens because of disruption of gut micro flora and as a result there is a modification in the digestion of sugars bile acids and unsaturated fatty acids resulting modifications in the digestion of sugars, short-chain unsaturated fats, and bile acids [19]. Probiotics are more powerful in reducing the onset of diarrhea as a result of use of antibiotic medications and these includes strains of $L$. acidophilus, yeast $S$. boulardii, L. delbrueckii, L. rhamnosus GG, L. fermentum, etc. [18]. However, further studies are needed to confirm the beneficial role of probiotics in various diseases, which probiotic is more potent and their recommended dosages [20].

\subsubsection{Traveler's diarrhea}

It has been assessed that around $20-60 \%$ of the people traveling around the world are affected by this type of diarrhea. It especially influences individuals those 
who travel from the developed or industrialized areas to the backward or remote areas, specifically traveling between tropical regions and other non-tropical areas. The major cases that are recognized are due to the microscopic organisms which accounts for approximately $60-85 \%$ of the cases and most causative bacteria for causing this is E. coli and Compylobacter jejuni and some other species of Salmonella and Shigella disease is also caused by parasites and viruses which accounts for around $10 \%$ and $5 \%$ toward causing the infection [21]. It was observed that the bacteria that was effective against Bacterial diarrhea is $S$. boulardii whereas the activity of Lactobacillus $G G$ was observed to be more potent against diarrhea caused by the virus and the idiopathic diarrhea [22-24]. Bacterial Strains that are thought to have preventive effect on the traveler's diarrhea include the Bifidobacteria, Lactobacilli, and Streptococci and Enterococci [18].

\subsubsection{Inflammatory bowel disorder (IBD)}

IBD is a long term degenerative disease which involves the severe irritation of G.I.T tract that leads of watery and bloody diarrhea along with the abdominal pain IBD affects the small intestines and a portion of large intestines that is colon and it includes three different conditions which are Crohn's disease, ulcerative colitis (UC) and pouchitis. The other factors that are associated with the onset of disease include the genetic factors, ecological factors, oxidative stress and the weakened immune system [25].

Crohn's disease and ulcerative colitis are long term diseases of the gastro-intestinal tracts that are associated with the inflammation of the immune and likely are because there is absence of balance of the natural immunity with the surroundings and the with the advancement of the culture [26]. Intake of probiotic bacteria can possibly balance out the immunological boundary in the gut mucosa by diminishing the production of nearby proinflammatory cytokines [27-29]. Bifidobacterium infantis 35,624 helps in elevating the symptoms of abdominal pain, bloating, passage of gas, straining, bowel dysfunction and incomplete evacuation in the patients of IBD. It has been observed through recent studies that Probiotic supplementation is very helpful in elevating the symptoms of IBD and in some cases even the medical therapy can be replaced by probiotic supplementation. However it is not recommended for the Crohn's disease as the data does not support the use of probiotics. Therefore Probiotics have shown promising role in reducing the symptoms of ulcerative colitis but not in the case of Crohn's disease [30].

\subsubsection{Ulcerative colitis (UC)}

Ulcerative colitis like Irritable bowel disorder fundamentally influences the inner layer of the rectum and that of large intestines. Long-term ulcerative colitis can lead to the development of colon cancer. Use of different probiotics including S. boulardii, L. casei, Bifidobacterium bifidum has demonstrated beneficial results in terms of this disease [31]. A Study was conducted and the results demonstrated that the addition of probiotics bacterial strains of L. acidophilus, B. bifidum, and B. breve in the fermented milks was helpful in mitigating the diseases in patients [32].

\subsubsection{Crohn's disease (CD)}

It is a type of Irritable bowel syndrome which ordinarily influences the digestive system; however it may affect any organ from the mouth to the end of the end of digestive tract. Crohn's disease leads to the development of the ulcers and irritation that influences the capacity of the body to process food, assimilate nutrients and excretion of unwanted products in a healthful form. The Bacterial strains that 
are involved in causing Crohn's disease include Salmonella, Clostridium difficile, Campylobacter jejuni, Mycoplasma and Adenovirus, There are various reports that influence the efficacy of various probiotics, e.g., S. boulardii, L. GG, VSL3, E. coli Nissel 1917, in combating the issues of CD in human beings [33].

The role of probiotics in therapeutic utilization of Crohn's disease is because of its competition with the groups of bacteria, maintaining the immune system and also destroying the various pathogenic microorganisms. Irritable bowel syndrome can additionally be prevented by using the probiotics which help in maintaining the defensive functions of the mucosa of intestines [34].

\subsubsection{Pouchitis}

Pouchitis is third kind of Irritable bowel syndrome where there is inflammation of ileal pouch particularly after the procedures such as colectomy and the other include anastomosis of ileal pouch. Various Studies were done and it was observed that the blend of probiotic VSL3 plays a significant role in the reduction of this disease [35].

The strains of powerful probiotic stimulate definite IL-10 and IL-4 mucosal cytokine. Also Probiotics may impact the cell to cell association of mucosa and integrity of the cells through upgrading activity of intestinal mucosa through the regulation of phosphorylation and cytoskeletal activity of tight junctional protein and furthermore through the production of enzymes having anti-oxidant nature. For example, catalase and superoxide dismutase hence remediating the symptoms of IBD [36].

Ileal pouch-anal anastomosis (IPAA) is the favored option to proctocolectomy with perpetual ileostomy in ulcerative colitis and the inherited disease in which adenomatous polyps are formed in the epithelial of large intestines. The most as often as possible noticed chronic problem of IPAA is potentially perpetual inflammation of the ileal supply which is either acute or chronic and is called pouchitis. Gionchetti et al. in a randomized, controlled treatment containing placebo preliminary in which VSL3 was regulated to 40 patients quickly after carefully surgical formation of ileal anal pouches, accomplished abeyance of $90 \%$ in the group treated with VSL3 versus $60 \%$ in the placebo treatment group following a year [37]. These examinations have confirmed the role of VSL3 in the administration of pouchitis [38].

According to the Rome II Crieteria irritable bowel syndrome is defined as syndrome that lasts for greater than 3 months with the implications of either diarrhea or constipation and also accompanied by the abdominal pain. Many studies on the role of probiotics in preventing Irritable bowel syndrome have been conducted [39-43]. Out of five surveys conducted three trials showed a decrease trend in the symptoms of Irritable Bowel Syndrome. As there is a beneficial role of the probiotics but the reduction in the symptoms of disease without the clinical manifestations has not yet confirmed. However, beneficial role of probiotics in terms of clinical improvement can be attained in reducing the symptoms related to the diarrhea. Many new studies are needed to be conducted on variety of bacterial strains to draw any conclusion regarding their beneficial role [44].

\subsubsection{Lactose intolerance}

It is a type of disorder that comprises of intolerance to the digestion of carbohydrate lactose that is present mainly in dairy products having prevalence of around $7-20 \%$ in Caucasians, $90-100 \%$ in Asians and from around $50-85 \%$ in Africans [45]. Lactose intolerance can be solved by using the probiotics that alleviate 
the symptoms by reducing the transit time through gastro-intestinal tract [46]. Probiotics such as Streptococcus thermophilus and Lactobacillus bulgaricus undergo the process of fermentation and as a result produces an enzyme lactase that helps in the breakdown of lactose into its subunit glucose and galactose. Thus, it is suggested that the intake of probiotics can help in the digestion of lactose inside the gut lumen and reducing the symptoms of lactose intolerance in both children and adults [47].

\subsubsection{Colon cancer}

The intake of probiotics and prebiotics has several antagonistic effects on mutagens $[48,49]$. The link between the colon cancer and diets that are high in fats and oils and low in fiber and some other western diets lead to the alteration in the bacterial enzymes in the feces. The process through which the probiotic bacteria such as lactobacilli reduce the onset of colon cancer may include various modifications on the metabolic pathways of the intestinal microflora, inhibiting and binding of the cancer causing agents, physicochemical alterations in binding to colon, formation of compounds cancer causing agents and several other mutagens. Improving the immune system and physiology of the host. There is a remarkable evidence on the basis of various animal models and controlled studies [50,51]. However, there is not enough data or studies to confirm the role of probiotics for protection against the onset of colon cancer.

The process through which the probiotics exhibit tumor suppressing activity includes the modification in the immune functions that are related with the various immune responses, Regulating cell differentiation and apoptosis, inhibiting the formation of the enzymes produced from the pathogenic bacteria $E$. coli and $C$. perferinges that includes the ureases different reductases specifically nitroreductases and oxidoreductases, $\beta$-glucuronidase and choloylglycine hydrolase. Enzymes such as ureases and beta glucosidases are involved in the conversion of pro carcinogens to the active carcinogens. In a study probiotic namely Propionibacterium freudenreichii produced Short chain fatty acids in the culture media and caused the cell death of gastric and colon cancer cells in humans [52, 53].

\subsubsection{Constipation}

It is common problem among the older population. Several controlled studies showed that in constipation either the bowel movements are increased or there is decrease in the transit time through the gastro-intestinal tract, for this purpose probiotics are utilized in the treatment of constipation $[54,55]$. The most frequently used laxative is lactulose which is also a probiotics is not affected by the disaccharidases of the humans and the microflora in the colon, bifidobacterium utilizes it as a substrate that breakdown it into the smaller subunits leading to the creation of the osmotic effect. However, larger controlled studies are needed in order to confirm the use of prebiotics and probiotics apart from lactulose [56, 57].

\subsubsection{Immunomodulation}

Probiotics are involved in the modulation of the immune responses, are antiinflammatory in nature and also have effect on humoral and cell regulated immunity. Probiotics are thought to involve in secretion of the factors that are responsible for regulating the immunity. For example the factors secreted from the probiotic strain $L$. reuteri limit the gene expression that is dependent on NF-Kb which results in the decrease in cell growth and greater protein kinases activated by nitrogen which leads to the induction of apoptosis [58]. 
Probiotics are present in greater quantity in fermented milks. During milk fermentation, L. helveticus is able to produce factors that are involved in enhancing the expression of calcineurin which is involved in the formation of mast and goblet cells in the gastrointestinal tract of mouse [59]. The intake of probiotic strain VSL3 is involved in down regulation of such immune responses by decreasing the secretion of IL-8, regardless of the presence of the bacterial pathogen Salmonella dublin [60].

\subsubsection{Helicobacter pylori}

The most common and worst bacterial infection found in human is the Helicobacter pylori. It causes a number of diseases like peptic ulcers, chronic gastritis, lymphoma, gastric adenocarcinoma and number of other diseases not related to gastrointestinal tract. Probiotics prevent the $H$. pylori infection by enhancing the immunoregulation functions that works as antagonistic to infection caused by H. pylori [61-63]. Many studies reported that H. pylori growth and gastritis infection can be minimized but the causative organism cannot be completely removed. It is noted that prebiotics plays their role for the suppression of $H$. pylori as well as they also enhance the efficacy of eradication therapy by stopping the side effects caused by antibiotics thus improving compliance [64]. saccharomyces boulardii is found helpful in reducing the symptoms of Helicobacter pylori.

\subsubsection{Liver disease}

\subsubsection{Hepatic encephalopathy}

By changing the microbiota count in the gut either by using probiotics or fermentable fiber has been related for the treatment of hepatic encephalopathy in experimental studies $[65,66]$. This therapy works as it lowers the blood ammonia level due to inhabitation of bacteria that is acid resistant as well as not producing urease Further work on this approach is still under work [67].

\subsubsection{Nonalcoholic fatty liver disease}

Nonalcoholic steatohepatitis is a disease in which patients are not edict of alcohol but showing the systems of liver biopsy. Experiments on model rats suffering from fatty liver disease have been indicated that intestinal microbiota, bacterial endotoxin and tumor necrosis factor $\alpha$ modulate liver damage caused by alcohol. There is a perception that intestinal microbiota produces endogenous signals, which shows a pathologic role in nonalcoholic fatty liver disease, suggests a role for novel probiotic therapy in this not so uncommon condition $[68,69]$. Recent studies have showed that nonalcoholic fatty liver disease is also thought to be linked with the dysbiosis of gut microbiota. By restoring and maintaining the gut microbiota, nonalcoholic fatty liver disease can be controlled. However extensive studies on the strains of gut microbiota and tests on various probiotics may be helpful in determining the use of specific probiotic for this disease [70].

\subsubsection{Probiotics in infants health}

Human milk defends infants from contagious diseases by several mechanisms. Human milk has various components that modulate the intestinal microbiota and bifidobacteria. These bacteria are the basic and significant constituent of the infants that are fed with human milk $[71,72]$. Human milk can also minimize the incidence and harmful effects of inhabiting pathogens $[73,74]$. Consequently, 
it has been observed that a balanced increased in bifidobacterial concentration and reduction in enteric bacterial count and luminal factors of host may show a positive role in defending premature offspring and infants from diarrheal disease. Alteration of the intestinal microbiota by improving the prevalence of nonpathogenic bacteria is an effective method to attain a therapeutic treatment against enteric pathogens [75].

\subsubsection{Urogenital infections and HIV}

Various urinary tract infections like yeast vaginitis, Bacterial vaginosis and frequent urinary tract infections are major problems faced by the patients. In premenopausal women normal microflora consist of lactobacilli that protect host from infections but various patho-physiologic causes can results infection due to unstable microflora. A very few studies that reports the importance of probiotics for urogenital health $[76,77]$. The awesome practices have reported that L. acidophilus has positive effect in urogenital health. Promising studies showed evidence that probiotics are also important in preventing recurrent urinary tract infection in women [78]. The women suffering from human immunodeficiency virus infection, prevention of bacterial vaginosis is very important. Previous literature indicates that women that have improper balance of lactobacilli (vaginosis) are in a great risk of human immunodeficiency syndrome $[79,80]$. Therefore an adequate level of lactobacilli and preventing bacterial vaginosis is a best method to reduce the risk of getting human immunodeficiency virus infection, gonorrhea and trichomoniasis. One of the recent study shown that a probiotic strain (Lactobacillus reuteri RC-14) specific for human vagina can give strong protection from virus that can reduce the transmission of sexual immunodeficiency virus infection. Still, further work is required to approve these results before the extensive use of probiotics for the treatment of these diseases can be suggested [81].

\subsubsection{Breast cancer}

Several studies have been conducted on animal and human models to check the effect of probiotics in breast cancer. Several in vitro studies have shown that probiotics are involved in reducing the tumor size and stopped the growth of tumour. In Human studies it was observed that the use of probiotic Lactobacillus casei shirota prevented the onset of breast cancer. Also the use of fermented dairy products such as yogurt and fermented milk was inversely linked with the onset of breast cancer. Probiotics can be used for both preventive and treatment purposes of breast cancer. However more studies are needed in order to confirm the safety and efficacy of probiotics in breast cancer [82].

\subsubsection{Type 2 diabetes mellitus}

Experiments have shown that Type 2 Diabetes Mellitus can be result of dysbiosis of gut microbiota. This microbiota is involved in the permeability of gut mucosa and immune system of host which are linked to the type 2 diabetes mellitus. Different type of probiotic strains either single or multiple can be used for intervening type 2 diabetes mellitus. Probiotics that are mainly used to treat the symptoms of type 2 diabetes are Lactococcus, Bifidobacterium and Lactobacillus. After the oral probiotic administration can be helpful in modulating the immune function, gut microbiota and balancing the energy metabolism. Therefore it was suggested that probiotics are involved in reducing the incidence, delaying and reversing the complications of Type 2 diabetes [83]. 


\section{Meat and dairy products as a functional agent}

\subsection{Dairy Products}

Authors have considered different traditional dairy products such as yogurt, milk and cheese as a functional products as these are rich source of various vitamins and minerals and other constituents that can be used as functional agents [84]. Such as conjugated linoleic acid (CLA) and Selenium, that play an important role in lowering the serum cholesterol level thus preventing the atherosclerosis and other cardiovascular diseases also having antioxidant functions in the body [85].

Yogurt is a traditional dairy product that was prescribed by physicians in Middle East as a treatment of gastrointestinal diseases [86]. Yogurt is manufactured using Streptococcus thermophilus and Lactobacillus bulgaricus which both work in synergism. Health benefits of yogurt can be enhanced by the addition of probiotic bacteria in yogurt such as Bifidobacterium, Lactobacillus acidophilus and L. rhamnosus [87]. Yogurt has been used a food source consisting of probiotic organism throughout the world.

A wide variety of fermented milks have also been developed and various health benefits were linked with the consumption of fermented milks such as lowering of cholesterol. They also contain the important probiotics strains that are involved in improving the health [88].

Probiotic cheeses are available in soft as well as hard varieties. Various Probiotic Strains such as Bifidobacterium and L. rhamnosus are readily used in such cheeses and these cheeses can be beneficial source of Probiotics [89].

\subsection{Meat products}

Meat products are good source of protein and fat along with water and other vitamins which are highly bioavailable. Meat products can be made highly beneficial for health either by incorporating any ingredient in it that is considered healthy or eliminating or reducing any component that can be considered harmful [90].

Fatty acid and cholesterol level of meat can be modified by selecting different breeds, modifying the feed patterns, addition of some feed additives and several interventions regarding animal metabolism [91].

Similarly addition of olive oil to variety of meat products was thought to be associated with the high biological value and decrease onset of breast cancer and heart diseases [92].

Soy protein can also be added into the meat products. In 1999, US FDA stated that any product low in saturated fats and cholesterol containing $25 \mathrm{~g}$ of soy proteins may be helpful in preventing the cardiovascular diseases [93].

Lipid oxidation is the major issue in meat products thus instead of using synthetic antioxidants that pose toxicity and other harmful effects can be replaced by the antioxidants from the plat source such as rosemary, tea, etc. Green tea is associated with reducing the level of Cholesterol in body as well as increasing the portion of High density Lipoproteins and decreased the oxidation of lipoproteins $[90,94,95]$.

Addition of salt for the preservation purpose can lead to high percentage of salt intake and can lead to the development of hypertension. Several substitutes were assessed and one of the best substitute was the addition of calcium ascorbate. This substitute causes higher acidification due to the fermentation by lactic acid bacteria. Replacement of salt with Calcium ascorbate helped in reducing the sodium chloride level as well enriching the meat with nutrition [96]. 


\section{Prebiotics}

Prebiotics are the food that is not digested in the human gut but food ingredients boost the growth and activity of bacteria that are good for our intestine, consequently they balance the intestine of an organism [97]. The most commonly used bacteria that are good for our health is amplified by prebiotics comprise of genus Bifidobacterium and Lactobacillus, which control the growth of harmful bacteria. Most commonly used prebiotics are mannan-oligosaccharides, galactoglucomannans, lactose, inulin and oligofructose. Short chain carbohydrates used as prebiotics consist of three to ten sugar units derived from the cell wall of yeast and plants. Prebiotics functionality are not alter by any food processing treatment and require little or no regulatory requirements, hence making their consumption more easy as compare to chemical treatment.

\subsection{Mode of action of prebiotics}

Important modes of action of prebiotics are:

- These are non-digestible carbohydrates that are not digested by the upper gastrointestinal tract and travel in the ileum and colon where fermented by the resident microbes.

- Prebiotics do cause intestinal homeostasis.

- Host surface receptors are coated by prebiotics.

- They produce bateriocins.

- Favorable bacteria produce short chain fatty acids with the help of non-digestible carbohydrates.

- Short-chain fatty acids are the energy source of epithelial cells.

- They regulate metabolic function and modulate immune system [98].

\subsection{Targets for prebiotics: gut microbiota and intestinal health}

Fermentation of resistant starches and dietary fiber caused by bacteria in colon release short chain fatty acid metabolites (SCFA). SCFA are well known for gut health as well as their part in provision of supplementary energy to the host in fatness is in debate. On contrary, $10 \%$ of entire energy in humans is provided by SCFA. According to energy yield hypothesis, dysbioticmicrobiomes have an amplified capacity to remove energy from the food, so that the bacterial conversion of non-digestible carbohydrates and dietary fiber to SCFAs could give additional energy to the host and result fatness of individual over time. Likewise, G-protein coupled receptors (GPR) can sense SCFAs that tie them with lipid and glucose breakdown. SCFAs activate the two major proteins, GPR41 and GPR43 which are expressed on adipocytes and enter endocrine $L$ cells. Peptide YY is released by stimulation of intestinal GPR41 which enhances gut passage time and increase satiety. Inflammation lessens by activation of intestinal GPR43 as well as it simulates glucagon-like peptide (GLP), a hormone which contributes in regulation of insulin secretion. Enteroendocrine L cells express GLP-1 as well as secrete the gut-trophic 
hormone GLP-2. Chief stimulus for GLP-2 secretion is nutrient consumption. SCFAs maintain the release of GLP-2 which is important in regulation of the gut fence system and decreases lipopolysaccharide translocation [99].

\subsection{Healthy diet for probiotic}

\subsubsection{Dietary fiber}

Diet is an element on which unequal antagonism exists between the microflora of gut and specific group of bacteria get their nutrition. It also serve as direct medium for the gut microflora since it may act as a direct substrate for the microbiota through its indigestible constituents and some by-products of digestion. Among all the nutritional constituents, dietary fibers are vital as they cannot be absorbed in the upper part of the digestive system; although they can be fermented in the lower part of the gut by the intestinal microbiota [100].

\subsubsection{Prebiotics}

Prebiotics are a subcategory of nutritional fibers that is not affected by the gastric acidity and the enzymes present in the digestive system of mammals which is very crucial for our health [101]. The main distinguishing benefit of prebiotics is their stimulation in growth of intestinal bacteria connected with fitness and comfort [102].

\subsubsection{Complex carbohydrate}

Some complex carbohydrates include resistant starch and plant cell-wall polysaccharides are not digested by the gut microflora. Polysaccharides comprising of cellulose, hemicelluloses (xylan, xyloglucan, mannan, $\beta$-glucan) and pectin. These all complex carbohydrates have positive simulative effect on microbial populations in the gut [103]. A number of bacteria present in human gut that possess genes programming with carbohydrate-active enzymes (CAZymes) in their genomes. These bacteria can digest such compound carbohydrates.

\subsubsection{Prebiotic carbohydrates}

Prebiotics definition is fulfilled by resistant starch [101]. In the colon prebiotic type of fermentation is provided by it and has lots of metabolic advantages, for instance it increase the bile salt production and laxation, lowers the danger of gastrointestinal tract cancers, and lowers the after meal glucose stimulus and blood lipid levels [104, 105]. Farther more it assists in growing of epithelial cells and propagation by increased butyrate concentration via its fermentation by the gut microbiota [106].

\subsubsection{Algal (AGAL) polysaccharides}

AGAL polysaccharide provides with dietary fiber, e.g., alginates, agars and carrageenan from seaweeds, consumed in food industry as thickeners and stabilizers or emulsifiers [107]. Many health benefits provided by dietary fibers due to its gel-forming ability and other physicochemical properties, including ability to ferment by the alimentary canal microbiota [108]. These benefits include controlled appetite, type 2 diabetes and obesity by increasing satiation, refining of gut barrier working and lessening the ad worse effects of luminal components. 
Gut bacteria cause fermentation of compound carbohydrates that has beneficial affect for the host. This activity makes complex carbohydrate as potential prebiotics. Proteolytic activity produce potential harmful product and the fermentation of complex carbohydrates reduce risk caused by these harmful metabolites [109]. Furthermore, some useful metabolites with anti-cancer and anti-inflammatory activities, like phenolic substances and short chain fatty acids are also produced by the microbial fermentation of complex carbohydrates in the gut [110].

Chemically, inulin-type fructans are a linear polydisperse carbohydrate material consisting mainly, if not exclusively, of $\beta$-(2-1)-fructosyl-fructose glycosidic bond linkages [81]. Fructans are proposed to be classified as "functional fiber" according to recent concepts drawn from physiological effects on human individuals [111].

Guar galactomannan was enzymatically hydrolyzed to obtain partially hydrolyzed guar gum which can be utilized as prebiotic source. Partially hydrolyzed guar can be considered as potential prebiotic compound that may further stimulate the growth of potentially probiotic bacteria or native gut microflora [112].

\subsubsection{Herbal prebiotics}

Some herbs are used for the treatment of inflammatory immune diseases that also have prebiotic effect in the host. These herbs include Ocimum sanctum, Piper nigrum and Zingiber officinale. Zingiber officinale and Ocimum sanctum exhibited greater prebiotic activity, with higher growth of Lactobacillus and Bifidobacterium as compare to most commonly used prebiotic, fructo-oligosaccharide (FOS). However, Piper nigrum have similar prebiotic activity as that of most commonly used prebiotic FOS. These herbs used to regulate gut microbiota which ultimately prevent systemic swelling and related disorders [113].

\subsubsection{Fractionated lotus seed resistance starch}

Fractionated lotus seed resistance starch (LRS3) was fractionated and tested for its structural properties and prebiotic activities. LRS3-20\% showed higher prebiotic activity against these bacteria Bifidobacterium adolescentis and Lactobacillus acidophilus as compared to LRS3-30\% and high concentration of amylose maize starch [114].

\subsubsection{Cereal grain fraction}

Most commonly used cereal grains to develop new classes of prebiotic are corn, rice, wheat, barley and oats which also have high economic value [115].

\subsubsection{Burdock root}

It is rich source of fructo-oligosaccharides and phenolic compound but its use in food products are limited. It is widely used in bakery product for consumers that search for functional foods of health benefits. Burdock roots are effective alternative for functional foods with health benefits [116].

\subsubsection{Lentil}

Lentil food are rich source of prebiotic carbohydrates which have raffinose family oligosaccharides, fructooligosaccharides, sugar alcohols and resistance starch. 


\subsection{Therapeutic potential of prebiotics}

\subsubsection{Prebiotic impact on intestinal micro flora}

Dietary fibers which are part of prebiotic play positive impact on intestinal micro flora [117]. In cholesterol metabolism prebiotic fibers play a very unique action specifically on fermentation of products and modulation of micro flora. Some research show both probiotics and prebiotics (in which non digestible food ingredients are more beneficial for host which stimulate the growth of colonic bacteria) to suppress tumor and preneoplastic lesions in the colons of animal treated with carcinogenic chemicals [118]. The presence of beneficial bacteria in gut of infants fed with human breast milk is supported by the metabolism of the complex mixture of oligo saccharides present in the milk. More mature gut microbiota is found in the formula milk. In adults formulation infants is used to achieve a type of intestinal microbiota. Improper gut microbiota (dysbiosis) can cause autoimmune disorders, infections and allergic reactions in old age [59].

\subsubsection{Colon cancer and prebiotics}

Aberrant crypt foci (ACF) is the first detectable abnormal growth of cells appears as lesions in the large intestine. To identify ACF lesions chromoscopic colonoscopy of high magnification is used, generally it appear as colonic mucosa. They comprised of crypts that are raised on upper side of normal mucosa. It consists of extremely condensed epithelia and has changed luminal openings visibly confined from the normal neighboring crypts. The development of the ACF to polyp, adenoma and adenocarcinoma equivalents buildup of numerous genetic and biochemical modifications. A little amount of ACF can be a cause of colon cancer. Presently, it is unidentified that which crypts are responsible for the development of tumor. Though, various researches support the idea of development of colon cancer from ACF [119]. Perrin et al. [120] reported that some fibers which stimulate the formation of stable butyrate-producing colonic ecosystem. This type of colonic environment diminished the rate of ACF. Therefore it is clear that colonic ecosystem that produces stable butyrate decreases the risks of developing colon cancer.

\subsubsection{Prebiotics modulation of immune function}

Immunological functions are modulated by our diet and affect resistance of host by various ways. Along with essential food components non-essential nutrients like non-digested carbohydrates also play an important role in controlling the immunological responses, particularly lymphoid tissues of the gut. Bodera [121] reviewed the previous literature by various scientist on the effects of prebiotics in enhancing the immunity of host and observed that there is sufficient proof indicating prebiotics such as inulin helps in the modulation of immunological functions. He suggests to take prebiotics for the modulation of immunological parameters in gut associated lymphoid tissues, secondary lymphoid tissues and peripheral circulation. First line defense is provided by the innate immune system and prevent the entry of contagious agents or eradicating entering pathogens. It encompasses physical fences like skin and mucous membranes, blood cells and tissue, such as phagocytes, natural killer cells and soluble mediators, like supplement proteins and cytokines.

\subsubsection{Prebiotics as dietary modulators of gut microbiota in obesity}

It is suggested that gut microbiota plays an important role in obesity and obesityassociated comorbidities that gut microbiota could be a possible goal for fatness 
involvements. It is assumed that microbial dysbiosis is associated with fatness, it is concluded that restoring the potential symbiosis between the gut microbiota and host holds great potential. Prebiotics are consumed so that gut microbiota can be modified. Prebiotics are not capable to be digested by host enzymes although they move in the large intestine and are particularly fermented in the gastrointestinal tract where they help in growth of bacteria particularly Bifidobacterium and Lactobacillus that have been related with health benefits [122].

\subsubsection{Prebiotics assist in the management of cognition}

Worldwide, Schizophrenia is the 25 leading cause of disabilities that decrease the life about 10-20 years. Inappropriate treatment like pharmacotherapy in the administration of cognitive defects and weight gain are recognized a significant contributors of these diseases; therefore there is a need to develop such treatments that alleviate one, or both, of these diseases would be very helpful. By using gut microbiome from dietary source like prebiotics for the treatment of these diseases may be one such intervention. Moreover, prebiotics also effect breakdown, and in case of obesity they rise the concentration of anorexigenic gut hormones such as peptide tyrosine tyrosine, glucagon-like peptide 1 and leptin and decrease the amount of orexigenic hormones such as ghrelin [123].

\subsubsection{Prebiotics for the improvement of enzyme activity and phosphate uptake}

Prebiotics improve the activity of enzymes and phosphate uptake in the intestine. One of study was conducted to recognize the impact of prebiotics supplementation in infant formula on enzyme activity and phosphate uptake in the small intestine of Sprague Dawley (SD) rats. Forty-eight fifteen days old SD rats of similar weight were divided into three groups randomly: A was selected as control group in which SD rats were fed with standard infant formula with no prebiotics treatment. Rats in groups B, C were nourished standard infant formula supplemented with oligosaccharides, and the standard infant formula supplemented with polysaccharides, correspondingly. The results were checked at 28 days. It was observed that as compared to group A, group B and C showed the following: (1) In SD rats group C showed greater activities of sucrose and lactase in the small intestine; (2) In SD rats of group $\mathrm{C}$ comparative expressions of lactase gene in the anterior and posterior segments of the small intestine were increased by 1.68 and 2.26, and the Mgam gene relative expression in the posterior segment of the small intestine was improved by 0.99 in SD rats of group C; (3) the relative expressions of $\mathrm{Na} / \mathrm{Pi}$-II b gene in the anterior and posterior segments of the small intestine were increased by 1.85 and 2.28 in SD rats of group C. These results specify that the supplementation of prebiotics in infant formula can stimulate enzyme movement in the small intestine by improving the relative expression of enzyme gene and $\mathrm{Na} / \mathrm{Pi}$-IIb gene and by reducing the intestinal injury. The polysaccharides improved to be healthier than that of oligosaccharides [124].

\subsubsection{Prebiotics and the bioavailability of minerals and trace elements}

Prebiotic carbohydrates have positive influence in the absorption of minerals and trace elements. There exist a promising evidence about the stimulatory impact of prebiotic carbohydrates (non-digestible oligosaccharides and lactulose) on the bioavailability of minerals and trace elements. However, most of the studies is on the rats because, the studies on the human is limited. It has been hypothesized that prebiotics create strong osmotic effect that reduce the $\mathrm{pH}$ and stimulate the exchange of 
protons and increase level of calbindin and butyrate. Colon surface area also enlarged that is a good source to increase the minerals and trace elements absorption [125].

\subsubsection{Prebiotics in diabetes and cardiovascular diseases}

Prediabetes is linked with the long term inflammation that is associated with greater risk of developing type 2 diabetes and cardiovascular diseases. Increased concentration of lipopolysaccharides is linked with dysbiosis of the natural microbiota that is involved in the development of type 2 diabetes and cardiovascular diseases. Prebiotics involved in the selective functioning of natural micro biota such as inulin decreases the concentration of endotoxin, reduces permeability of the intestines and limit the metabolic dysfunction in rodents. The impact of prebiotics on the cardiovascular functions in patients at the risk of type 2 diabetes is still unknown. The prebiotic supplementation along with inulin could be used as preventive strategy for limiting the risk of cardiovascular diseases in the patients at risk of type 2 diabetes. This strategy can affect the clinical practices by setting and accepting dietary recommendation of prebiotics by medical and scientific community [126].

\subsubsection{Prebiotics and renal profile}

It is well documented that prebiotics, probiotics and the symbiotic supplementation had resulted in the improvement of renal function. Firouzi and Haghighatdoost [127] studied renal profile of a meta-analysis of a clinical trial. They pointed out that level of glomerular filtration rate was reduced whereas the concentration of creatinine was increased in the intervention group in comparison to the placebo group and the results were non-significant. The combined effect on the blood urea nitrogen demonstrated that the level declined as compared to the placebo group. Whereas the levels of uric acid increased in intervention group in comparison with the placebo group. The supplementation of prebiotics, probiotics and symbiotic should be limited among those in which renal function is compromised until well designed and large scale randomized controlled trials prove the efficiency and safety of prebiotics, probiotics and symbiotic supplementation for having improved effects on the renal function.

\subsubsection{Prebiotics in controlling cancer}

A study was conducted to check the impact of prebiotics intake consisting of xylo-oligosaccharides, fructo-oligosaccharides, resistant dextrin and polydextrose on immunity and the structure of gut microbiota in perioperative colorectal cancer patients.

A double blind, randomized clinical trial was conducted that consisted of 140 perioperative colorectal cancer patients involving 50 females and 90 males having age between 40 and 75 years. Patients were divided on random basis into two groups consisting of intervention group that received $30 \mathrm{~g} /$ day of prebiotic supplementation for the period of 7 days and control group that did not receive supplementation. The immunological and nutritional indices of both groups were evaluated before and after operation and were compared with their baseline levels. Also the fecal samples of random 40 patients from the both groups were taken to examine the gut microbiota. There was significant reduction in the abundance of intestinal microbiata from pre to post operation in the control group. Intake of prebiotics is recommended to improve immunological indices in patient having colorectal cancer for 7 days before operation. Prebiotics enhanced the concentration of four commensal microorganism containing opportunistic pathogens in patients having colorectal cancer. Surgical stress decreased the population of intestinal microbiota 
but increased the population of commensal microbiota and opportunistic microorganisms. For further research Bacteroides is considered as a relevant bacterial species on the mechanism of prebiotics [128].

\subsubsection{Anxiolytic effect of prebiotics}

Long term treatment of prebiotics particularly combination of fructooligosaccharides and galactooligosaccharides have antidepressant effects and also involved in combating the issues related to anxiety. The effect of Galactooligosaccharide (GOS) and the combination of fructooligosaccharides and galactooligosaccharides is involved in reducing the level of corticosterone level in the body by mainly limiting its release. Prebiotics are involved in modifying the expression of specific genes related to the concentration of short chain fatty acids in the hypothalamus and hippocampus. Administration of Prebiotics resulted in the increased level of acetate and propionate and reduction in the concentration of isobutyrate that have significant correlation with the positive effects on behavior. Moreover, the administration fructooligosaccharides and galactooligosaccharides reduced the level of corticosterone and proinflammatory cytokines resulted from the chronic stress as well as normalizing the anxiety and depression like behavior along with mitigating the impact of stress on the microbiota [129].

\section{Conclusion}

Probiotics and prebiotics are functional foods that have significant biotechnological benefits with wonderful potential for invention. Though probiotics and prebiotics are likely to be used in treating many communicable and non-communicable disorders but it is very hard to draw conclusions from a number of researches that indicating the therapeutic potential of probiotics and prebiotics because scientists used different strains and prescriptions for various disorders. Further research using reliable regulations will permit more decisive results on the effects of probiotics and prebiotics for treatment of various diseases. Although various products with probiotic, prebiotics and symbiotic are usually available in food and supplement formats, in near future these products will target to specific disease and will be available as drug.

\section{Author details}

Nabila Gulzar*, Iqra Muqaddas Saleem ${ }^{1}$, Saima Rafiq ${ }^{2}$ and Muhammad Nadeem ${ }^{1}$

1 University of Veterinary and Animal Sciences, Lahore, Pakistan

2 University of Poonch Rawalakot, Azad Kashmir, Pakistan

*Address all correspondence to: nabila.gulzar@uvas.edu.pk

IntechOpen

(C) 2019 The Author(s). Licensee IntechOpen. This chapter is distributed under the terms of the Creative Commons Attribution License (http://creativecommons.org/licenses/ by/3.0), which permits unrestricted use, distribution, and reproduction in any medium, provided the original work is properly cited. (cc) BY 


\section{References}

[1] Parker RB. Probiotics, the other half of the antibiotic story. Animal Nutrition and Health. 1974;29:4-8

[2] Fuller R. Probiotics in man and animals. Journal of Applied Bacteriology. 1989;66:365-378

[3] Moriarty DJW. 2007 Control of luminous Vibrio species in penaeid aquaculture ponds. Aquaculture. 1998;164:351-358

[4] Wang YB, Xu ZR, Xia MS. The effectiveness of commercial probiotics in Northern White Shrimp (Penaeus vannamei L.) ponds. Fisheries Science. 2005;71:1034-1039

[5] Hill C, Guarner F, Reid G, Gibson GR, Merenstein DJ, Pot B, et al. Expert consensus document. The International Scientific Association for Probiotics and Prebiotics consensus statement on the scope and appropriate use of the term probiotic. Nature Reviews Gastroenterology \& Hepatology. 2014;11:506-514

[6] Guslandi M, Giollo P, Testoni PA. A pilot trial of Saccharomyces boulardii in ulcerative colitis. European Journal of Gastroenterology \& Hepatology. 2003;15(14):697-698

[7] Mansour-Ghanaei F, Dehbashi N, Yazdanparast K, Shafaghi A. Efficacy of Saccharomyces boulardii with antibiotics in acute amoebiasis. World Journal of Gastroenterology. 2003;9(13):1832-1833

[8] Steidler L, Hans W, Schotte L, Neirynck S, Obermeier F, Falk $\mathrm{W}$, et al. Treatment of murine colitis by Lactococcus lactis secreting interleukin-10. Science. 2000;16(289):1352

[9] Sartor RB. Therapeutic manipulation of the enteric microflora in inflammatory bowel diseases:
Antibiotics, probiotics and prebiotics. Gastroenterology. 2004;17(126):1620

[10] EC (European Commission). Guidance on the implementation of regulation no. 1924/2006 on nutrition and health claims made on foods. Conclusion of the Standing Committee on the Food Chain and Animal Health. [Internet document]. 2007. Available from: http://ec.europa.eu/food/safety/ docs/labelling_nutrition_claim_reg2006-124_guidance_en.pdf [Accessed: 13 May 2016]

[11] Health Canada Guidance document. The use of probiotic microorganisms in food. [Internet document]. 2009. Available from: http://www.hc-sc.gc.ca/fn-an/ legislation/guide-ld/probiotics_ guidance orientation_probiotiqueseng.php [Accessed: 29 Jan 2019]

[12] Thomas LV. Probiotics-The journey continues. International Journal of Dairy Technology. 2016;69(4):469-480

[13] Chapman CMC, Gibson GR, Rowland I. Health benefits of probiotics: Are mixtures more effective than single strains? European Journal of Nutrition. 2011;50(1):1-17

[14] Harish K, Varghese T. Probiotics in humans-evidence based review. Calicut Medical Journal. 2006;4(4):e3

[15] Narayan SS, Jalgaonkar S, Shahani S, Kulkarni VN. Probiotics: Current trends in the treatment of diarrhoea. Hong Kong Medical Journal. 2010;16(3):213-218

[16] Szymański H, Pejcz J, Jawień M, Chmielarczyk A, Strus M, Heczko PB. Treatment of acute infectious diarrhoea in infants and children with a mixture of three Lactobacillus rhamnosus strains-A randomized, 
double-blind, placebo-controlled trial. Alimentary Pharmacology \& Therapeutics. 2006;23(2):247-253

[17] Hord NG. Eukaryotic-microbiota crosstalk: Potential mechanisms for health benefits of prebiotics and probiotics. Annual Review of Nutrition. 2008;28:215-231

[18] McFarland LV. Meta-analysis of probiotics for the prevention of antibiotic associated diarrhea and the treatment of Clostridium difficile disease. The American Journal of Gastroenterology. 2006;101(4):812-822

[19] Bartlett JG. Antibiotic-associated diarrhea. The New England Journal of Medicine. 2002;346(5):334-339

[20] Sudha RM, Bhonagiri S. Efficacy of Bacillus coagulans strain unique IS-2 in the treatment of patients with acute diarrhea. International Journal of Probiotics \& Prebiotics. 2012;7(1)

[21] Hill DR, Ryan ET. Management of travellers' diarrhoea. British Medical Journal. 2008;337:a1746

[22] Katelaris PH, Salam I, Farthing MJ. Lactobacilli to prevent traveler's diarrhea? The New England Journal of Medicine. 1995;333(44):1360

[23] Kollaritsch H, Holst H, Grobara P, Wiedermann G. Prevention of traveler's diarrhea with Saccharomyces boulardii. Results of a placebo controlled doubleblind study. Fortschritte der Medizin. 1993;111(43):152-156

[24] Oksanen PJ, Salminen S, Saxelin M, Hamalainen P, IhantolaVormisto A, Muurasniemi-Isoviita L, et al. Prevention of travellers' diarrhea by Lactobacillus GG. Annals of Medicine. 1990;22(45):53-56

[25] Moeinian M, FarnazGhasemi-Niri S, Mozaffari S, Abdollahi M. Synergistic effect of probiotics, butyrate and
1-Carnitine in treatment of IBD. Journal of Medical Hypotheses and Ideas. 2013;7(2):50-53

[26] Matsumoto S, Hara T, Hori T, Mitsuyama K, Nagaoka M, Tomiyasu N, et al. Probiotic Lactobacillusinduced improvement in murine chronic inflammatory bowel disease is associated with the down-regulation of pro-inflammatory cytokines in lamina propria mononuclear cells. Clinical and Experimental Immunology. 2005;140(3):417-426

[27] Ishikawa H, Akedo I, Umesaki Y, Tanaka R, Imaoka A, Otani T.

Randomized controlled trial of the effect of bifidobacteria-fermented milk on ulcerative colitis. Journal of the American College of Nutrition. 2003;22:56-63

[28] Kruis W, Schutz E, Fric P, Fixa B, Judmaier G, Stolte M. Doubleblind comparison of an oral Escherichia coli preparation and mesalazine in maintaining remission of ulcerative colitis. Alimentary Pharmacology \& Therapeutics. 1997;11:853-858

[29] Rembacken BJ, Snelling AM, Hawkey PM, Chalmers DM, Axon AT. Nonpathogenic Escherichia coli versus mesalazine for the treatment of ulcerative colitis: A randomized trial. Lancet. 1999;354:635-639

[30] Coqueiro AY, Raizel R, Bonvini A, Tirapegui J, Rogero MM. Probiotics for inflammatory bowel diseases: A promising adjuvant treatment. International Journal of Food Sciences and Nutrition. 2018;28:1-10

[31] Kelesidis T, Pothoulakis C. Efficacy and safety of the probiotic Saccharomyces boulardii for the prevention and therapy of gastrointestinal disorders. Therapeutic Advances in Gastroenterology. 2012;5(2):111-125

[32] Asto E, Mendez I, Audivert S, FarranCodina A, Espadaler J. The efficacy of 
probiotics, prebiotic inulin-type fructans, and synbiotics in human ulcerative colitis: A systematic review and metaanalysis. Nutrients. 2019;11(2):293

[33] Jonkers D, Penders J, Masclee A, Pierik M. Probiotics in the management of inflammatory bowel disease. Drugs. 2012;72(6):803-823

[34] Van Immerseel F, Ducatelle R, De Vos M, Boon N, Van De Wiele T, Verbeke K, et al. Butyric acid-producing anaerobic bacteria as a novel probiotic treatment approach for inflammatory bowel disease. Journal of Medical Microbiology. 2010;59(2):141-143

[35] Veerappan GR, Betteridge J, Young PE. Probiotics for the treatment of inflammatory bowel disease. Current Gastroenterology Reports. 2012;14(4):324-333

[36] Howarth GS. Inflammatory bowel disease, a dysregulated hostmicrobiota interaction: Are probiotics a new therapeutic option. Journal of Gastroenterology and Hepatology. 2008;23(12):1777-1779

[37] Gionchetti P, Rizzello F, Helwig U, Venturi A, Lammers KM, Brigidi $\mathrm{P}$, et al. Prophylaxis of pouchitis onset with probiotic therapy: A double-blind, placebo-controlled trial. Gastroenterology. 2003;124:1202-1209

[38] Lichtenstein L, Avni-Biron I, Ben-Bassat $O$. The current place of probiotics and prebiotics in the treatment of pouchitis. Best Practice \& Research: Clinical Gastroenterology. 2016;30(1):73-80

[39] Kim HJ, Camilleri M, McKinzie S, Lempke MB, Burton DD, Thomforde $\mathrm{GM}$, et al. A randomized controlled trial of a probiotic, VSL\#3, on gut transit and symptoms in diarrhea predominant irritable bowel syndrome. Alimentary Pharmacology \& Therapeutics. 2003;17:895-904
[40] Niedzielin K, Kordecki H, Birkenfeld B. A controlled, doubleblind, randomized study on the efficacy of Lactobacillus plantarum $299 \mathrm{~V}$ in patients with irritable bowel syndrome. European Journal of Gastroenterology \& Hepatology. 2001;13:1143-1147

[41] Nobaek S, Johansson ML, Molin G, Ahrne S, Jeppsson B. Alteration of intestinal microflora is associated with reduction in abdominal bloating and pain in patients with irritable bowel syndrome. The American Journal of Gastroenterology. 2000;95:1231-1238

[42] O’Sullivan MA, O’Morain CA. Bacterial supplementation in the irritable bowel syndrome. A randomized double-blind placebo controlled crossover study. Digestive and Liver Disease. 2000;32:294-301

[43] Sen S, Mullan MM, Parker TJ, Woolner JT, Tarry SA, Hunter JO. Effect of Lactobacillus plantarum $299 \mathrm{~V}$ on colonic fermentation and symptoms of irritable bowel syndrome. Digestive Diseases and Sciences. 2002; 47:2615-2620

[44] Connell M, Shin A, JamesStevenson T, Xu H, Imperiale TF, Herron J. Systematic review and metaanalysis: Efficacy of patented probiotic, VSL\#3, in irritable bowel syndrome. Neurogastroenterology and Motilility. 2018;30(12):124-128

[45] Scrimshaw NS, Murray AB. The acceptability of milk and milk products in populations with a high prevalence of lactose intolerance. American Journal of Clinical Nutrition. 1988;48:1083

[46] Sanders ME. Summary of the conclusions from a consensus panel of experts on health attributes on lactic cultures: Significance to fluid milk products containing cultures. Journal of Dairy Science. 1993;76:1819-1828

[47] Oak SJ, Jha R. The effects of probiotics in lactose intolerance: $\mathrm{A}$ 
systematic review. Critical Reviews in Food Science and Nutrition.

2018;59(11):1675-1683. DOI: 10.1080/10408398.2018.14259

[48] Hirayama K, Rafter J. The role of lactic acid bacteria in colon cancer prevention: Mechanistic considerations. Antonie Van Leeuwenhoek. 1999;76:391-394

[49] Marotta F, Naito Y, Minelli E, Tajiri H, Bertuccelli J, Wu CC, et al. Chemopreventive effect of a probiotic preparation on the development of preneoplastic and neoplastic colonic lesions: An experimental study. HepatoGastroenterology. 2003;50:1914-1918

[50] Rafter J. Lactic acid bacteria and cancer: Mechanistic perspective. The British Journal of Nutrition. 2002;88:S89-S94

[51] Rafter J. Probiotics and colon cancer. Best Practice \& Research: Clinical Gastroenterology. 2003;17:849-859

[52] Lee SY, Jeon HM, Ju MK, Kim $\mathrm{CH}$, Yoon G, Han SI, et al. Wnt/Snail signaling regulates cytochrome $\mathrm{C}$ oxidase and glucose metabolism. Cancer Research. 2012;72(14):3607-3617

[53] Mario U, Giulia M, Francesco B, Velia D, Michele M, Gaetano B, et al. Potential role of probiotics on colorectal cancer prevention. BMC Surgery. 2012;12(Suppl 1):S1-S35

[54] Koebnick C, Wagner I, Leitzmann P, Stern U, Zunft HJ. Probiotic beverage containing Lactobacillus casei Shirota improves gastrointestinal symptoms in patients with chronic constipation. Canadian Journal of Gastroenterology. 2003;17:655-659

[55] Ouwehand AC, Lagstrom H, Suomalainen T, Salminen S. Effect of probiotics on constipation, fecal azoreductase activity and fecal mucin content in the elderly. Annals of Nutrition and Metabolism. 2002;46:159-162

[56] Martínez-Martínez IM, CalabuigTolsá R, Cauli O. The effect of probiotics as a treatment for constipation in elderly people: A systematic review. Archives of Gerontology and Geriatrics. 2017;71:142-149

[57] McFarland LV. Meta-analysis of probiotics for the prevention of traveler's diarrhea. Travel Medicine and Infectious Disease. 2007;5(2):97-105

[58] Delcenserie V, Martel D, Lamoureux M, Amiot J, Boutin Y, Roy D. Immunomodulatory effects of probiotics in the intestinal tract. Current Issues in Molecular Biology. 2008;10(1/2):37

[59] Isolauri E, Sherman PM, Walker WA, editors. Intestinal Microbiome: Functional Aspects in Health and Disease, Nestlé Nutr Inst Workshop Series, Nestec Ltd., Vevey/S. Karger AG., Basel, @. Vol. 88. 2017. pp. 161-170. DOI: $10.1159 / 000455400$

[60] Hardy H, Harris J, Lyon E, Beal J, Foey AD. Probiotics, prebiotics and immunomodulation of gut mucosal defenses: Homeostasis and immunopathology. Nutrients. 2013;5(6):1869-1912

[61] Canducci F, Cremonini F, Armuzzi A, Di Caro S, Gabrielli M, Santarelli L, et al. Probiotics and Helicobacter pylori eradication. Digestive and Liver Disease. 2002;34:S81-S83

[62] Felley C, Michetti P. Probiotics and Helicobacter pylori. Best Practice \& Research: Clinical Gastroenterology. 2003;17:785-791

[63] Hamilton-Miller JM. The role of probiotics in the treatment and prevention of Helicobacter pylori infection. International Journal of Antimicrobial Agents. 2003;22:360-366 
[64] Cremonini F, Di Caro S, Covino M, Armuzzi A, Gabrielli M, Santarelli $\mathrm{L}$, et al. Effect of different probiotic preparations on anti-Helicobacter pylori therapy-related side effects: A parallel group, triple blind, placebocontrolled study. The American Journal of Gastroenterology. 2002;97:2744-2749

[65] Liu Q, Duan ZP, da Ha K, Bengmark S, Kurtovic J, Riordan SM. Synbiotic modulation of gut flora: Effect on minimal hepatic encephalopathy in patients with cirrhosis. Hepatology. 2004;39:1441

[66] Loguercio C, Abbiati R, Rinaldi M, Romano A, Del Vecchio Blanco C, Coltorti M. Long-term effects of enterococcus faecium SF68 versus lactulose in the treatment of patients with cirrhosis and grade 1-2 hepatic encephalopathy. Journal of Hepatology. 1995;23:39-46

[67] Dalal R, McGee RG, Riordan SM, Webster AC. Probiotics for people with hepatic encephalopathy. Cochrane Database of Systematic Reviews. 2017;2:1465-1858. Art. No.: CD008716. DOI: 10.1002/14651858.CD008716.pub3

[68] Li Z, Yang S, Lin H, Huang J, Watkins PA, Moser AB, et al. Probiotics and antibodies to TNF inhibit inflammatory activity and improve nonalcoholic fatty liver disease. Hepatology. 2003;37:343-350

[69] Olah A, Belagyi T, Issekutz A, Gamal ME, Bengmark S. Randomized clinical trial of specific lactobacillus and fiber supplement to early enteral nutrition in patients with acute pancreatitis. The British Journal of Surgery. 2002;89:1103-1107

[70] Chen J, Thomeson M, Vitetta L. Interaction of gut microbiota with dysregulation of bile acids in the pathogenesis of nonalcoholic fatty liver disease and potential therapeutic implications of probiotics.
Journal of Cellular Biochemistry. 2019;120(3):2713-2720

[71] Drasar BS, Roberts AK. Control of the large bowel microflora. In: Hill MJ, Marsh PD, editors. Human Microbial Ecology. Boca Raton, FL: CRC Press; 1990. pp. 87-111

[72] Yoshita M, Fujita K, Sakata H. Development of the normal intestinal flora and its clinical significance in infants and children. Bifidobacteria and Microflora. 1991;10:11-27

[73] Maxson RT, Jackson RJ, Smith $\mathrm{SD}$. The protective role of enteral IgA supplementation in neonatal gut origin sepsis. Journal of Pediatric Surgery. 1995;176:2313

[74] Steinwender G, Schimpl G, Sixl B, Kerbler S, Ratschek M, Kilzer S, et al. Effect of early nutritional deprivation and diet on translocation of bacteria from the gastrointestinal tract in the newborn rat. Pediatric Research. 1995;39:415-420

[75] Xiao L, Ding G, Ding Y, Deng C, Ze $X$, Chen L, et al. Effect of probiotics on digestibility and immunity in infant: A study protocol for a randomized controlled trial. Medicine (Baltimore). 2017;96(14):e5953

[76] Hilton E, Isenberg HD, Alperstein $\mathrm{P}$, France K, Borenstein MT. Ingestion of yogurt containing Lactobacillus acidophilus as prophylaxis for candidal vaginitis. Annals of Internal Medicine. 1992;116:353-357

[77] Williams AB, Yu C, Tashima K, Burgess J, Danvers K. Evaluation of two self-care treatments for prevention of vaginal candidiasis in women with HIV. Journal of the Association of Nurses in AIDS Care. 2001;12:51-57

[78] Falagas ME, Betsi GI, Tokas T, Athanasiou S. Probiotics for prevention of recurrent urinary tract infections in 
women: A review of the evidence from microbiological and clinical studies. Drugs. 2006;66:1253-1261

[79] Cohen CR, Duerr A, Pruithithada N, Rugpao S, Hillier S, Garcia P, et al. Bacterial vaginosis and HIV seroprevalence among female commercial sex workers in Chiang Mai, Thailand. AIDS Journal. 1995;9:1093-1097

[80] Sewankambo N, Gray RH, Wawer MJ, Paxton L, McNaim D, WabwireMangen F, et al. HIV-1 infection associated with abnormal vaginal flora morphology and bacterial vaginosis. Lancet. 1997;350:546-550

[81] Liu JJ, Reid G, Jiang Y, Turner MS, Tsai CC. Activity of HIV entry and fusion inhibitors expressed by the human vaginal colonizing probiotic Lactobacillus reuteri $\mathrm{RC}-14$. Cellular Microbiology. 2006;9(1):120-130

[82] Ranjbar S, Seyednejad SA, Azimi H, Rezaeizadeh H, Rahimi R. Emerging roles of probiotics in prevention and treatment of breast cancer: A comprehensive review of their therapeutic potential. Nutrition and Cancer. 2019;71(1):1-12

[83] Sun Z, Sun X, Li J, Li Z, Hu Q, $\mathrm{Li} \mathrm{L}$, et al. Using probiotics for type 2 diabetes mellitus intervention: Advances, questions, and potential. Critical Reviews in Food Science and Nutrition. 2019;59:1-14. DOI: 10.1080/10408398.2018.1547268

[84] Parodi PW. Anticancer agents in milk fat. Australian Journal of Dairy Technology. 2003;58:114-118

[85] Thom E, Wadstein J, Gudmunsden O. Conjugated linoleic acid reduces body fat in healthy excercising humans. Journal of International Medical Research. 2001;29:392-396

[86] Metchinkoff E. The Prolongation of Life, Optimistic Studies (English translation edited by PC Michelle). New York, London: G.P Putnam's and Sons; 1998

[87] Zouhari A, Accolas JP, Desmazeaud MJ. Metabolism and biochemical characteristics of yogurt bacteria. A review. Lait. 1992;72:1-34

[88] Playne MJ. Functional dairy foods and ingredients. Australian Dairy Foods. 2003;58(3):242

[89] Playne MJ. Researching, developing and commercializing probiotic cheese. Australian Dairy Foods. 2002;23(2):28-30

[90] Fernández-Ginés JM, FernándezLopez J, Sayas-Barberá E, Pérez-Alvarez JA. Meat products as functional foods: A review. Journal of Food Science. 2005;70(2):R37-R43

[91] Chizzolini R, Zanardi E, Dorigoni V, Ghidini S. Calorific value and cholesterol content of normal and low-fat meat and meat products. Trends in Food Science and Technology. 1999;10:119-128

[92] Pappa IC, Bloukas JG, Arvanitoyannis IS. Optimization of salt, olive oil and pectin level for low-fat frankfurters produced by replacing pork backfat with olive oil. Meat Science. 2000;56:81-88

[93] Sadler MJ. Meat alternatives market developments and health benefits. Trends in Food Science and Technology. 2004;15:250-260

[94] Ferrari CKB, Torres EAFS. Biochemical pharmacology of functional foods and prevention of chronic diseases of aging. Biomedicine and Pharmacotherapy. 2003;57:251-260

[95] Tang S, Kerry JP, Sheehan D, Joe Bukley D, Morrissey PA. Antioxidative effect of added tea catechins on susceptibility of cooked red meat, 
poultry and fish patties to lipid oxidation. Food Research International. 2001;34:651-657

[96] Ruusunen M, Vainionpaa J, Poulanne E, Lyly M, Lähteenmäki L, Niemistö M, et al. Physical and sensory properties of low-salt phosphate free frankfurters composed with various ingredients. Meat Science. 2003;63:9-16

[97] Gibson GR, Roberfroid MD. Dietary modulation of the human colonic microbiota-Introducing the concept of prebiotics. The Journal of Nutrition. 1995;125:1401-1412

[98] Yoo JY, Kim SS. Probiotics and prebiotics: Present status and future perspectives on metabolic disorders. Nutrients. 2016;8(3):173

[99] den Besten G, van Eunen K, Groen AK, Venema K, Reijngoud DJ, Bakker BM. The role of short-chain fatty acids in the interplay between diet, gut microbiota, and host energy metabolism. Journal of Lipid Research. 2013;54(9):2325-2340

[100] Markowiak P, Śliżewska K. Effects of probiotics, prebiotics, and synbiotics on human health. Nutrients. 2017;9(9):1021

[101] Slavin J. Fiber and prebiotics: Mechanisms and health benefits. Nutrients. 2013;5:1417-1435

[102] Gibson RG, Probert HM, Van LJ, Rastall RA, Roberfroid MB. Dietary modulation of the human colonic microbiota: Updating the concept of prebiotics. Nutrition Research Reviews. 2004;17:259-275

[103] Flint HJ. The impact of nutrition on the human microbiome. Nutrition Reviews. 2012;70:3-10

[104] Bindels LB, Walter J, RamerTait AE. Resistant starches for the administration of metabolic diseases.
Current Opinion in Clinical Nutrition \& Metabolic Care. 2015;18:559-565

[105] Fuentes-Zaragoza E, SánchezZapata E, Sendra E, Sayas E, Navarro C, Fernández-López J, et al. Resistant starch as prebiotic: A review. Starch/ Staerke. 2011;63:406-415

[106] Lesmes U, Beards EJ, Gibson GR, Tuohy KM, Shimoni E. Starch type III polymorphseffects on human colon microbiota and short chain fatty acids in human alimentary canal. Journal of Agricultural and Food Chemistry. 2008;56:5415-5421

[107] Brownlee IA, Allen A, Pearson JP, et al. Alginic acid salt or ester as a dietary fiber. Critical Reviews in Food Science and Nutrition. 2005;45:497-510

[108] Dettmar PW, Strugala V, Craig RJ. Important part alginates contributes in health. Food Hydrocolloids. 2011;25:263-266

[109] Russell WR, Gratz SW, Duncan $\mathrm{SH}$, et al. High-protein, reducedcarbohydrate weight-loss diets promote metabolite profiles likely to be detrimental to colonic health. The American Journal of Clinical Nutrition. 2011;93:1062-1072

[110] ElKaoutari A, Armougom

F, Gordon JI, Raoult D, Henrissat

$B$. The abundance and variety of carbohydrate-active enzymes in the human gut microbiota. Nature Reviews. Microbiology. 2013;11(7):497-504

[111] Madrigal L, Sangronis E. Inulin and derivates as key ingredients in functional foods. Archivos Latinoamericanos de Nutrición. 2007;57(4):387-396

[112] Mudgil D, Sheweta B, Ami Rameshbhai P, Nihir PS. Partially hydrolyzed guar gum as a potential prebiotic source. International 
Journal of Biological Macromolecules. 2018;112:207-210

[113] Liu Y, Sun M, Yao H, Liu Y, Gao R. Herbal medicine for the treatment of obesity: An overview of scientific evidence from 2007 to 2017. EvidenceBased Complementary and Alternative Medicine. 2017;17. Article ID: 8943059

[114] Zeng H, Peilin C, Chuanjie C, Cancan H, Shan L, Baodong Z, et al. Structural properties and prebiotic activities of fractionated lotus seed resistant starches. Food Chemistry. 2018;15(251):33-40

[115] Zhuang X, Zhao C, Liu K, Rubinelli P, Ricke SC, Atungulu GG. Chapter 10. Cereal grain fractions as potential sources of prebiotics: Current status, opportunities, and potential applications. In: Ricke SC, Atungulu GG, Park SH, Rainwater CE, editors. Food and Feed Safety Systems and Analysis. San Diego, CA: Elsevier Inc.; 2017. pp. 173-191

[116] Moro TMA, Celegatti CM, Pereira APA, Lopes AS, Barbin DF, Pastore $\mathrm{GM}$, et al. Use of burdock root flour as a prebiotic ingredient in cookies. LWT. 2018;90:540-546

[117] DeVrese M, Schrezenmeir J. Probiotics, Prebiotics, and Synbiotics in Food Biotechnology. Berlin, Heidelberg: Springer; 2008. pp. 1-66

[118] Uccello M, Malaguarnera G, Basile F, D'agata V, Malaguarnera M, Bertino $\mathrm{G}$, et al. Potential role of probiotics on colorectal cancer prevention. BMC Surgery. 2012;12(1):S35

[119] Alrawi SJ, Schiff M, Carroll RE, Dayton M, Gibbs JF, Kulavlat M, et al. Aberrant crypt foci. Anticancer Research. 2006;26:107-119

[120] Perrin P, Pierre F, Patry Y, Champ M, Berreur M, Pradal G, et al. Only fibres promoting a stable butyrate producing colonic ecosystem decrease the rate of aberrant crypt foci in rats. Gut. 2001;48(1):53-61

[121] Bodera P. Influence of prebiotics on the human immune system (GALT). Recent Patents on Inflammation \& Allergy Drug Discovery. 2008;2:19-153. DOI: $10.2174 / 187221308784543656$

[122] Nicolucci AC, Reimer RA. Prebiotics as a modulator of gut microbiota in paediatric obesity. Pediatric Obesity. 2017;12:265-273

[123] Chia-Ching KA, Burnet PWJ, Lennox BR. Can prebiotics assist in the management of cognition and weight gain in schizophrenia? Psychoneuroendocrinology. 2018;95:179-185

[124] Zhou S, Hang Y, Wang J, Fang R. Enzyme activity and phosphate uptake in the small intestine of Sprague Dawley rats improved by supplementation of infant formula with prebiotics. Animal Nutrition. 2018;4(3):300-304

[125] Bongers A, van den Heuvel EGHM. Prebiotics and the bioavailability of minerals and trace elements. Food Reviews International. 2003;4(19):397-422

[126] Mitchell CM, Davy BM, Halliday TM, Hulver MW, Neilson AP, Ponder MA, et al. The effect of prebiotic supplementation with inulin on cardiometabolic health: Rationale, design, and methods of a controlled feeding efficacy trial in adults at risk of type 2 diabetes. Contemporary Clinical Trials. 2015;45:328-337

[127] Firouzi S, Haghighatdoost F.

The effects of prebiotic, probiotic, and synbiotic supplementation on blood parameters of renal function: A systematic review and metaanalysis of clinical trials. Nutrition. 2018;51-52:104-113 
[128] Xie X, Yaqin H, Hai L, Dong Y, Li $\mathrm{N}$, Ting S, et al. Effects of prebiotics on immunological indicators and intestinal microbiota structure in perioperative colorectal cancer patients. Nutrition. 2019;61:132-142

[129] Aurelijus B, Silvia A, Rachel D, Moloney VL, Kiera M, Gerard C, et al. Targeting the microbiota-gutbrain axis: Prebiotics have anxiolytic and antidepressant-like effects and reverse the impact of chronic stress in mice. Biological Psychiatry. 2017;82(7):472-487 


\title{
Gut-Brain Axis: Probiotic, Bacillus subtilis, Prevents Aggression via the Modification of the Central Serotonergic System
}

\author{
Heng-Wei Cheng, Sha Jiang and Jiaying Hu
}

\begin{abstract}
Intestinal bacteria release various neuroactive compounds directly or indirectly regulating brain function to modulate host health and behavior through the gut-brain axis. Probiotics have been used as dietary supplements to target gut microbiota (microbiome) for prevention or therapeutic treatment of various diseases including mental disorders. In our study, chickens were used as an animal model to assess, if dietary supplementation of probiotic, Bacillus subtilis, reduces aggressive behaviors following social challenge. Chickens of an aggressive line were housed in single-hen cages. At 24 weeks of age, the hens were paired with similar body weight to identify the dominance rank (day 0 ). The subordinate and dominant of each pair were fed a regular layer diet or the diet mixed with $250 \mathrm{ppm}$ probiotics for 2 weeks, then the second behavior test was performed between the same pair (day 14). The display of aggressive behaviors in the regular diet-fed chickens was not affected between the levels at day 0 and day 14, while the frequency of threat and aggressive pecking were reduced in the probiotic-fed chickens compared to the levels at day 0 . These results suggest dietary probiotic, Bacillus subtilis, could be a suitable strategy for increasing hosts' mental health.
\end{abstract}

Keywords: probiotics, Bacillus subtilis, aggression, serotonergic system, gut-brain axis

\section{Introduction}

Human emotional susceptibility in an inter-group is associated with individual differences in the functions of the hormonal and/or neurochemical systems in response to internal and external stimulations. Aggression, as one of emotional disorders, has been commonly defined as feeling of anger or antipathy of an organism during social interaction, leading to hostile of violent behavior or attitude, provoking attack or confront toward another individual [1]. Aggression affects millions of people's health and welfare around the world annually, resulting in significant social destruction and economic costs.

Intestinal bacteria, as a virtual endocrine organ, release various neuroactive compounds directly or indirectly regulating brain function, including the serotonergic system, to regulate host health and behavior through the gut-brain 
axis [2-10]. Intestinal bacteria, as well as Bacillus subtilis, used as probiotics are involved in tryptophan metabolism [11-14]. Tryptophan metabolites have roles in protecting intestinal mucosa from inflammation and regulating gut immune homeostasis [15-18]. Tryptophan, a precursor of 5-HT, directly affects brain 5-HT synthesis as that tryptophan can pass the brain-blood barrier $[19,20]$. The brain serotonergic system plays a critical role in regulating behaviors, especially aggression [21, 22]. Concentrations of 5-HT and its metabolites, as well as the density of 5-HT receptors, have been used as major indicators of aggressive behaviors in humans and experimental animals [23-26].

Probiotics (also called psychobiotics or bio-friendly agents), defined "as a source of live (viable) naturally occurring microorganisms (direct-fed microbials, DFMs)", have been used as dietary supplements to target gut microbiota (microbiome) for a novel promising therapeutic approach of various diseases including social stressinduced mental disorders in humans and various experimental animals [27-36]. Different probiotic strains, for example, have been investigated as functional food or therapeutic treatment of various diseases, including Bifidobacterium bifidum [37-39]; Bifidobacterium bifidum (BGN4) and Bifidobacterium longum (BORI) [40, 41]; Bifidobacterium pseudocatenulatum [42]; Lactobacillus helveticus [31, 32]; Lactobacillus plantarum [43]; Lactobacillus paracasei (KW3110, [44]); Lactobacillus rhamnosus [45]; and Clostridium butyricum [46]. The results collected from these studies indicate that the effects of probiotics on physiological homeostasis, immunity, stress resistance, and related health status are affected by multiple factors, including the probiotic species, its concentration, and duration as well as the host's age and health status $[47,48]$.

Bacillus subtilis, as one of the three most common species of probiotic products in the United States [49], has been widely used as functional feed supplements, such as in a number of dairy and non-dairy fermented foods, for improving human health and well-being [50-52]. Similarly, Bacillus subtilis, as growth promoters, has been demonstrated to improve chickens' growth performance [53-55]; regulate intestinal microstructure [56] and digestive enzymes [57, 58]; synthesize and release antimicrobial and antibiotic compounds [15, 59-63]; increase immunity $[57,64]$ and neurochemical activities including serotonin $[8,65,66]$ as well as affect animal behavior $[67,68]$ following various stressors. In addition, Bacillus subtilis can overproduce L-tryptophan $[11,69]$, consequently increase 5-HT in the hypothalamus [70], function as an antidepressant and anti-anxiety agent [71, 72], and eliminate nervous tension in mice [73]. In the current study, chickens were used as an animal model to assess if dietary supplementation of probiotic, Bacillus subtilis, reduces aggressive behaviors following social challenge.

\section{Gut microbiota and the gut-brain axis}

Gut microbiota is a collective name of ten of trillions of microorganisms living in our intestine, including more than 35,000 different species of known bacteria [74]. Microbiome refers to the collective genomes of more than 3 million genes of the microorganisms in a particular environment. Gut microbiota, like a virtual endocrine organ, reacts to various internal and external stimuli $[5,75-78]$. Consequently, gut microbiota influences and regulates hosts' health and mood statue including aggression by integrating metabolic, immune, endocrine, and neural reactions through the bidirectional communication of the gut-brain axis (Figure 1) [7, 33, 79-83]. Gut microbiota in hosts, for example, regulates brain neurotransmitters [84-87] such as serotonin (5-HT) through releasing its precursor, tryptophan, an essential amino acid [75, 88-90]. Serotonin is a key neurotransmitter within the brain, contributing to the development of the central nervous system (CNS) 
[91-94] and social behavior [95, 96], affecting mental health [97-100] and providing therapeutic strategy for treating or preventing stress reaction and related neuropsychiatric disorders $[94,97]$.

\subsection{Social stress and the hypothalamic-pituitary-adrenal axis}

The social world is filled with different types of interactions, such that social challenges (fight-or-flight) and social environmental changes (group instability), as stressors, can cause highly potent stress [101-103]. Some management practices used in the intensive farm animal production systems, for example, may cause stress in animals. Farm animals are often housed in large groups at high densities, and during the animals' lifetimes, they are repeatedly transported to new environments and mixed with unfamiliar individuals. Based on the social network theory, animal group disruption can lead to social stress and related aggression [104] when they are unable to cope with these management practices and/or to reset their dominance rank (a form of animal social structure hierarchy) [105, 106].

Aggression has been commonly defined as feeling of anger or antipathy during social interactions, leading to hostile or destructive behaviors or attitudes, provoking physical or verbal attack or confront toward another individual [1]. Aggressive encounters among conspecifics for obtaining or maintaining a socially dominant position or rank cause a negative or unstable social environment to activate the hypothalamic-pituitary-adrenal (HPA) axis which is known as the key stress response system [107-109]. Cortisol (or corticosterone, CORT, in rodents and birds), as one of the final hormones released from the adrenal cortex, has multifunctional functions in both normal and abnormal states, regulating behavioral styles, metabolic patterns, and endocrine and immune functions, and ensuring an adequate coping strategy and well-being [110-112]. In mammals, hypercortisolism in response to novel environment exposures has been evidenced to be of adrenal origin $[113,114]$. The value of circulating cortisol (or CORT) has been used as a criterion of stress response in humans and various animals [115-117]. Corticotrophinreleasing factor facilitates aggression $[118,119]$, and related elevation of CORT (or cortisol) also affects neuroendocrine functions through binding to their receptors $[120,121]$, causing neuron loss in the hippocampus [122], dysfunction of the serotonergic system [123], and inhibition of immunity (increased pro-inflammatory cytokines as neuroinflammatory response) within stress-sensitive brain regions [124]. These changes finally lead to the development of psychological disorders such as aggression $[109,125]$. Similar to that the HPA hyperactivity generates aggressive behavior, exogenous glucocorticoid treatments increase exacerbated aggressiveness in both humans and experimental animals $[123,126]$. Taken together, emerging

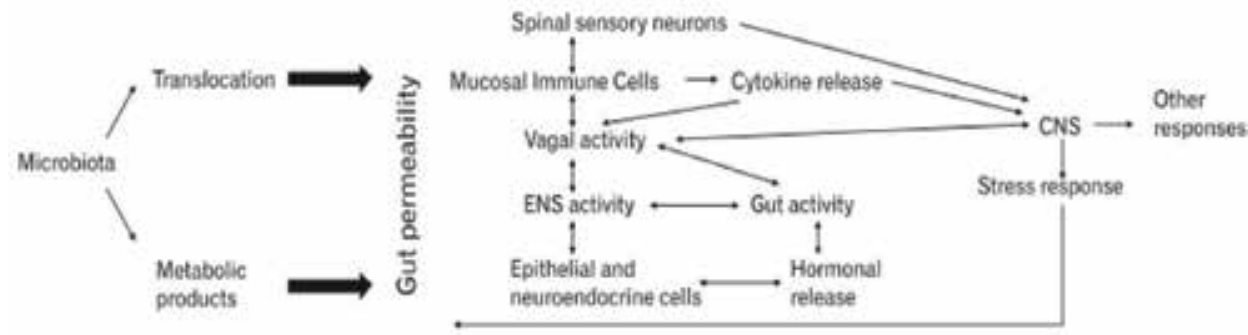

Figure 1.

The microbiota-host interaction occurs at the level of the gastrointestinal mucosa via local neural, endocrine, and immune activities, influencing brain neurotransmitter expression, physiological homeostasis, and immunity (modified from [79]). 
evidence have indicated that the changes of the programming of HPA stress reactivity [127] cause long-term effects on the host physiological homeostasis and neurobehavioral functions [128].

\subsection{Microbiota, stress-associated aggression}

Aggression within a group is to establish a dominance hierarchy when the animals are first brought together in a common environment [129-131]. From an evolutionary perspective, aggression is adaptive behaviors that are related to an individual's survival, growth, and reproductive success within a group [132, 133]. However, aggression with long-term impact is often destructive and maladaptive in today's society, affecting millions of people's health and well-being around the world annually, resulting in significant social destruction and economic costs [134-136].

Intestinal microbiota plays an important role in regulation of social behavior, emotional expression, and mental health within the animal kingdom [3, 137, 138]. They are essential players in stabilizing homeostasis of the GI tract in response to both acute and chronic stress via the microbiota-gut-brain axis $[16,139]$. Normally, intestinal microbiota provides protection for animals by competing for attachment sites and nutrients with pathogens as well as production of antimicrobial peptides and neuroactive compounds $[140,141]$. The gut microbiota is also a key pathway to modulate brain processing the integrated information received from the peripheral nerve systems (the vagus nerve, enteric nerve, and autonomic nervous system), hormone signaling, the immune system, and microbial metabolites (short-chain fatty acids) [5,137]. Under social challenges, stress and related oxidative damage cause anatomical and functional disorders of the GI tract by: (1) disrupting the commensal bacterial populations and colonization, thus reducing beneficial bacteria and increasing pathogens; (2) increasing pathogen survivability and innovating capability; (3) disrupting absorption of nutrients and minerals, including calcium;

(4) disrupting microbial neuroendocrine functions; (5) disrupting the gut epithelial barrier, thereby increasing intestinal permeability causing the gut to leak certain bacteria (leaky gut), resulting in metabolic disorder; (6) damaging epithelial cells, thus producing free radicals and reducing antioxidant efficacy; and (7) interrupting intestinal integrity, thereby leading to intestinal inflammation [142-144]. These changes in gut microenvironment affect brain functions, resulting in exacerbated HPA axis activity, increased chronic inflammation, and/or disrupted neurotransmitter balance, leading to emotional damage $[139,145]$ and mental disorders $[137,138]$. Sudo et al. [146] reported a correlation between the changes of gut microbiota and the function of the HPA axis. Germ-free (GF, antibiotic-treated microbiota-deficient or raised without any exposure to microorganisms) rats show exaggerated HPA responses to psychological stress [75, 147] with significantly higher levels of both ACTH and CORT in response to restraint stress compared to control rats [146]. In GF mice, gut microbiota also modulates the 5-HT synthesis and release at both the brain and peripheral levels directly and indirectly via the microbiota-host interactions [148]. Reduced 5-HT activity (a 5-HT deficiency) has been associated with personality traits (interspecific social behavior), such as impulsivity and aggression, and deteriorated stress coping capability (increased stress response) in humans and various animals $[149,150]$ including chickens [24, 151-154].

\section{Serotonin and aggression}

Serotonin, as an ancient chemical, is a key neurotransmitter. It plays a critical role in shaping social responses by regulating both basic (proactive) behaviors 
(such as feeding, drinking, and sexuality) and reactive behaviors (fearfulness, anxiety, and cognition) including aggressive behaviors $[155,156]$ and mood disorders $[157,158]$. Abnormalities of blood and brain levels of 5-HT, 5-HIAA (its metabolite, 5-hydroxyindoleacetic acid), tryptophan, and its receptors have been used as major indicators or targets in the diagnoses and treatments of psychiatric and compulsive disorders in humans and various experimental animals [62, 63, 159, 160].

In the CNS, 5-HT functions to inhibit aggression, thereby controlling domestic behaviors [161-163]. The 5-HT deficiency theory of aggression is driven from the negative correlation between the changes of the CNS 5-HT and aggressiveness in humans $[164,165]$, non-human primates [166], rodents [25, 167], and chickens $[24,168]$. Aggressive animals have low levels of 5-HT in the brain, including in the hypothalamus [169-171]. Experimental increase of 5-HT and/or 5-HIAA in the brain, such as in the lateral hypothalamus and amygdala, blocks or retracts killing behavior in rodents $[172,173]$. Hypothalamic injection of a 5-HT1a agonist inhibits aggression in male hamsters [174]. Depletion of brain 5-HT in TPH2 mutant mice marks aggression and lowers habituation in novel environments [149]. In addition, 5-HT1BR knockout mice show increased aggression and impulsivity $[175,176]$. The implication of 5-HT successfully relieves the depression syndromes in humans [177] and reduces aggressive behaviors in primates and rodents [178, 179].

In the peripheral system, however, pathophysiological roles of 5-HT in behavioral and motivational regulations are unclear. Reduced, elevated, and unchanged blood 5-HT concentrations have all been reported in association with behavioral dysfunctions, including aggressiveness $[180,181]$. The conflicting data from different investigations could be related to the differences in species of animals, behavioral evaluations, and/or stressors used as well as duration and frequency of stressors presented.

\section{Chicken as an animal model for social stress and related aggression}

Human emotional susceptibility in an inter-group is associated with individual differences in the functions of the hormonal and neurochemical systems in response to internal and external stimulations [182, 183]. Various social and biological factors are associated with the development and expression of aggressive behaviors, including environmental, genetic, cognitive, hormonal, and neurotransmitter circumstances [184]. Aggression and associated mental illness are an emerging public health problem [29]. Animal models are critical for investigating the potential biological processes involved in human aggression and mental disorders.

Although there are dissimilarities between humans and chickens, as indicated, the neural circuitry for aggression and social behavior appear to be evolutionarily conserved across the vertebrates [185]; chickens have been used as an animal model in various clinical and psychopharmacological studies, such as anxiety, depression, and aggression $[186,187]$. A commercial hen can have more than 300 offspring with similar genetic characteristics during her lifetime, and chicks can be hatched without maternal condition effects. Previous studies have reported that birds' brain possess a core "social behavioral network" which is humongous to the social behavioral network of mammals [188]. There are evidences that the central nuclei involved in moodiness in avian, at least in part, are morphofunctional homologous to the mammalian nuclei [189], such as the hypothalamus [190], nucleus taeniae (homo$\log$ to the amygdala of mammals, [191, 192]), and Raphe nucleus [193]. These nuclei exert similar cognitive abilities and consciousness [194] with capability of plasticity in response to environmental stimulations [195]. In addition, there are similar distributions of neurotransmitter receptors, including serotonergic receptors 


\begin{tabular}{ll}
\hline Behavior & Description \\
\hline $\begin{array}{l}\text { Feather } \\
\text { pecking }\end{array}$ & $\begin{array}{l}\text { One bird pecking at feathers of another bird, can be gentle (nibbling or gentle pecking } \\
\text { in which feathers are not removed or pulled) or severe (vigorous pecking to feathers in } \\
\text { which feathers are often pulled, broken, or removed) }\end{array}$ \\
\hline Threat & One bird standing with its neck erect and hackle feathers raised in front of another bird \\
\hline $\begin{array}{l}\text { Aggressive } \\
\text { pecking }\end{array}$ & Forceful downward pecks directed at the head or neck of other birds \\
\hline Threat kick & One bird forcefully extending one or both legs such that the foot strikes another bird \\
\hline
\end{tabular}

Table 1.

Behavioral ethogram.

between birds and mammals [196, 197]. Particularly, it has been evidenced that the development and function of avian HPA axis in response to stimuli are analogous to those of mammals $[198,199]$ and there are similar distributions of cortisol-like molecules in the same organs from both birds and mammals [200]. Birds' CORT biosynthesis and metabolism can be stimulated in the same way as that of mammals [201-203]. During breeding, functional integrations among behavior, physiology, morphology, and environment in chickens may create suites of various traits that are simultaneously acted upon each selection program [204]. For example, selection based on individual production capability (phenotypic characteristics) increases animals' competition and aggression $[205,206]$ such as potentially injurious feather pecking and cannibalism. For instance, through more than 20 years of selection, egg production had been increased significantly in a former commercial Dekalb XL strain, whereas mortality due to aggression and cannibalism in non-beak trimmed hens had also increased about 10 -fold [132, 152].

Results from previous studies conducted in our laboratory have found that chicken strain differs in social reactions through a diversely genetic selection program. The DXL hens have distinct stress levels in attempting to adapt to their social environments [207, 208] and exhibit different levels of aggressiveness [168]. In addition, neurotransmitters, 5-HT and dopamine (DA), and the hypothalamicpituitary-adrenal (HPA) axis are regulated differently between chicken strains $[168,207]$. There results suggest that injurious behaviors and related social sensitivity of chickens, similar to that in mammals, are regulated via the serotonergic system and the HPA axis [123, 209], and mechanisms underlying aggression in laying hens may be analogous to those of humans and rodents [210]. Similarly in humans and rodents, stress-induced destruction of intestinal bacteria disturbs the bilateral connection of the microbiota-gut-brain axis in chickens, affecting physiological homeostasis and behavioral exhibition [211]. In one of our studies, the role of probiotic, Bacillus subtilis, on aggression in DXL line was examined. In the study, one-day-old female chicks were reared in single-bird cages up to 24 weeks. At 24 weeks of age, the hens with similar body weight were paired for the first aggression test (pre-treatment, day 0) in a novel floor pen [212]. Behaviors were video-taped for $2 \mathrm{~h}$ immediately after releasing the two hens simultaneously into the floor pen to determine the dominant individual per pair. Following the behavioral test, the subordinate hens were continuously fed the regular diet, while the dominant hens were fed the diet mixed with $250 \mathrm{ppm}$ probiotic $\left(1.0 \times 10^{6} \mathrm{cfu} / \mathrm{g}\right.$ of feed) for 2 weeks. The probiotic contains three proprietary strains of B. subtilis. After the treatment (day 14), the second aggression test was conducted within the same pair of hens. The video recording was analyzed for frequency of feather pecking, threat, aggressive pecking, and threat kick by the routine lab procedures (Table 1) [154, 213]. 


\section{Probiotic, Bacillus subtilis, and aggression}

As social animals, chickens show fear, depression, and/or anxiety in novel environments and show aggression toward ones for establishing social dominance rank in unfamiliar social groups $[214,215]$, which is similar to rodents used in human psychopharmacological studies [216, 217]. The paired social ranking-associated behavioral test used in this study has been routinely performed in chicken behavioral analysis $[154,213,218]$. The rationale and cellular mechanisms of the test is similar to the resident-intruder test which is a standardized method used in rodents for detecting social stress-induced aggression and violence [219, 220].

\subsection{Probiotics and Bacillus spp.}

A healthy intestinal microbiota community is important for maintaining physiological and behavioral homeostasis as that the gut microbiota regulates appetite, local and systemic immunity, stress responses of the HPA and sympatheticmedullary-adrenal (SMA) axes, and circadian rhythms [5, 221]. The new strategies of psychotherapy aimed at restoring the normal gut microbiota and intestinal homeostasis have been developed for the prevention and/or reduction of stressinduced abnormal behaviors and mental disorders.

Probiotics are commensal bacteria ("direct-fed microbials", DFM) that offer potential health beneficial bio-physiological effects to the host's stress response (acute, chronic, or both). Probiotics aid animals in adapting to their environments and protect against pathogens by: (1) altering the microbiota profile with beneficial bacteria to prevent the growth of pathogens and to compete with enteric pathogens for the limited availability of nutrient and attachment sites; (2) producing bacteriocins (such as bacteriostatic and bactericidal substances) and short-chain fatty acids against pathogens to regulate the activity of intestinal digestive enzymes and energy homeostasis and to increase mineral solubility; (3) reducing oxidative stress, inflammation, and acinar cell injury; (4) modulating host immune and inflammatory responses and restoring the intestinal barrier integrity which prevents pathogens from crossing the mucosal epithelium; (5) stimulating the endocrine system and attenuating stress-induced disorders of the HPA and/or SMA axes via the gut-brain axis; and (6) inducing epithelial heat shock proteins to protect cells from oxidative damage; and (7) synthesis and secretion of neurotransmitter such as 5-HT and tryptophan [16, 17, 222-226]. In both human and rodent studies, probiotics reduce cognitive dysfunction, decrease the stress response and related oxidative damage by lowing plasma CORT and ACTH levels, restore hippocampal 5-HT levels, and normalize immunity with low plasma levels of TNF- $\alpha$ (tumor necrosis factor- $\alpha$ ), a proinflammatory cytokine, but high levels of IL-10 (Interleukin-10), an anti-inflammatory cytokine [67, 227-230]. It has been stated in nonhuman primate models that the composition of the gut microbiota has potential effects on hosts' aggressive behaviors and anxiety symptoms [127], which is similar to the findings reported in humans [137, 231-233]. In rodent studies, GF animals with exaggerated HPA responses to social stress can be normalized by certain probiotics [147]. In addition, probiotics have successfully attenuated anxiety and depressive behaviors in rat offspring separated from their mother [234-236] and the obsessivecompulsive-like behaviors in house mice $[28,237]$. These results support the psychobiotics theory [238] and provide a new insight into the possible use of probiotics to improve a host's cognitive function in humans [9, 40, 41, 239-243].

A proposed strategy for improving human health is dietary supplement with probiotic microorganisms including Bacillus species $[52,244]$. Bacillus subtilis is spore-forming bacteria. They have heat stability and low $\mathrm{pH}$-resistance (the 
gastric barrier), and tolerate multiple environmental stressors [245, 246]. Several Bacillus spp. such as $B$. coagulans and B. subtilis have been used as probiotics in both humans [247-249] and animals [246] including poultry [65, 67, 250, 251]. Several mechanisms of action of Bacillus spp. have been proposed: the improvement of hosts' growth, survival, and health status via their anti-inflammatory functions through immunomodulation and cytoprotection [252, 253]. And, they have been used as antibiotic growth promoters alternatives with health-promoting benefits by naturally synthesizing proteins, enzymes, antimicrobial peptides, vitamins, gut flora modulation to promote beneficial microbiota along the GI tract and to correct and repair immunological and gut morphological alterations [244, 246, $250,254,255]$. In addition, numerous studies have shown that probiotic-induced changes in the composition of gut microbiota lead to alterations of neuroendocrine functions. For example, in response stimulations, B. subtilis alleviate oxidative stress, provoke a specific biological response, and improve mood status of hosts via the gut-brain axis [52, 147, 256].

\subsection{Bacillus subtilis-based probiotic and social challenge-induced aggression}

Aggression, in nature, is associated with competition (natural selection) for survival and reproduction [22, 257, 258] (please also see above for the detailed description). However, in artificial production environments, such as in the poultry industry, aggression causes increased social stress and feather and body damage, in some instances these injuries leading ultimately to cannibalism. Cannibalism is a major concern related to non-beak trimmed bird deaths in current housing environments $[259,260]$. Beak trimming (BT) is a routine procedure practiced in the US egg industry for reducing social stress by preventing and/or inhibiting feather pecking and cannibalism. However, BT is criticized for causing tissue damage and pain (acute, chronic, or both), negatively affecting the welfare of billions of chickens annually [261,262]. Considerable concern from the public has led to a growing movement against procedures causing pain and suffering in farm animals. In response to growing pressures, housing environments of laying hens have been modified and/or various dietary supplementations have been provided in attempts to prevent social stress and stress-associated injurious behaviors. For instance, modifications include reducing light intensity, changing the nutritive value or taste of diets [263-265], providing straw or grain [266, 267] or pelleted diets [263], housing hens in floor-pens [268], and developing enriched cages $[269,270]$. However, these methods have had limited success and provide no guarantee of preventing these injurious behaviors. Therefore, an obvious solution is to develop a welfare-friendly alternative to BT that minimizes social stress, thereby preventing feather pecking and cannibalism. The hypothesis was tested in this study: probiotics could be an alternative to beak trimming in chickens for reducing feather pecking and aggression via regulating the gut-brain axis.

Based on the 5-HT deficiency theory of aggression, social challenge-induced changes in 5-HT concentration were examined in this study. In the current study, the data showed that prior to the treatment (day 0), plasma 5-HT levels were higher (26\% increase) in the dominant hens than that of subordinate hens but were not statistically significant $\left(P=0.24\right.$. Dominant ${ }_{5-\mathrm{HT}}=17.46 \mathrm{ng} / \mathrm{ml}$, Subordinate $_{5-\mathrm{HT}}=13.87 \mathrm{ng} / \mathrm{ml}$ ). This finding is in agreement with the results reported previously $[152,168]$. In those studies, higher plasma levels of 5-HT were detected in hens from mean bad bird (MBB) strain, a high aggressive strain selected for both low productivity and low longevity resulting from injurious pecking and cannibalism, compared to hens from kind gentle bird (KGB), a low aggressive strain selected for both high productivity and high longevity. In 
addition, Bolhuis et al. [271] proposed that blood 5-HT activity is correlated with the development of severe feather pecking in laying hens. A similar correlation between blood 5-HT levels and aggressiveness has also been detected in humans and various other animals, that is, a lower blood 5-HT level was associated with less aggressive individuals in humans [180, 272] and canine [273], while an elevated blood 5-HT level was determined in patients with aggressive behaviors [274] and in aggressive teleost fish [275].

Post-treatment (day 14), plasma 5-HT levels were reduced toward the levels of controls (subordinates) in the probiotic fed dominant hens $(P=0.02)$ compared to their related levels prior to treatment (day 0) (Figure 2). There were no treatment effects on plasma 5-HT concentrations in subordinate hens fed a regular diet $(P=0.88)$. Although the reasons of the reduction of plasma 5-HT concentrations in probiotic fed hens are still unclear but could be similar to those proposed in probiotic-treated patients with intestinal inflammatory disorders such as irritable bowel syndrome (IBS) and IBS experimental animals. Probiotics reduce IBS-associated abdominal pain and abnormal bowel habits $[276,277]$ through regulation of both the central and peripheral serotonergic systems via the microbiota-gut-brain axis $[278,279]$ and gut epithelial enterochromaffin cells [19]. In the peripheral system, probiotics reduce or inhibit IBS-associated serotonergic system abnormalities, that is, great hypersensitivity and spontaneous release of 5-HT [280, 281]. Serotonin reuptake transporter (SERT or 5-HTT) has functions in inactivating 5-HT. Downregulation of SERT receptors has been found in the intestinal mucosa of IBS patient whose symptoms are similar to those found in the SERT knockout mice [282]. Serotonin 5-HT3 receptor antagonist also has shown efficacy in treating IBS patients $[278,283]$. In addition, Wikoff et al. [284] reported that conventional mice had lower concentrations of 5-HT compared to GF mice. GF mice also had an exaggerated stress response [146] with anxiety-like behaviors [285]. These abnormal behaviors in GF mice can be inhibited or reduced by feeding probiotics [286] or transplanting fecal samples of conventional mice [287]. The current and previous

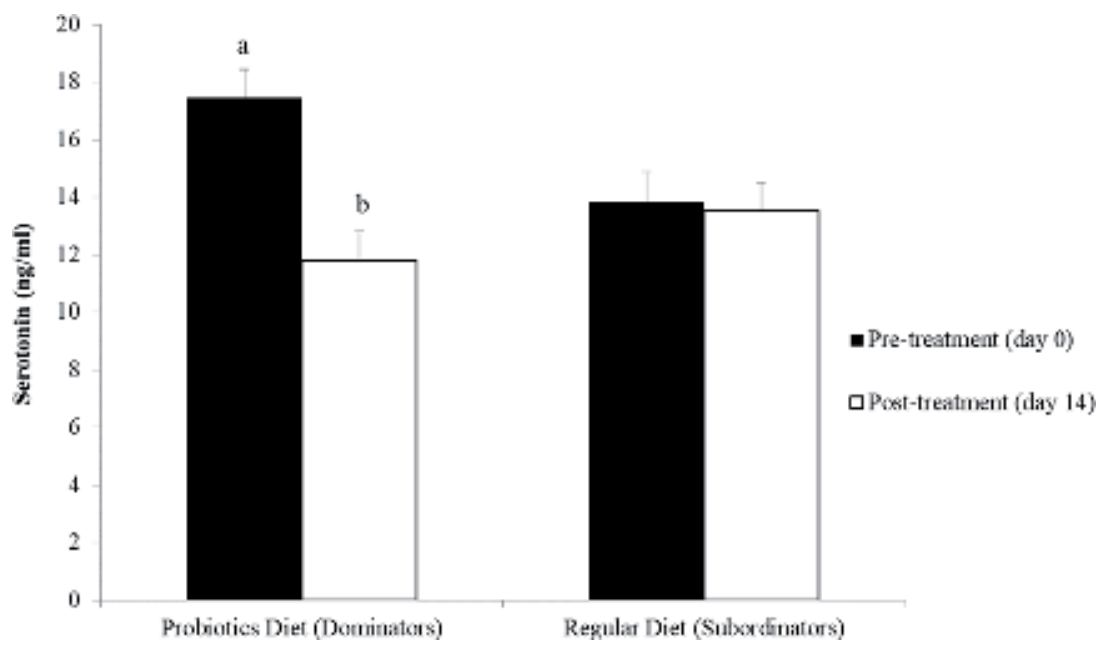

Figure 2.

Plasma serotonin (5-HT) levels at day o (pre-treatment) and day 14 (post-treatment) in probiotic fed dominant hens and regular diet fed subordinate hens. Compared to subordinate hens, plasma 5-HT concentrations were higher in dominant hens at day o but without statistical difference $(P=0.24)$; the difference disappeared at day 14. Compared to the levels at day o, blood concentrations of 5-HT were reduced in probiotic fed dominant hens at day $14(P=0.02)$ but were not in regular diet fed subordinate hens $(P>0.05) .{ }^{a, b}$ between the concentrations at day 0 and day 14 , least square means lacking common superscripts differ $(P<0.05)$. 
results indicate that normal health gut microbiota plays an important role in regulating social stress and stress-associated behaviors.

Whether the changes of blood 5-HT levels in probiotic fed dominant hens represent a similar change of 5-HT concentrations in the brain is unclear, as 5-HT cannot pass the brain-blood barrier and is regulated differently between brain neurons and peripheral tissues [288]. The plasma 5-HT is synthesized mainly by the EC cells of the gut and stored in the platelets [289]. However, it has been proposed that platelet 5-HT uptake is a peripheral marker of brain 5-HT [273]. Dietary probiotic, Lactobacillus plantarum strain PS128, increases the levels of 5-HT as well as dopamine in the striatum, which is correlated with the improvement of anxietylike behaviors in GF mice [290]. Similar results have been received from our current studies. In one study, chickens (broilers) were fed Bacillus subtilis from day one. At day 43, Bacillus subtilis fed chickens had higher levels of 5-HT in the raphe nuclei and lower levels of norepinephrine and DA in the hypothalamus than controls [291]. Probiotic fed chickens also had improved bone traits (bone mineral density, bone mineral content, and robusticity index). Under heat stress $\left(32^{\circ} \mathrm{C}\right)$, Bacillus subtilis fed chickens had lower heat stress-related behaviors and inflammatory response and reduced IL-6 levels in the hypothalamus compared to controls [67]. Further studies, however, are needed to examine if there are correlations between the regulations of peripheral 5-HT and CNS 5-HT in probiotic fed hens.

The gut commensal microflora may have an indirect effect on 5-HT synthesis by regulating tryptophan metabolism. The degradation of tryptophan, a precursor of $5-\mathrm{HT}$, is mainly through the kynurenine pathway which regulates over $95 \%$ of tryptophan in the peripheral system and is functionally mediated by gut microbiota and probiotics $[147,292]$. In the present study, the tryptophan level was not significantly affected by dietary probiotic $(P=0.35)$, but the initial levels of tryptophan in dominant hens were approximately $28 \%$ higher than the subdominant hens $(P=0.21)$ (Figure 3$)$. The pattern of changes in blood concentrations of tryptophan in probiotic fed dominant hens was correlated with the changes of peripheral concentrations of 5-HT, indicating that probiotic may directly or indirectly regulate 5-HT synthesis in the peripheral system.

In this study, behavioral changes in dominant hens were correlated with the changes of blood 5-HT concentrations following fed probiotic. In the probiotic fed dominant hens, the levels of threat kick were reduced (Figure 4a, $P=0.04$ ), and the frequency of aggressive pecking tended to be lower (Figure $4 \mathbf{b}, P=0.053$ ). The levels of feather pecking in dominant hens were reduced compared to their initial levels at day 0 but without statistic significant (Figure 4c, 58\%, $P>0.05$ ). There was no change in injurious behaviors in the regular diet fed subordinate hens between day 0 and day 14 (Figure 4a-d). The same or similar cellular mechanisms proposed in humans and rodents may be applied to the changes in the probiotic fed dominant hens. In humans and rodents, probiotics directly manipulate commensal bacteria releasing neuroactive factors, such as 5-HT and norepinephrine [8], and indirectly affect the neurotransmitter metabolisms, such as tryptophan as well as cytokines, through the microbiota-gut-brain axis [5, 40, 41, 279, 293-297]. In addition, the effects of probiotics, including B. sublitis, on behavioral exhibitions have been conducted on GF mice. Bercik et al. [287] reported that anxiety behaviors can be induced in less anxious phenotypic mice by colonization of the gut bacteria from anxiety-like phenotypic mice (FMT, fecal microbiota transplant). Probiotics also have therapeutic effects on neurodevelopmental disorders [28, 95, 298-301], for example, reduced anxiety-like behaviors by providing L. helveticus, Mycobacterium vaccae, and/or Bifidobacterium strains [231, 287, 302, 303], and alleviated autismrelated stereotypic behaviors by treating with Bacteroides fragilis [304] and behavioral dysfunction with Lactobacillus reuteri [301, 305]. 
Gut-Brain Axis: Probiotic, Bacillus subtilis, Prevents Aggression via the Modification... DOI: http://dx.doi.org/10.5772/intechopen.86775

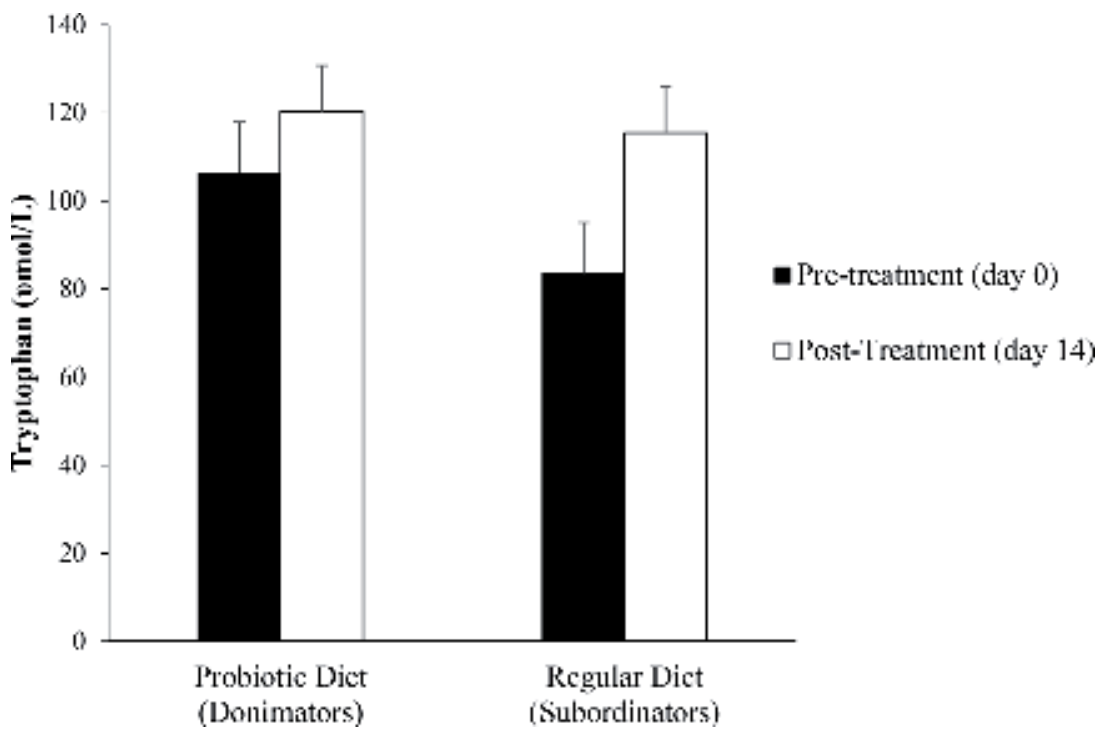

Figure 3.

Plasma tryptophan levels at day o (pre-treatment) and day 14 (post-treatment) in probiotic fed hens and regular diet fed hens. Prior to treatment, dominant hens had higher tryptophan concentrations compared to subordinates but the difference did not reach statistical difference $(P=0.21)$. There were no treatment effects on tryptophan concentrations in both probiotic fed hens and regular diet fed hens $(P>0.05$, respectively).
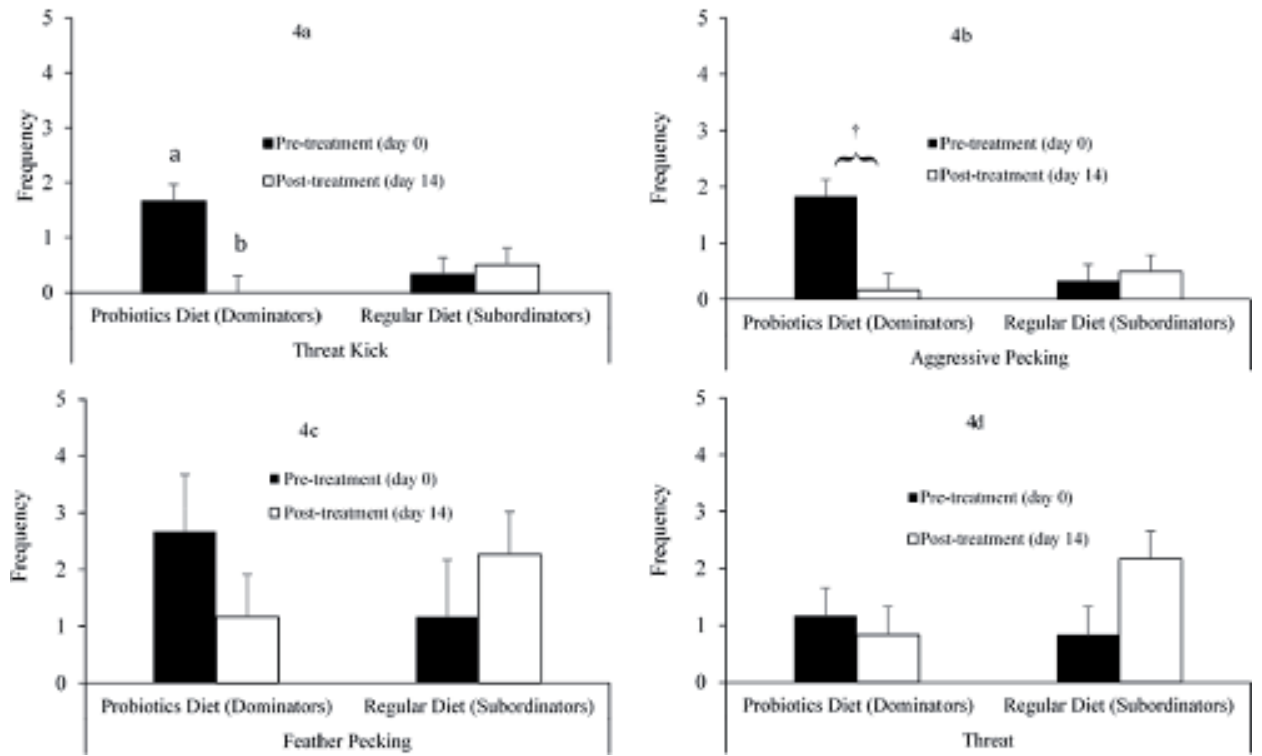

Figure 4.

Frequency of aggressive behaviors at day o (pre-treatment) and day 14 (post-treatment) in probiotic fed hens and regular diet fed hens followed the paired social test. The exhibitions of aggressive behaviors in the regular diet fed subordinates were not affected by treatment $(P>0.05$, respectively), while the frequency of threat kick $(P=0.04)$ was reduced, aggressive pecking $(P=0.053)$ was tend to be lower, and feather packing was declined $(60 \%, P=0.33)$ in probiotic fed dominates post-treatment. Notes: the treatment effects on the measured behaviors were reversed between dominants and subordinates during the 2 nd social rank test. ${ }^{a, b}$ between the frequency at day o and day 14, least square means lacking common superscripts differ $(P<0.05)$; and ${ }^{\dagger}$ a trend difference $(0.05 \leq P<0.10)$.

In the current study, body weight gain and hen-day egg production were not affected in the probiotic fed hens compared with the regular diet fed control hens $($ Control $=2.83 \%$, Probiotics $=2.2 \%, P=0.76 ;$ Control $=73.6 \%$, Probiotics $=87.5 \%$, 
$P=0.18$, respectively). Previous studies have reported the beneficial effects of dietary supplementation of probiotics on daily weight gain, finished body weight, and feed conversion rate in broiler chickens [306, 307], turkeys [308], and swine [309]. Several studies also reported that probiotic diets improved egg production in hens [310]. The underlying mechanisms of these effects may be related to the beneficial bacterial growth in the gastrointestinal tract to facilitate the fermentation process which improves the digestion and utilization of nutrients in animals [311]. The beneficial effects on growth performance, however, are affected by the bacterial strains, preparation process, dosage, animal's age, and genetic type [312, 313]. In the current study, the probiotic was provided for 2 weeks only, which may not be sufficient to functionally improve both growth and production performance.

\section{Conclusions}

Our data suggest that dietary inclusion of probiotics has positive effects on reducing agonistic behaviors in laying hens through modification of the serotonergic system without negative effects on growth and production performance. The data indicate that dietary probiotic supplementation could be a useful management tool for preventing aggressive behaviors in laying hens. In addition, the current chicken strain could be a useful model to investigate mechanisms underlying the potentially probiotic therapy for preventing and reducing emotional susceptibility associated with psychiatric disorders such as depression and anxiety in humans.

\section{Author details}

Heng-Wei Cheng ${ }^{1 *}$, Sha Jiang ${ }^{2}$ and Jiaying $\mathrm{Hu}^{3}$

1 USDA-Agricultural Research Service, Livestock Behavior Research Unit, West Lafayette, IN, USA

2 College of Animal Science and Technology, Southwest University, Chongqing, PR China

3 Department of Animal Sciences, Purdue University, West Lafayette, IN, USA

*Address all correspondence to: heng-wei.cheng@ars.usda.gov

IntechOpen

(C) 2019 The Author(s). Licensee IntechOpen. This chapter is distributed under the terms of the Creative Commons Attribution License (http://creativecommons.org/licenses/ by/3.0), which permits unrestricted use, distribution, and reproduction in any medium, provided the original work is properly cited. (cc) BY 
Gut-Brain Axis: Probiotic, Bacillus subtilis, Prevents Aggression via the Modification... DOI: http://dx.doi.org/10.5772/intechopen.86775

\section{References}

[1] De Almeida RM, Cabral JC, Narvaes R. Behavioural, hormonal and neurobiological mechanisms of aggressive behaviour in human and nonhuman primates. Physiology \& Behavior. 2015;143:121-135

[2] Arneth BM. Gut-brain axis biochemical signalling from the gastrointestinal tract to the central nervous system: Gut dysbiosis and altered brain function. Postgraduate Medical Journal. 2018;94:446-452

[3] Cussotto S, Sandhu KV, Dinan TG, Cryan JF. The neuroendocrinology of the microbiota-gut-brain axis: A behavioural perspective. Frontiers in Neuroendocrinology. 2018;51:80-101

[4] Di Sabatino A, Lenti MV, Cammalleri L, Corazza GR, Pilotto A. Frailty and the gut. Digestive and Liver Disease. 2018;50(6):533-541

[5] Farzi A, Fröhlich EE, Holzer P. Gut microbiota and the neuroendocrine system. Neurotherapeutics. 2018;15:5-22

[6] Gerhardt S, Mohajeri MH. Changes of colonic bacterial composition in parkinson's disease and other neurodegenerative diseases. Nutrients. 2018;10. pii: E708

[7] Liu L, Zhu G. Gut-brain axis and mood disorder. Frontiers in Psychiatry. 2018;9:223

[8] Lyte JM. Probiotics function mechanistically as delivery vehicles for neuroactive compounds: Microbial endocrinology in the design and use of probiotics. BioEssays. 2011;33:574-581

[9] Lyte JM. Eating for $3.8 \times 1013$ : Examining the impact of diet and nutrition on the microbiotagut-brain axis through the lens of microbial endocrinology. Frontiers in Endocrinology. 2019;9:796
[10] Yang H, Duan Z. The local defender and functional mediator: Gut microbiome. Digestion. 2018;97:137-145

[11] Bjerre K, Cantor MD, Nørgaard JV, Poulsen HD, Blaabjerg K, Canibe N, et al. Development of Bacillus subtilis mutants to produce tryptophan in pigs. Biotechnology Letters. 2017;39:289-295

[12] Hussain S, Andrews D, Hill BC. Using tryptophan mutants to probe the structural and functional status of BsSCO, a copper binding, cytochrome c oxidase assembly protein from Bacillus subtilis. Biochemistry. 2017;56:6355-6367

[13] Okada M, Sugita T, Abe I.

Posttranslational isoprenylation of tryptophan in bacteria. Beilstein Journal of Organic Chemistry. 2017;13:338-346

[14] Sheng QK, Yang ZJ, Zhao HB, Wang XL, Guo JF. Effects of L-tryptophan, fructan, and casein on reducing ammonia, hydrogen sulfide, and skatole in fermented swine manure. AsianAustralasian Journal of Animal Sciences. 2015;28:1202-1208

[15] Chen S, Wang M, Yin L, Ren W, Bin P, Xia Y, et al. Effects of dietary tryptophan supplementation in the acetic acid-induced colitis mouse model. Food \& Function. 2018;9:4143-4152

[16] Gao J, Xu K, Liu H, Liu G, Bai M, Peng $\mathrm{C}$, et al. Impact of the gut microbiota on intestinal immunity mediated by tryptophan metabolism. Frontiers in Cellular and Infection Microbiology. 2018;8:13

[17] Mukhtar K, Nawaz H, Abid

S. Functional gastrointestinal disorders and gut-brain axis: What does the future hold? World Journal of Gastroenterology. 2019;25:552-566

[18] Wen H, Feng L, Jiang W, Liu Y, Jiang J, Li S, et al. Dietary tryptophan 
modulates intestinal immune response, barrier function, antioxidant status and gene expression of TOR and Nrf2 in young grass carp (Ctenopharyngodon idella). Fish \& Shellfish Immunology. 2014;40(1):275-287

[19] Gershon MD. 5-Hydroxytryptamine (serotonin) in the gastrointestinal tract. Current Opinion in Endocrinology, Diabetes, and Obesity. 2013;20:14-21

[20] Pardridge WM, Fierer G. Transport of tryptophan into brain from the circulating, albumin-bound pool in rats and in rabbits. Journal of Neurochemistry. 1990;54:971-976

[21] de Boer SF, Buwalda B, Koolhaas JM. Untangling the neurobiology of coping styles in rodents: Towards neural mechanisms underlying individual differences in disease susceptibility. Neuroscience \& Biobehavioral Reviews. 2017;74(Pt B):401-422

[22] Veroude K, Zhang-James Y, Fernàndez-Castillo N, Bakker MJ, Cormand B, Faraone SV. Genetics of aggressive behavior: An overview. American Journal of Medical Genetics. Part B, Neuropsychiatric Genetics. 2016;171B(1):3-43

[23] Coccaro EF. What is the nature of serotonergic abnormalities in human aggression? Biological Psychiatry. 2012;72:980-981

[24] Dennis RL, Chen ZQ, Cheng HW. Serotonergic mediation of aggression in high and low aggressive chicken strains. Poultry Science. 2008;87:612-620

[25] Liu Y, Sun Y, Zhao X, Kim JY, Luo L, Wang Q, et al. Enhancement of aggression induced by isolation rearing is associated with a lack of central serotonin. Neuroscience Bulletin. 2019. https://doi. org/10.1007/s12264-019-00373-w

[26] Prokšelj T, Jerin A, Muck-Seler D, Kogoj A. Decreased platelet serotonin concentration in Alzheimer's disease with involuntary emotional expression disorder. Neuroscience Letters. 2014;578:71-74

[27] Bharwani A, Mian MF, Surette MG, Bienenstock J, Forsythe P. Oral treatment with Lactobacillus rhamnosus attenuates behavioural deficits and immune changes in chronic social stress. BMC Medicine. 2017;15:7

[28] Latalova K, Hajda M, Prasko J. Can gut microbes play a role in mental disorders and their treatment? Psychiatria Danubina. 2017;29(1):28-30

[29] Marx W, Moseley G, Berk M, Jacka F. Nutritional psychiatry: The present state of the evidence. The Proceedings of the Nutrition Society. 2017;76:427-436

[30] Misra S, Mohanty D. Psychobiotics: A new approach for treating mental illness? Critical Reviews in Food Science and Nutrition. 2017;30:1-7

[31] Li B, Evivie SE, Lu J, Jiao Y, Wang C, Li Z, et al. Lactobacillus helveticus KLDS1.8701 alleviates D-galactoseinduced aging by regulating Nrf-2 and gut microbiota in mice. Food $\&$ Function. 2018;9:6586-6598

[32] Li N, Wang Q, Wang Y, Sun A, Lin $\mathrm{Y}$, Jin $\mathrm{Y}$, et al. Oral probiotics ameliorate the behavioral deficits induced by chronic mild stress in mice via the gut microbiota-inflammation axis. Frontiers in Behavioral Neuroscience. 2018;12:266

[33] Bermúdez-Humarán LG, Salinas E, Ortiz GG, Ramirez-Jirano LJ, Morales JA, Bitzer-Quintero OK. From probiotics to psychobiotics: Live beneficial bacteria which act on the brain-gut axis. Nutrients. 2019;11. pii: E890

[34] Morris G, Fernandes BS, Puri BK, Walker AJ, Carvalho AF, Berk M. Leaky brain in neurological and psychiatric 
disorders: Drivers and consequences. The Australian and New Zealand Journal of Psychiatry. 2018;52:924-948

[35] Plaza-Diaz J, Ruiz-Ojeda FJ, GilCampos M, Gil A. Mechanisms of action of probiotics. Advances in Nutrition. 2019;10(suppl_1):S49-S66

[36] Taylor AM, Holscher HD. A review of dietary and microbial connections to depression, anxiety, and stress. Nutritional Neuroscience. 2018;9:1-14

[37] Gomi A, Yamaji K, Watanabe O, Yoshioka M, Miyazaki K, Iwama Y, et al. Bifidobacterium bifidum YIT 10347 fermented milk exerts beneficial effects on gastrointestinal discomfort and symptoms in healthy adults: A doubleblind, randomized, placebo-controlled study. Journal of Dairy Science. 2018;101:4830-4841

[38] Satish Kumar CS, Kondal Reddy K, Boobalan G, Gopala Reddy A, Sudha Rani Chowdhary CH, Vinoth A, et al. Immunomodulatory effects of Bifidobacterium bifidum 231 on trinitrobenzenesulfonic acid-induced ulcerative colitis in rats. Research in Veterinary Science. 2017;110:40-46

[39] Wang BG, Wu Y, Qiu L, Shah NP, $\mathrm{Xu} F$, Wei H. Integration of genomic and proteomic data to identify candidate genes in HT-29 cells after incubation with Bifidobacterium bifidum ATCC 29521. Journal of Dairy Science. 2016;99(9):6874-6888

[40] Kim MJ, Ku S, Kim SY, Lee HH, Jin H, Kang S, et al. Safety evaluations of Bifidobacterium bifidum BGN4 and Bifidobacterium longum BORI. International Journal of Molecular Sciences. 2018;19. pii: E1422

[41] Kim N, Yun M, Oh YJ, Choi HJ. Mind-altering with the gut: Modulation of the gut-brain axis with probiotics. Journal of Microbiology. 2018;56:172-182
[42] Mauricio MD, Serna E, FernándezMurga ML, Portero J, Aldasoro M, Valles SL, et al. Bifidobacterium pseudocatenulatum CECT 7765 supplementation restores altered vascular function in an experimental model of obese mice. International Journal of Medical Sciences.

2017;14:444-451

[43] Zhai Q, Liu Y, Wang C, Zhao J, Zhang $\mathrm{H}$, Tian F, et al. Increased cadmium excretion due to oral administration of Lactobacillus plantarum strains by regulating enterohepatic circulation in mice. Journal of Agricultural and Food Chemistry. 2019;67:3956-3965

[44] Morita Y, Miwa Y, Jounai K, Fujiwara D, Kurihara T, Kanauchi O. Lactobacillus paracasei KW3110 prevents blue light-induced inflammation and degeneration in the retina. Nutrients. 2018;10. pii: E1991

[45] Orlando A, Linsalata M, Bianco G, Notarnicola M, D'Attoma B, Scavo MP, et al. Lactobacillus rhamnosus GG protects the epithelial barrier of Wistar rats from the pepsin-trypsindigested gliadin (PTG)-induced enteropathy. Nutrients. 2018;10(11). pii: E1698

[46] Kato M, Hamazaki Y, Sun S, Nishikawa Y, Kage-Nakadai E. Clostridium butyricum MIYAIRI 588 increases the lifespan and multiplestress resistance of Caenorhabditis elegans. Nutrients. 2018;10. pii: E1921. DOI: $10.3390 /$ nu10121921

[47] Eom T, Kim YS, Choi CH, Sadowsky MJ, Unno T. Current understanding of microbiota- and dietary-therapies for treating inflammatory bowel disease. Journal of Microbiology. 2018;56:189-198

[48] Silley P. Do bacteria need to be regulated? Journal of Applied Microbiology. 2006;101:607-615 
[49] Joerger RD, Ganguly A. Current status of the preharvest application of pro- and prebiotics to farm animals to enhance the microbial safety of animal products. Microbiology Spectrum. 2017;5:1-10

[50] De Baets L, Van Iwaarden P, Meeus N, Schimmel H, Philipp W, Emons H. First certified reference materials for molecular fingerprinting of two approved probiotic Bacillus strains. International Journal of Food Microbiology. 2009;129:16-20

[51] Isticato R, Ricca E. Spore surface display. Microbiology Spectrum. 2014;2(5):1-15

[52] Jeżewska-Frąckowiak J, Seroczyńska K, Banaszczyk J, Jedrzejczak G, Żylicz-Stachula A, Skowron PM. The promises and risks of probiotic Bacillus species. Acta Biochimica Polonica. 2018;65:509-519

[53] Goodarzi Boroojeni F, Vahjen W, Männer K, Blanch A, Sandvang D, Zentek J. Bacillus subtilis in broiler diets with different levels of energy and protein. Poultry Science.

2018;97:3967-3976

[54] Musa BB, Duan Y, Khawar H, Sun Q, Ren Z, Elsiddig Mohamed MA, et al. Bacillus subtilis B21 and Bacillus licheniformis B26 improve intestinal health and performance of broiler chickens with Clostridium perfringensinduced necrotic enteritis. Journal of Animal Physiology and Animal Nutrition. 2019;00:1-11. https://doi. org/10.1111/jpn.13082

[55] Upadhaya SD, Rudeaux F, Kim IH. Effects of inclusion of Bacillus subtilis (Gallipro) to energy- and protein-reduced diet on growth performance, nutrient digestibility, and meat quality and gas emission in broilers. Poultry Science.

2019;98(5):2169-2178
[56] Samanya M, Yamauchi K.

Histological alterations of intestinal villi in chickens fed dried Bacillus subtilis var. natto. Comparative Biochemistry and Physiology. Part A, Molecular \& Integrative Physiology. 2002;133:95-104

[57] Bar Shira E, Friedman A. Innate immune functions of avian intestinal epithelial cells: Response to bacterial stimuli and localization of responding cells in the developing avian digestive tract. PLoS One. 2018;13:e0200393

[58] Fernandez-Alarcon MF, Trottier N, Steibel JP, Lunedo R, Campos DMB, Santana AM, et al. Interference of age and supplementation of direct-fed microbial and essential oil in the activity of digestive enzymes and expression of genes related to transport and digestion of carbohydrates and proteins in the small intestine of broilers. Poultry Science. 2017;96:2920-2930

[59] Gadde U, Oh ST, Lee YS, Davis E, Zimmerman N, Rehberger $\mathrm{T}$, et al. The effects of direct-fed microbial supplementation, as an alternative to antibiotics, on growth performance, intestinal immune status, and epithelial barrier gene expression in broiler chickens. Probiotics and Antimicrobial Proteins. 2017;9:397-405

[60] Jayaraman S, Das PP, Saini PC, Roy $\mathrm{B}$, Chatterjee PN. Use of Bacillus subtilis PB6 as a potential antibiotic growth promoter replacement in improving performance of broiler birds. Poultry Science. 2017;96:2614-2622

[61] Abudabos AM, Hussein EOS, Ali MH, Al-Ghadi MQ. The effect of some natural alternative to antibiotics on growth and changes in intestinal histology in broiler exposed to Salmonella challenge. Poultry Science. 2019;98:1441-1446

[62] Wang YQ, Lin WW, Wu N, Wang SY, Chen MZ, Lin ZH, et al. Structural insight into the serotonin (5-HT) 
receptor family by molecular docking, molecular dynamics simulation and systems pharmacology analysis. Acta Pharmacologica Sinica. 2019. DOI: 10.1038/s41401-019-0217-9

[63] Wang X, Peebles ED, Kiess AS, Wamsley KGS, Zhai W. Effects of coccidial vaccination and dietary antimicrobial alternatives on the growth performance, internal organ development, and intestinal morphology of Eimeria-challenged male broilers. Poultry Science. 2019;98(5):2054-2065

[64] Galagarza OA, Smith SA, Drahos DJ, Eifert JD, Williams RC, Kuhn DD. Modulation of innate immunity in Nile tilapia (Oreochromis niloticus) by dietary supplementation of Bacillus subtilis endospores. Fish and Shellfish Immunology. 2018;83:171-179

[65] Fan Y, Zhao L, Ma Q, Li X, Shi H, Zhou T, et al. Effects of Bacillus subtilis ANSB060 on growth performance, meat quality and aflatoxin residues in broilers fed moldy peanut meal naturally contaminated with aflatoxins. Food and Chemical Toxicology. 2013;59:748-753

[66] Gong L, Wang B, Mei X, Xu H, Qin Y, Li W, et al. Effects of three probiotic Bacillus on growth performance, digestive enzyme activities, antioxidative capacity, serum immunity, and biochemical parameters in broilers. Animal Science Journal. 2018;89:1561-1571

[67] Wang WC, Yan FF, Hu JY, Huang $\mathrm{XH}$, Kamel OM, Cheng HW.

Supplementation of Bacillus subtilis based probiotic reduces heat stressrelated behaviors and inflammatory response in broiler chickens. Journal of Animal Science. 2018;96:1654-1666

[68] Zaghar M, Zahroojian N, Riahi M, Parhizkar S. Effect of Bacillus Subtilis Spore (GalliPro) nutrients equivalency value on broiler chicken performance.
Italian Journal of Animal Science. 2015;14:94-98

[69] Sarsero JP, Merino E, Yanofsky C. A Bacillus subtilis operon containing genes of unknown function senses tRNATrp charging and regulates expression of the genes of tryptophan biosynthesis. Proceedings of the National Academy of Sciences of the United States of America. 2000;97:2656-2661

[70] Gollnick P, Babitzke P, Antson A, Yanofsky C. Regulation of sigL expression by the catabolite control protein CcpA involves a roadblock mechanism in Bacillus subtilis: Potential connection between carbon and nitrogen metabolism. Annual Review of Genetics. 2005;39:47-68

[71] Porter MR, Joyce PR, Luty SE. Tryptophan and tyrosine availability and response to antidepressant treatment in major depression. Journal of Affective Disorders. 2005;86:129-134

[72] van Veen JF, van Vliet IM, de Rijk RH, van Pelt J, Mertens B, Fekkes D, et al. Tryptophan depletion affects the autonomic stress response in generalized social anxiety disorder. Psychoneuroendocrinology. 2009;34:1590-1594

[73] Aune TM, Pogue SL. Inhibition of tumor cell growth by interferon-gamma is mediated by two distinct mechanisms dependent upon oxygen tension: Induction of tryptophan degradation and depletion of intracellular nicotinamide adenine dinucleotide. The Journal of Clinical Investigation. 1989;84:863-875

[74] Frank DN, St Amand AL, Feldman RA. Molecular-phylogenetic characterization of microbial community imbalances in human inflammatory bowel diseases. Proceedings of the National Academy of Sciences of the United States of America. 2007;104:13780-13785 
[75] O’Callaghan TF, Ross RP, Stanton C, Clarke G. The gut microbiome as a virtual endocrine organ with implications for farm and domestic animal endocrinology. Domestic Animal Endocrinology. 2016;56(Suppl):S44-S55

[76] Jia Q, Xie Y, Lu C, Zhang A, Lu Y, $\mathrm{Lv} S$, et al. Endocrine organs of cardiovascular diseases: Gut microbiota. Journal of Cellular and Molecular Medicine. 2019;23:2314-2323

[77] Lach G, Schellekens H, Dinan TG, Cryan JF. Anxiety, depression, and the microbiome: A role for gut peptides. Neurotherapeutics. 2018;15:36-59

[78] Villageliu DN, Lyte M. Microbial endocrinology: Why the intersection of microbiology and neurobiology matters to poultry health. Poultry Science. 2017;96:2501-2508

[79] Yarandi SS, Peterson DA, Treisman GJ, Moran TH, Pasricha PJ. Modulatory effects of gut microbiota on the central nervous system: How gut could play a role in neuropsychiatric health and Diseases. Journal of Neurogastroenterology and Motility. 2016;22:201-212

[80] Cheung SG, Goldenthal AR, Uhlemann AC, Mann JJ, Miller JM, Sublette ME. Systematic review of gut microbiota and major depression. Frontiers in Psychiatry. 2019;10:34

[81] Huang TT, Lai JB, Du YL, Xu Y, Ruan LM, Hu SH. Current understanding of gut microbiota in mood disorders: An update of human studies. Frontiers in Genetics. 2019;10:98

[82] Ma Q, Xing C, Long W, Wang HY, Liu Q, Wang RF. Impact of microbiota on central nervous system and neurological diseases: The gut-brain axis. Journal of Neuroinflammation. 2019;16:53

[83] Molina-Torres G, RodriguezArrastia M, Roman P, Sanchez-Labraca
N, Cardona D. Stress and the gut microbiota-brain axis. Behavioural Pharmacology. 2019;30 (2 and 3special issue):187-200

[84] Gao K, Pi Y, Mu CL, Farzi A, Liu Z, Zhu WY. Increasing carbohydrate availability in the hindgut promotes hypothalamic neurotransmitter synthesis: Aromatic amino acids linking the microbiotabrain axis. Journal of Neurochemistry. 2019;149:641-659

[85] Jameson KG, Hsiao EY. Linking the gut microbiota to a brain neurotransmitter. Trends in Neurosciences. 2018;41:413-414

[86] Martin CR, Osadchiy V, Kalani A, Mayer EA. The brain-gut-microbiome axis. Cellular and Molecular Gastroenterology and Hepatology. 2018;6:133-148

[87] Strandwitz P. Neurotransmitter modulation by the gut microbiota. Brain Research. 2018;1693(Pt B):128-133

[88] O’Mahony SM, Clarke G, Borre YE, Dinan TG, Cryan JF. Serotonin, tryptophan metabolism and the braingut-microbiome axis. Behavioural Brain Research. 2015;277:32-48

[89] Jenkins TA, Nguyen JC, Polglaze KE, Bertrand PP. Influence of tryptophan and serotonin on mood and cognition with a possible role of the gut-brain axis. Nutrients. 2016;8. pii: E56. DOI: 10.3390/nu8010056

[90] Kennedy PJ, Cryan JF, Dinan TG, Clarke G. Kynurenine pathway metabolism and the microbiotagut-brain axis. Neuropharmacology. 2017;112(Pt B):399-412

[91] Browne CJ, Abela AR, Chu D, Li Z, Ji X, Lambe EK, et al. Dorsal raphe serotonin neurons inhibit operant responding for reward via inputs to the ventral tegmental area but 
not the nucleus accumbens: Evidence from studies combining optogenetic stimulation and serotonin reuptake inhibition. Neuropsychopharmacology. 2019;44:793-804

[92] Pratelli M, Pasqualetti M.

Serotonergic neurotransmission manipulation for the understanding of brain development and function: Learning from Tph2 genetic models. Biochimie. 2018;161:3-14

[93] Revill AL, Chu NY, Ma L, LeBlancq MJ, Dickson CT, Funk GD. Postnatal development of persistent inward currents in rat XII motoneurons and their modulation by serotonin, muscarine and norepinephrine. The Journal of Physiology. 2019. DOI: 10.1113/JP277572

[94] Warner BB. The contribution of the gut microbiome to neurodevelopment and neuropsychiatric disorders. Pediatric Research. 2018;85:216-224

[95] Needham BD, Tang W, Wu WL. Searching for the gut microbial contributing factors to social behavior in rodent models of autism spectrum disorder. Developmental Neurobiology. 2018;78:474-499

[96] Reales G, Paixão-Côrtes VR, Cybis GB, Gonçalves GL, Pissinatti A, Salzano FM, et al. Serotonin, behavior, and natural selection in New World monkeys. Journal of Evolutionary Biology. 2018;31:1180-1192

[97] Conio B, Martino M, Magioncalda $\mathrm{P}$, Escelsior A, Inglese M, Amore M, et al. Opposite effects of dopamine and serotonin on resting-state networks: Review and implications for psychiatric disorders. Molecular Psychiatry. 2019. DOI: $10.1038 / \mathrm{s} 41380-019-0406-4$

[98] Dinan TG, Cryan JF. Braingut-microbiota axis and mental health. Psychosomatic Medicine. 2017;79:920-926
[99] Sirgy MJ. Positive balance: A hierarchical perspective of positive mental health. Quality of Life Research. 2019. https://doi.org/10.1007/ s11136-019-02145-5

[100] Sjögren M, Nielsen ASM, Hasselbalch KC, Wøllo M, Hansen JS. A systematic review of blood-based serotonergic biomarkers in Bulimia Nervosa. Psychiatry Research. 2018. https://doi.org/10.1016/j. psychres.2018.12.16

[101] Cameron JL, Eagleson KL, Fox NA, Hensch TK, Levitt P. Social origins of developmental risk for mental and physical illness. The Journal of Neuroscience. 2017;37(45):10783-10791

[102] Fahey AG, Cheng HW. Effects of social disruption on physical parameters, corticosterone concentrations, and immune system in two genetic lines of White Leghorn layers. Poultry Science. 2008;87:1947-1954

[103] Mumtaz F, Khan MI, Zubair M, Dehpour AR. Neurobiology and consequences of social isolation stress in animal model - A comprehensive review. Biomedicine \& Pharmacotherapy. 2018;105:1205-1222

[104] Kleinhappel TK, John EA, Pike TW, Wilkinson A, Burman OH. Animal welfare: A social networks perspective. Science Progress. 2016;99:68-82

[105] Lin ED, Sun M, Choi EY, Magee D, Stets C, During MJ. Social overcrowding as a chronic stress model that increases adiposity in mice. Psychoneuroendocrinology. 2015;51:318-330

[106] Mench JA. The welfare of poultry in modern production system. Poultry Science Reviews. 1992;4:107-123

[107] Escribano D, Ko HL, Chong Q, Llonch L, Manteca X, Llonch P. Salivary 
biomarkers to monitor stress due to aggression after weaning in piglets. Research in Veterinary Science. 2019;123:178-183

[108] Haller J. The role of the lateral hypothalamus in violent intraspecific aggression-The glucocorticoid deficit hypothesis. Frontiers in Systems Neuroscience. 2018;12:26

[109] Masis-Calvo M, Schmidtner AK, de Moura Oliveira VE, Grossmann CP, de Jong TR, Neumann ID. Animal models of social stress: The dark side of social interactions. Stress. 2018;10:1-16

[110] de Bruijn R, Romero LM. The role of glucocorticoids in the vertebrate response to weather. General and Comparative Endocrinology. 2018;269:11-32

[111] Haller J, Millar S, van de Schraaf J, de Kloet RE, Kruk MR. The active phase-related increase in corticosterone and aggression are linked. Journal of Neuroendocrinology. 2000;12:431-436

[112] Vitellius G, Trabado S, Bouligand J, Delemer B, Lombès M. Pathophysiology of Glucocorticoid Signaling. Annales d'endocrinologie. 2018;79:98-106

[113] Désautés C, Sarrieau A, Caritez JC, Mormède P. Behavior and pituitaryadrenal function in large white and Meishan pigs. Domestic Animal Endocrinology. 1999;16:193-205

[114] Reynolds RM. Glucocorticoid excess and the developmental origins of disease: Two decades of testing the hypothesis-2012 Curt Richter Award Winner. Psychoneuroendocrinology. 2013;38:1-11

[115] Joëls M, Karst H, Sarabdjitsingh RA. The stressed brain of humans and rodents. Acta Physiologica (Oxford, England). 2018;223(2):e13066

[116] Peeters B, Langouche L, Van den Berghe G. Adrenocortical stress response during the course of critical illness. Comprehensive Physiology. 2017;8:283-298

[117] Ralph CR, Tilbrook AJ. Invited review: The usefulness of measuring glucocorticoids for assessing animal welfare. Journal of Animal Science. 2016;94:457-470

[118] Carpenter RE, Korzan WJ, Bockholt C, Watt MJ, Forster GL, Renner KJ, et al. Corticotropin releasing factor influences aggression and monoamines: Modulation of attacks and retreats. Neuroscience. 2009;158:412-425

[119] Fortes PM, Albrechet-Souza L, Vasconcelos M, Ascoli BM, Menegolla AP, de Almeida RMM. Social instigation and repeated aggressive confrontations in male Swiss mice: Analysis of plasma corticosterone, CRF and BDNF levels in limbic brain areas. Trends in Psychiatry and Psychotherapy. 2017;39:98-105

[120] Kinlein SA, Phillips DJ, Keller CR, Karatsoreos IN. Role of corticosterone in altered neurobehavioral responses to acute stress in a model of compromised hypothalamic-pituitary-adrenal axis function. Psychoneuroendocrinology. 2019;102:248-255

[121] Reul JM, de Kloet ER. Two receptor systems for corticosterone in rat brain: Microdistribution and differential occupation. Endocrinology. 1985;117:2505-2511

[122] Algamal M, Ojo JO, Lungmus CP, Muza P, Cammarata C, Owens MJ, et al. Chronic hippocampal abnormalities and blunted HPA axis in an animal model of repeated unpredictable stress. Frontiers in Behavioral Neuroscience. 2018;12:150

[123] Ahmed AA, Ma W, Ni Y, Wang S, Zhao R. Corticosterone in ovo modifies aggressive behaviors and reproductive 
performances through alterations of the hypothalamic-pituitary-gonadal axis in the chicken. Animal Reproduction Science. 2014;146:193-201

[124] Audet MC, McQuaid RJ, Merali Z, Anisman H. Cytokine variations and mood disorders: Influence of social stressors and social support. Frontiers in Neuroscience. 2014;8:416

[125] Walker SE, Papilloud A, Huzard $\mathrm{D}$, Sandi C. The link between aberrant hypothalamic-pituitary-adrenal axis activity during development and the emergence of aggression-Animal studies. Neuroscience and Biobehavioral Reviews. 2018;91:138-152

[126] Veenit V, Cordero MI, Tzanoulinou $\mathrm{S}$, Sandi C. Increased corticosterone in peripubertal rats leads to long-lasting alterations in social exploration and aggression. Frontiers in Behavioral Neuroscience. 2013;7:26

[127] Foster JA, McVey Neufeld KA. Gut-brain axis: How the microbiome influences anxiety and depression. Trends in Neurosciences.

2013;36:305-312

[128] Walker SE, Sandi C. Long-term programing of psychopathology-like behaviors in male rats by peripubertal stress depends on individual's glucocorticoid responsiveness to stress. Stress. 2018;7:1-10

[129] Cant MA, LlopJB, Field J. Individual variation in social aggression and the probability of inheritance: Theory and a field test. The American Naturalist. 2006;167:837-852

[130] Foister S, Doeschl-Wilson A, Roehe R, Arnott G, Boyle L, Turner S. Social network properties predict chronic aggression in commercial pig systems. PLoS One. 2018;13:e0205122

[131] Greenwood EC, van Wettere WHEJ, Rayner J, Hughes PE, Plush KL.
Provision point-source materials stimulates play in sows but does not affect aggression at regrouping. Animals (Basel). 2019;9(1): pii: E8. DOI: 10.3390/ani9010008

[132] Cheng HW. Breeding of tomorrow's chickens to improve well-being. Poultry Science. 2010;89:805-813

[133] Rauw WM, Johnson AK, GomezRaya L, Dekkers JCM. A hypothesis and review of the relationship between selection for improved production efficiency, coping behavior, and domestication. Frontiers in Genetics. 2017;8:134

[134] Brimblecombe N, Evans-Lacko S, Knapp M, King D, Takizawa R, Maughan B, et al. Long term economic impact associated with childhood bullying victimisation. Social Science \& Medicine. 2018;208:134-141

[135] Ramsay SE, Bartley A, Rodger AJ. Determinants of assault-related violence in the community: Potential for public health interventions in hospitals. Emergency Medicine Journal. 2014;31:986-989

[136] Whitaker S. Preventing violent conflict: A revised mandate for the public health professional? Journal of Public Health Policy. 2013;34:46-54

[137] Bruce-Keller AJ, Salbaum JM, Berthoud HR. Harnessing gut microbes for mental health: Getting from here to there. Biological Psychiatry. 2018;83:214-223

[138] Rieder R, Wisniewski PJ, Alderman BL, Campbell SC. Microbes and mental health: A review. Brain, Behavior, and Immunity. 2017;66:9-17

[139] Sylvia KE, Demas GE. A gut feeling: Microbiome-brain-immune interactions modulate social and affective behaviors. Hormones and Behavior. 2018;99:41-49 
[140] Lin L, Zhang J. Role of intestinal microbiota and metabolites on gut homeostasis and human diseases. BMC Immunology. 2017;18:2

[141] Pickard JM, Zeng MY, Caruso R, Núñez G. Gut microbiota: Role in pathogen colonization, immune responses, and inflammatory disease. Immunological Reviews. 2017;279:70-89

[142] Bermon S, Petriz B, Kajènienè A, Prestes J, Castell L, Franco OL. The microbiota: An exercise immunology perspective. Exercise Immunology Review. 2015;21:70-79

[143] Bruce-Keller AJ, Salbaum JM, Luo M, Blanchard E, Taylor CM, Welsh DA, et al. Obese-type gut microbiota induce neurobehavioral changes in the absence of obesity. Biological Psychiatry.

2015;77:607-615

[144] Lallès JP. Microbiota-host interplay at the gut epithelial level, health and nutrition. Journal of Animal Science and Biotechnology. 2016;7:66

[145] Delaney S, Hornig M. Environmental exposures and neuropsychiatric disorders: What role does the gut-immune-brain axis play? Current Environmental Health Reports. 2018;5:158-169

[146] Sudo N, Chida Y, Aiba Y, Sonoda J, Oyama N, Yu XN, et al. Postnatal microbial colonization programs the hypothalamic-pituitary-adrenal system for stress response in mice. The Journal of Physiology. 2004;558:263-275

[147] Cryan JF, Dinan TG. Mind-altering microorganisms: The impact of the gut microbiota on brain and behaviour. Nature Reviews. Neuroscience. 2012;13:701-712

[148] Clarke G, Stilling RM, Kennedy PJ, Stanton C, Cryan JF, Dinan TG. Minireview: Gut microbiota: The neglected endocrine organ. Molecular Endocrinology. 2014;28:1221-1238
[149] Maddaloni G, Migliarini S, Napolitano F, Giorgi A, Nazzi S, Biasci $D$, et al. Serotonin depletion causes valproate-responsive manic-like condition and increased hippocampal neuroplasticity that are reversed by stress. Scientific Reports. 2018;8:11847

[150] Manchia M, Carpiniello B, Valtorta F, Comai S. Serotonin dysfunction, aggressive behavior, and mental illness: Exploring the link using a dimensional approach. ACS Chemical Neuroscience. 2017;8:961-972

[151] Birkl P, Franke L, Bas Rodenburg T, Ellen E, Harlander-Matauschek A.

A role for plasma aromatic amino acids in injurious pecking behavior in laying hens. Physiology \& Behavior. 2017;175:88-96

[152] Cheng HW, Dillworth G, Singleton P, Chen Y, Muir WM. Effects of group selection for productivity and longevity on blood concentrations of serotonin, catecholamine and corticosterone of laying hens. Poultry Science. 2001;80:1278-1285

[153] de Haas EN, van der Eijk JAJ. Where in the serotonergic system does it go wrong? Unravelling the route by which the serotonergic system affects feather pecking in chickens. Neuroscience and Biobehavioral Reviews. 2018;95:170-188

[154] Dennis RL, Fahey AG, Cheng HW. Alterations to embryonic serotonin change aggression and fearfulness. Aggressive Behavior. 2013;39:91-98

[155] Lesch KP, Araragi N, Waider J, van den Hove D, Gutknecht L. Targeting brain serotonin synthesis: Insights into neurodevelopmental disorders with long-term outcomes related to negative emotionality, aggression and antisocial behaviour. Philosophical Transactions of the Royal Society of London. Series B, Biological Sciences. 2012;367:2426-2443 
[156] Olivier B. Serotonergic mechanisms in aggression. Novartis Foundation symposium. 2005;268:171-183; discussion 183-179, 242-153

[157] Olivier B. Serotonin: A neverending story. European Journal of Pharmacology. 2015;753:2-18

[158] Reif A, Lesch KP. Toward a molecular architecture of personality. Behavioural Brain Research.

2003;139:1-20

[159] Bubak AN, Watt MJ, Renner KJ, Luman AA, Costabile JD, Sanders EJ, et al. Sex differences in aggression: Differential roles of 5-HT2, neuropeptide $\mathrm{F}$ and tachykinin. PLoS One. 2019;14(1):e0203980

[160] Godar SC, Mosher LJ, Scheggi S, Devoto P, Moench KM, Strathman HJ, et al. Gene-environment interactions in antisocial behavior are mediated by earlylife 5-HT2A receptor activation.

Neuropharmacology. 2019. https://doi. org/10.1016/j.neuropharm.2019.01.028

[161] Popova NK, Naumenko VS, Plyusnina IZ. Involvement of brain serotonin 5 -HT1A receptors in genetic predisposition to aggressive behavior. Neuroscience and Behavioral Physiology. 2007;37:631-635

[162] van Hierden YM, Korte SM, Ruesink EW, van Reenen CG, Engel B, KorteBouws GA, et al. Adrenocortical reactivity and central serotonin and dopamine turnover in young chicks from a high and low feather-pecking line of laying hens. Physiology \& Behavior. 2002;75:653-659

[163] Wright HF, Mills DS, Pollux PM. Behavioural and physiological correlates of impulsivity in the domestic dog (Canis familiaris). Physiology \&

Behavior. 2012;105:676-682

[164] Klasen M, Wolf D, Eisner PD, Eggermann T, Zerres K, Zepf FD, et al.
Serotonergic contributions to human brain aggression networks. Frontiers in Neuroscience. 2019;13:42

[165] Kolla NJ, Houle S. Single-photon emission computed tomography and positron emission tomography studies of antisocial personality disorder and aggression: A targeted review. Current Psychiatry Reports. 2019;21:24

[166] Weinberg-Wolf H, Chang SWC. Differences in how macaques monitor others: Does serotonin play a central role? Wiley Interdisciplinary Reviews: Cognitive Science. 2019;18:e1494. DOI: 10.1002/wcs

[167] Kästner N, Richter SH, Urbanik S, Kunert J, Waider J, Lesch KP, et al. Brain serotonin deficiency affects female aggression. Scientific Reports. 2019;9:1366

[168] Cheng HW, Muir WM.

Mechanisms of aggression and production in chickens: Genetic variations in the functions of serotonin, catecholamine, and corticosterone. World's Poultry Science Journal. 2007;63:233-254

[169] Veenema AH. Early life stress, the development of aggression and neuroendocrine and neurobiological correlates: What can we learn from animal models? Frontiers in Neuroendocrinology. 2009;30:497-518

[170] Melloni RH Jr, Ricci LA. Adolescent exposure to anabolic/androgenic steroids and the neurobiology of offensive aggression: A hypothalamic neural model based on findings in pubertal Syrian hamsters. Hormones and Behavior. 2010;58(1):177-191

[171] Haller J. The neurobiology of abnormal manifestations of aggression-A review of hypothalamic mechanisms in cats, rodents, and humans. Brain Research Bulletin. 2013;93:97-109 
[172] Nikulina EM. Neural control predatory aggression in wild and domesticated animals. Neuroscience \& Biobehavioral Reviews. 1991;15:545-547

[173] Tani Y, Kataoka Y, Sakurai Y, Yamashita K, Ushio M, Ueki S. Changes of brain monoamine contents in three models of experimentally induced muricide in rats. Pharmacology, Biochemistry, and Behavior. 1987;26:725-729

[174] Ferris CF, Stolberg T, Delville Y. Serotonin regulation of aggressive behavior in male golden hamsters (Mesocricetus auratus). Behavioral Neuroscience. 1999;113:804-815

[175] Levinstein MR, Neumaier JF. Striatal 5-HT1B receptors and aggression. Biological Psychiatry. 2017;82:235-236

[176] Nautiyal KM, Tanaka KF, Barr MM, Tritschler L, Le Dantec Y, David DJ, et al. Distinct circuits underlie the effects of 5-HT1B receptors on aggression and impulsivity. Neuron. 2015;86:813-826

[177] Köhler S, Cierpinsky K, Kronenberg G, Adli M. The serotonergic system in the neurobiology of depression: Relevance for novel antidepressants. Journal of Psychopharmacology. 2016;30:13-22

[178] Berman ME, McCloskey MS, Fanning JR, Schumacher JA, Coccaro EF. Serotonin augmentation reduces response to attack in aggressive individuals. Psychological Science. 2009;20:714-720

[179] Fanning JR, Berman ME, Guillot CR, Marsic A, McCloskey MS. Serotonin (5-HT) augmentation reduces provoked aggression associated with primary psychopathy traits. Journal of Personality Disorders. 2014;28:449-461

[180] Moffitt TE, Brammer GL, Caspi A, Fawcett JP, Raleigh M, Yuwiler A, et al. Whole blood serotonin relates to violence in an epidemiological study. Biological Psychiatry. 1998;43:446-457

[181] Rosado B, Garcia-Belenguer S, Leon M, Chacon G, Villegas A, Palacio J. Effect of fluoxetine on blood concentrations of serotonin, cortisol and dehydroepiandrosterone in canine aggression. Journal of Veterinary Pharmacology and Therapeutics. 2011;34:430-436

[182] Laricchiuta D, Petrosini L. Individual differences in response to positive and negative stimuli: Endocannabinoid-based insight on approach and avoidance behaviors. Frontiers in Systems Neuroscience. 2014;8:238

[183] Petrican R, Grady CL. The intrinsic neural architecture of inhibitory control: The role of development and emotional experience. Neuropsychologia. 2019;127:93-105

[184] Palumbo S, Mariotti V, Iofrida C, Pellegrini S. Genes and aggressive behavior: Epigenetic mechanisms underlying individual susceptibility to aversive environments. Frontiers in Behavioral Neuroscience. 2018;12:117

[185] Ettrup KS, Sørensen JC, Rodell A, Alstrup AK, Bjarkam CR. Hypothalamic deep brain stimulation influences autonomic and limbic circuitry involved in the regulation of aggression and cardiocerebrovascular control in the Göttingen minipig. Stereotactic and Functional Neurosurgery. 2012;90:281-291

[186] Johnsson M, Williams MJ, Jensen P, Wright D. Genetical genomics of behavior: A novel chicken genomic model for anxiety behavior. Genetics. 2016;202:327-340

[187] Stern CD. The chick; a great model system becomes even greater. Developmental Cell. 2005;8:9-17 
[188] Goodson JL. The vertebrate social behavior network: Evolutionary themes and variations. Hormones and Behavior. 2005;48:11-22

[189] Kuenzel WJ. Research advances made in the avian brain and their relevance to poultry scientists. Poultry Science. 2014;93:2945-2952

[190] Kuenzel WJ. Mapping the brain of the chicken (Gallus gallus), with emphasis on the septal-hypothalamic region. General and Comparative Endocrinology. 2018;256:4-15

[191] Soma KK, Bindra RK, Gee J, Wingfield JC, Schlinger BA. Androgenmetabolizing enzymes show region-specific changes across the breeding season in the brain of a wild songbird. Journal of Neurobiology. 1999;41:176-188

[192] Thompson RR, Goodson JL, Ruscio MG, Adkins-Regan E. Role of the archistriatal nucleus taeniae in the sexual behavior of male Japanese quail (Cotunix japonica): A comparison of function with the medial nucleus of the amygdala in mammals. Brain, Behavior and Evolution. 1998;51:215-229

[193] Challet E, Miceli D, Pierre J, Reperant J, Masicotte G, Herbin $\mathrm{M}$, et al. Distribution of serotoninimmunoreactivity in the brain of the pigeon (Columba livia). Anatomy and Embryology. 1996;193:209-227

[194] Butler AB. Evolution of brains, cognition, and consciousness. Brain Research Bulletin. 2008;75:442-449

[195] Tramontin AD, Brenowitz EA. Seasonal plasticity in the adult brain. Trends in Neurosciences. 2000;23:251-258

[196] Dietl MM, Palacios JM.

Neurotransmitter receptors in the avian brain. I. Dopamine receptors. Brain Research. 1988;439:354-359
[197] Walker EA, Yamamoto T, Hollingsworth PJ, Smith CB, Woods JH. Discriminative-stimulus effects of quipazine and 1-5-hydroxytryptophan in relation to serotonin binding sites in the pigeon. The Journal of Pharmacology and Experimental Therapeutics. 1991;259:772-782

[198] Savory CJ, Mann JS. Feather pecking in groups of growing bantams in relation to floor litter substrate and plumage colour. British Poultry Science. 1999;40:565-572

[199] Smulders TV. The avian hippocampal formation and the stress response. Brain, Behavior and Evolution. 2017;90(1):81-91

[200] Ottaviani E, Franchini A, Franceschi C. Presence of immunoreactive corticotropin-releasing hormone and cortisol molecules in invertebrate haemocytes and lower and higher vertebrate thymus. The Histochemical Journal. 1998;30:61-67

[201] Carsia RV, Macdonald GJ, Malamed S. Steroid control of steroidogenesis in isolated adrenocortical cells: Molecular and species specificity. Steroids. 1983;41:741-755

[202] Palme R, Rettenbacher S, Touma C, El-Bahr SM, Möstl E. Stress hormones in mammals and birds: Comparative aspects regarding metabolism, excretion, and noninvasive measurement in fecal samples. Annals of the New York Academy of Sciences. 2005;1040:162-171

[203] Vylitová M, Miksík I, Pácha J. Metabolism of corticosterone in mammalian and avian intestine. General and Comparative Endocrinology. 1998;109:315-324

[204] Stange M, Núñez-León D, Sánchez-Villagra MR, Jensen P, Wilson LAB. Morphological variation under 
domestication: How variable are chickens? Royal Society Open Science. 2018;5:180993

[205] Cheng HW. Animal welfare: Should we change housing to better accommodate the animal of change the animal to accommodate the housing? CAB Review: Perspectives in Agriculture, Veterinary Science, Nutrition and Nature Resources. 2007;2:47-61

[206] Muir WM. Group selection for adaptation to multiple-hen cages: Selection program and direct responses. Poultry Science. 1996;75:447-458

[207] Cheng HW, Muir WM. Chronic social stress differentially regulates neuroendocrine responses in laying hens: II. Genetic basis of adrenal responses under three different social conditions. Psychoneuroendocrinology. 2004;29:961-971

[208] Cheng HW, Singleton P, Muir WM. Social stress in laying hens: Differential effect of geneticenvironmental interactions on plasma dopamine concentrations and adrenal function in genetically selected chickens. Poultry Science. 2003;82:192-198

[209] Cicchetti D, Posner MI. Cognitive and affective neuroscience and developmental psychopathology. Development and Psychopathology. 2005;17:569-575

[210] Siever LJ. The neurobiology of aggression and violence. CNS Spectrums. 2015;20:254-279

[211] Dinan TG, Cryan JF. Mood by microbe: Towards clinical translation. Genome Medicine. 2016;8:36

[212] Hu JY, Chen H, Cheng HW. Effect of direct-fed microbials, Bacillus subtilis, on production performance, serotonin concentrations and behavioral parameters in a selected dominant strain of White Leghorn hens. International Journal of Poultry Science. 2018;17:106-115

[213] Dennis RL, Cheng HW. The dopaminergic system and aggression in laying hens. Poultry Science. 2011;90:2440-2448

[214] D'Eath RB, Keeling LJ. Social discrimination and aggression by laying hens in large groups: From peck orders to social tolerance. Applied Animal Behaviour Science. 2003;84:197-212

[215] Rushen J. The peck orders of chickens-How do they develop and why are they linear. Animal Behaviour. 1982;30:1129-1137

[216] File SE. Factors controlling measures of anxiety and responses to novelty in the mouse. Behavioural Brain Research. 2001;125:151-157

[217] Fox AS, Kalin NH. A translational neuroscience approach to understanding the development of social anxiety disorder and its pathophysiology. The American Journal of Psychiatry. 2014;171:1162-1173

[218] Guhl AM. Psycho-physiological factors and social behavior related to sexual behavior in birds. Transactions of the Kansas Academy of Science. 1960;63:85-95

[219] Jager A, Maas DA, Fricke K, de Vries RB, Poelmans G, Glennon JC. Aggressive behavior in transgenic animal models: A systematic review. Neuroscience and Biobehavioral Reviews. 2018;91:198-217

[220] Koolhaas JM, Coppens CM, de Boer SF, Buwalda B, Meerlo P, Timmermans PJ. The resident-intruder paradigm: A standardized test for aggression, violence and social stress. Journal of Visualized Experiments. 2013;77:e4367 
Gut-Brain Axis: Probiotic, Bacillus subtilis, Prevents Aggression via the Modification... DOI: http://dx.doi.org/10.5772/intechopen.86775

[221] de Weerth C. Do bacteria shape our development? Crosstalk between intestinal microbiota and HPA axis. Neuroscience and Biobehavioral Reviews. 2017;83:458-471

[222] Aslam H, Green J, Jacka FN, Collier F, Berk M, Pasco J, et al. Fermented foods, the gut and mental health: A mechanistic overview with implications for depression and anxiety. Nutritional Neuroscience. 2018;11:1-13

[223] Cerdó T, García-Santos JA, G Bermúdez M, Campoy C. The role of probiotics and prebiotics in the prevention and treatment of obesity. Nutrients. 2019;11. pii: E635

[224] Cuevas-Sierra A, Ramos-Lopez O, Riezu-Boj JI, Milagro FI, Martinez JA. Diet, gut microbiota, and obesity: Links with host genetics and epigenetics and potential applications. Advances in Nutrition. 2019;10(suppl_1):S17-S30

[225] Ma T, Suzuki Y, Guan LL. Dissect the mode of action of probiotics in affecting host-microbial interactions and immunity in food producing animals. Veterinary Immunology and Immunopathology. 2018;205:35-48

[226] Roubalová R, Procházková $\mathrm{P}$, Papežová H, Smitka K, Bilej M, Tlaskalová-Hogenová H. Anorexia nervosa: Gut microbiota-immunebrain interactions. Clinical Nutrition. 2019. https://doi.org/10.1016/j. clnu.2019.03.023

[227] Abautret-Daly Á, Dempsey E, Parra-Blanco A, Medina C, Harkin A. Gut-brain actions underlying comorbid anxiety and depression associated with inflammatory bowel disease. Acta Neuropsychiatrica. 2018;30:275-296

[228] Foster JA, Lyte M, Meyer E, Cryan JF. Gut microbiota and brain function: An evolving field in neuroscience. The International
Journal of Neuropsychopharmacology. 2015;19:1-7

[229] Lopes RCSO, Balbino KP, Jorge MP, Ribeiro AQ, Martino HSD, Alfenas RCG. Modulation of intestinal microbiota, control of nitrogen products and inflammation by pre/probiotics in chronic kidney disease: A systematic review. Nutrición Hospitalaria. 2018;35:722-730

[230] Park C, Brietzke E, Rosenblat JD, Musial N, Zuckerman H, Ragguett RM, et al. Probiotics for the treatment of depressive symptoms: An anti-inflammatory mechanism? Brain, Behavior, and Immunity. 2018;73:115-124

[231] Kane L, Kinzel J. The effects of probiotics on mood and emotion. JAAPA: Official journal of the American Academy of Physician Assistants. 2018;31:1-3

[232] Pirbaglou M, Katz J, de Souza RJ, Stearns JC, Motamed M, Ritvo P. Probiotic supplementation can positively affect anxiety and depressive symptoms: A systematic review of randomized controlled trials. Nutrition Research.

2016;36:889-898

[233] Reis DJ, Ilardi SS, Punt SEW. The anxiolytic effect of probiotics: A systematic review and meta-analysis of the clinical and preclinical literature. PLoS One. 2018;13:e0199041

[234] Desbonnet L, Garrett L, Clarke G, Kiely B, Cryan JF, Dinan TG. Effects of the probiotic Bifidobacterium infantis in the maternal separation model of depression. Neuroscience. 2010;170:1179-1188

[235] Sanders A, Rackers H, Kimmel M. A role for the microbiome in motherinfant interaction and perinatal depression. International Review of Psychiatry. 2019;20:1-15 
[236] Slykerman RF, Hood F, Wickens K, JMD T, Barthow C, Murphy R, et al. Effect of Lactobacillus rhamnosus HN001 in pregnancy on postpartum symptoms of depression and anxiety: A randomised double-blind placebocontrolled trial. eBioMedicine.

2017;24:159-165

[237] Kantak PA, Bobrow DN, Nyby JG. Obsessive-compulsive-like behaviors in house mice are attenuated by a probiotic (Lactobacillus rhamnosus GG). Behavioural Pharmacology. 2014;25:71-79

[238] Romijn AR, Rucklidge JJ.

Systematic review of evidence to support the theory of psychobiotics.

Nutrition Reviews. 2015;73:675-693

[239] Gareau MG. Microbiota-gut-brain axis and cognitive function. Advances in Experimental Medicine and Biology. 2014;817:357-371

[240] Mohajeri MH, La Fata G, Steinert RE, Weber P. Relationship between the gut microbiome and brain function. Nutrition Reviews. 2018;76:481-496

[241] Solas M, Milagro FI, Ramírez MJ, Martínez JA. Inflammation and gut-brain axis link obesity to cognitive dysfunction: Plausible pharmacological interventions. Current Opinion in Pharmacology. 2017;37:87-92

[242] Ticinesi A, Tana C, Nouvenne A, Prati B, Lauretani F, Meschi T. Gut microbiota, cognitive frailty and dementia in older individuals: A systematic review. Clinical Interventions in Aging. 2018;13:1497-1511

[243] Joseph JM, Law C. Cross-species examination of single- and multistrain probiotic treatment effects on neuropsychiatric outcomes. Neuroscience and Biobehavioral Reviews. 2019;99:160-197

[244] Elisashvili V, Kachlishvili E, Chikindas ML. Recent advances in the physiology of spore formation for bacillus probiotic production. Probiotics and Antimicrobial Proteins. 2018. https://doi.org/10.1007/ s12602-018-9492-x

[245] Cartman ST, La Ragione RM, Woodward MJ. Bacillus subtilis spores germinate in the chicken gastrointestinal tract. Applied and Environmental Microbiology. 2008;74:5254-5258

[246] Mingmongkolchai S, Panbangred W. Bacillus probiotics: An alternative to antibiotics for livestock production. Journal of Applied Microbiology. 2018;124:1334-1346

[247] Duc LH, Hong HA, Barbosa TM, Henriques AO, Cutting SM. Characterization of Bacillus probiotics available for human use. Applied and Environmental Microbiology. 2004;70:2161-2171

[248] Hong HA, Huang JM, Khaneja R, Hiep LV, Urdaci MC, Cutting SM. The safety of Bacillus subtilis and Bacillus indicus as food probiotics. Journal of Applied Microbiology. 2008;105:510-520

[249] Konuray G, Erginkaya Z. Potential use of Bacillus coagulans in the food industry. Foods. 2018;7. pii: E92

[250] Grant A, Gay CG, Lillehoj HS. Bacillus spp. as direct-fed microbial antibiotic alternatives to enhance growth, immunity, and gut health in poultry. Avian Pathology.

2018;47:339-351

[251] Latorre JD, Hernandez-Velasco X, Vicente JL, Wolfenden R, Hargis BM, Tellez G. Effects of the inclusion of a Bacillus direct-fed microbial on performance parameters, bone quality, recovered gut microflora, and intestinal morphology in broilers consuming a grower diet containing corn distillers dried grains with solubles. Poultry Science. 2017;96:2728-2735 
[252] Foligne B, Peys E,

Vandenkerckhove J, Van Hemel J, Dewulf J, Breton J, et al. Spores from two distinct colony types of the strain Bacillus subtilis PB6 substantiate anti-inflammatory probiotic effects in mice. Clinical Nutrition. 2012;31:987-994

[253] Okamoto K, Fujiya M, Nata $\mathrm{T}$, Ueno $\mathrm{N}$, Inaba $\mathrm{Y}$, Ishikawa $\mathrm{C}$, et al. Competence and sporulation factor derived from Bacillus subtilis improves epithelial cell injury in intestinal inflammation via immunomodulation and cytoprotection. International Journal of Colorectal Disease. 2012;27:1039-1046

[254] Bernardeau M, Lehtinen MJ, Forssten SD, Nurminen P. Importance of the gastrointestinal life cycle of Bacillus for probiotic functionality. Journal of Food Science and Technology. 2017;54:2570-2584

[255] Elshaghabee FMF, Rokana N, Gulhane RD, Sharma C, Panwar H. Bacillus as potential probiotics: Status, concerns, and future perspectives. Frontiers in Microbiology. 2017;8:1490

[256] El Aidy S, Dinan TG, Cryan JF. Gut microbiota: The conductor in the orchestra of immune-neuroendocrine communication. Clinical Therapeutics. 2015;37:954-967

[257] Duncan IJ. Behavior and behavioral needs. Poultry Science. 1998;77:1766-1772

[258] Fraser D, Rushen J. Aggressive behavior. The Veterinary Clinics of North America. Food Animal Practice. 1987;3:285-305

[259] Rodenburg TB, Tuyttens FA, Sonck B, De Reu K, Herman L, Zoons J. Welfare, health, and hygiene of laying hens housed in furnished cages and in alternative housing systems. Journal of Applied Animal Welfare Science. 2005;8:211-226

[260] Tablante NL, Vaillancourt JP, Martin SW, Shoukri M, Estevez I. Spatial distribution of cannibalism mortality in commercial laying hens. Poultry Science. 2000;79:705-708

[261] Cheng HW. Morphopathological changes and pain in beak trimming laying hens. World's Poultry Science Journal. 2006;62:41-52

[262] Hester PY. Impact of science and management on the welfare of egg laying strains of hens. Poultry Science. 2005;84:687-696

[263] Kriegseis I, Bessei W, Meyer B, Zentek J, Würbel H, HarlanderMatauschek A. Feather-pecking response of laying hens to feather and cellulose-based rations fed during rearing. Poultry Science. 2012;91:1514-1521

[264] van Krimpen MM, Kwakkel RP, van der Peet-Schwering CM, den Hartog LA, Verstegen MW. Effects of nutrient dilution and nonstarch polysaccharide concentration in rearing and laying diets on eating behavior and feather damage of rearing and laying hens. Poultry Science. 2009;88:759-773

[265] van Krimpen M. Feeding to prevent feather pecking in layers. World Poultry. 2012. Available from: http://www.worldpoultry.net/Layers/ Nutrition/2012/5/Feeding-to-preventfeather-pecking-in-layers-WP010372W/ [Accessed: October 2018]

[266] Blokhuis HJ, van der Haar JW. Effects of pecking incentives during rearing on feather pecking of laying hens. British Poultry Science. 1992;33:17-24

[267] Kalmendal R, Bessei W. The preference for high-fiber feed in laying hens divergently selected on 
feather pecking. Poultry Science. 2012;91:1785-1789

[268] Lambton SL, Nicol CJ, Friel M, Main DC, McKinstry JL, Sherwin CM, et al. A bespoke management package can reduce levels of injurious pecking in loose-housed laying hen flocks. The Veterinary Record. 2013;172:423

[269] Appleby MC. Modification of laying hen cages to improve behavior. Poultry Science. 1998;77:1828-1832

[270] Hartcher KM, Tran KT, Wilkinson SJ, Hemsworth PH, Thomson PC, Cronin GM. The effects of environmental enrichment and beaktrimming during the rearing period on subsequent feather damage due to feather-pecking in laying hens. Poultry Science. 2015;94:852-859

[271] Bolhuis JE, Ellen ED, Van Reenen CG, De Groot J, Ten Napel J, Koopmanschap RE, et al. Effects of genetic group selection against mortality on behavior and peripheral serotonin in domestic laying hens with trimmed and intact beaks. Physiology \& Behavior. 2009;97:470-475

[272] Hercigonja Novkovic V, Rudan V, Pivac N, Nedic G, Muck-Seler D. Platelet serotonin concentration in children with attention-deficit/hyperactivity disorder. Neuropsychobiology. 2009;59:17-22

[273] Rosado B, Garcia-Belenguer S, Palacio J, Chacon G, Villegas A, Alcalde AI. Serotonin transporter activity in platelets and canine aggression. Veterinary Journal. 2010;186:104-105

[274] Mann JJ, Brent DA, Arango V. The neurobiology and genetics of suicide and attempted suicide: A focus on the serotonergic system. Neuropsychopharmacology. 2001;24:467-477

[275] McDonald MD, Gonzalez A, Sloman KA. Higher levels of aggression are observed in socially dominant toadfish treated with the selective serotonin reuptake inhibitor, fluoxetine. Comparative Biochemistry and Physiology Part C: Toxicology \& Pharmacology. 2011;153:107-112

[276] Darbaky Y, Evrard B, Patrier S, Falenta J, Garcin S, Tridon A, et al. Oral probiotic treatment of Lactobacillus rhamnosus Lcr35(R) prevents visceral hypersensitivity to a colonic inflammation and an acute psychological stress. Journal of Applied Microbiology. 2016;122:188-200

[277] Giannetti E, Staiano A. Probiotics for irritable Bowel syndrome: Clinical data in children. Journal of Pediatric Gastroenterology and Nutrition. 2016;63:S25-S26

[278] Lacy BE, Chey WD, Lembo AJ. New and emerging treatment options for irritable Bowel syndrome. Gastroenterol Hepatol (N Y). 2015;11 (4 Suppl 2):1-19

[279] Liang S, Wang T, Hu X, Luo J, Li W, Wu X, et al. Administration of lactobacillus helveticus Ns8 improves behavioral, cognitive, and biochemical aberrations caused by chronic restraint stress. Neuroscience. 2015;310:561-577

[280] Cremon C, Carini G, Wang B, Vasina V, Cogliandro RF, De Giorgio R, et al. Intestinal serotonin release, sensory neuron activation, and abdominal pain in irritable bowel syndrome. The American Journal of Gastroenterology. 2011;106:1290-1298

[281] Kanauchi O, Mitsuyama K, Komiyama Y, Yagi M, Andoh A, Sata M. Preventive effects of enzymetreated rice fiber in a restraint stressinduced irritable bowel syndrome model. International Journal of Molecular Medicine. 2010;25:547-555 
[282] Gershon MD. Review article:

Serotonin receptors and transporters-

Roles in normal and abnormal

gastrointestinal motility. Alimentary

Pharmacology \& Therapeutics

(Suppl). 2004;7:3-14

[283] Tack J, Vanuytsel T, Corsetti M. Modern management of irritable Bowel syndrome: More than motility. Digestive Diseases. 2016;34:566-573

[284] Wikoff WR, Anfora AT, Liu J, Schultz PG, Lesley SA, Peters EC, et al. Metabolomics analysis reveals large effects of gut microflora on mammalian blood metabolites. Proceedings of the National Academy of Sciences of the United States of America. 2009;106:3698-3703

[285] Bravo JA, Julio-Pieper M, Forsythe P, Kunze W, Dinan TG, Bienenstock $\mathrm{J}$, et al. Communication between gastrointestinal bacteria and the nervous system. Current Opinion in Pharmacology. 2012;12:667-672

[286] Neufeld KM, Kang N, Bienenstock J, Foster JA. Reduced anxiety-like behavior and central neurochemical change in germ-free mice. Neurogastroenterology and Motility. 2011;23:255-264

[287] Bercik P, Denou E, Collins J, Jackson W, Lu J, Jury J, et al. The intestinal microbiota affect central levels of brain-derived neurotropic factor and behavior in mice.

Gastroenterology. 2011;141:599-609.e3

[288] Pietraszek MH, Takada Y, Yan D, Urano T, Serizawa K, Takada A. Relationship between serotonergic measures in periphery and the brain of mouse. Life Sciences. 1992;51:75-82

[289] Sarrias MJ, Martínez E, Celada P, Udina C, Alvarez E, Artigas F. Plasma free $5 \mathrm{HT}$ and platelet $5 \mathrm{HT}$ in depression: Case-control studies and the effect of antidepressant therapy. Advances in Experimental Medicine and Biology. 1991;294:653-658
[290] Guslandi M. Probiotic agents in the treatment of irritable bowel syndrome. The Journal of International Medical Research. 2007;35:583-589

[291] Yan FF, Wang WC, Cheng HW. Bacillus sutilis based probiotic improved bone mass and altered brain serotonergic and dopaminergic systems in broiler chickens. Journal of Functional Foods. 2018;49:501-509

[292] Forsythe P, Sudo N, Dinan T, Taylor VH, Bienenstock J. Mood and gut feelings. Brain, Behavior, and Immunity. 2010;24:9-16

[293] Bienenstock J, Kunze W, Forsythe P. Microbiota and the gut-brain axis. Nutrition Reviews. 2015;73:28-31

[294] Di Meo F, Donato S, Di Pardo A, Maglione V, Filosa S, Crispi S. New therapeutic drugs from bioactive natural molecules: The role of gut microbiota metabolism in neurodegenerative diseases. Current Drug Metabolism. 2018;19:478-489

[295] Kuo PH, Chung YE. Moody microbiome: Challenges and chances. Journal of the Formosan Medical Association. 2019;118(Suppl 1):S42-S54

[296] Liang S, Wu X, Jin F. Gutbrain psychology: Rethinking psychology from the microbiotagut-brain axis. Frontiers in Integrative Neuroscience. 2018;12:33

[297] Roy Sarkar S, Banerjee S. Gut microbiota in neurodegenerative disorders. Journal of Neuroimmunology. 2019;328:98-104

[298] Campion D, Ponzo P, Alessandria C, Saracco GM, Balzola F. The role of microbiota in autism spectrum disorders. Minerva Gastroenterologica e Dietologica. 2018;64:333-350

[299] Cekici H, Sanlier N. Current nutritional approaches in managing 
autism spectrum disorder: A review. Nutritional Neuroscience. 2019;22(3):145-155

[300] Martin CR, Mayer EA. Gutbrain axis and behavior. Nestlé Nutrition Institute Workshop Series. 2017;88:45-53

[301] Tabouy L, Getselter D, Ziv O, Karpuj M, Tabouy T, Lukic I, et al. Dysbiosis of microbiome and probiotic treatment in a genetic model of autism spectrum disorders. Brain, Behavior, and Immunity. 2018;73:310-319

[302] Luk B, Veeraragavan S, Engevik M, Balderas M, Major A, Runge J, et al. Postnatal colonization with human "infant-type" bifidobacterium species alters behavior of adult gnotobiotic mice. PLoS One. 2018;13:e0196510

[303] Matthews DM, Jenks SM. Ingestion of Mycobacterium vaccae decreases anxiety-related behavior and improves learning in mice. Behavioural Processes. 2013;96:27-35

[304] Hsiao EY, McBride SW, Hsien S, Sharon G, Hyde ER, McCue T, et al. Microbiota modulate behavioral and physiological abnormalities associated with neurodevelopmental disorders. Cell. 2013;155:1451-1463

[305] Salvatore S, Pensabene L, Borrelli O, Saps M, Thapar N, Concolino D, et al. Mind the gut: Probiotics in paediatric neurogastroenterology. Beneficial Microbes. 2018;10:1-16

[306] Cengiz O, Koksal BH, Tath O, Sevim O, Ahsan U, Uner AG, et al. Effect of dietary probiotic and high stocking density on the performance, carcass yield, gut microflora, and stress indicators of broilers. Poultry Science. 2015;94:2395-2403

[307] Liao XD, Ma G, Cai J, Fu Y, Yan XY, Wei XB, et al. Effects of Clostridium butyricum on growth performance, antioxidation, and immune function of broilers. Poultry Science. 2015;94:662-667

[308] Grimes JL, Rahimi S, Oviedo E, Sheldon BW, Santos FB. Effects of a direct-fed microbial (Primalac) on turkey poult performance and susceptibility to oral Salmonella challenge. Poultry Science. 2008;87:1464-1470

[309] Davis ME, Parrott T, Brown DC, de Rodas BZ, Johnson ZB, Maxwell CV, et al. Effect of a Bacillus-based direct-fed microbial feed supplement on growth performance and pen cleaning characteristics of growing-finishing pigs. Journal of Animal Science.

2008;86:1459-1467

[310] Yoruk MA, Gul M, Hayirli A, Macit $M$. The effects of supplementation of humate and probiotic on egg production and quality parameters during the late laying period in hens. Poultry Science. 2004;83:84-88

[311] Lee DK, Park JE, Kim MJ, Seo JG, Lee JH, Ha NJ. Probiotic bacteria, B. longum and L. acidophilus inhibit infection by rotavirus in vitro and decrease the duration of diarrhea in pediatric patients. Clinics and Research in Hepatology and Gastroenterology. 2015;39:237-244

[312] Lee KW, Lee SH, Lillehoj HS, Li GX, Jang SI, Babu US, et al. Effects of direct-fed microbials on growth performance, gut morphometry, and immune characteristics in broiler chickens. Poultry Science. 2010;89:203-216

[313] Sen S, Ingale SL, Kim YW, Kim JS, Kim KH, Lohakare JD, et al. Effect of supplementation of Bacillus subtilis LS 1-2 to broiler diets on growth performance, nutrient retention, caecal microbiology and small intestinal morphology. Research in Veterinary Science. 2012;93:264-268 


\title{
Oral Health by Using Probiotic Products
}

\author{
Razzagh Mahmoudi, Sara Moosazad and Katayoon Aghaei
}

\begin{abstract}
One of the most prevalent and important health problems in the world is periodontal and plaque-related diseases that antibiotic drugs are used with their side effects as their treatment. With increasing resistance to antibiotics and a desire from the general public for "natural" therapies, there is a need to minimize antibiotic use and develop new treatments for oral diseases without antimicrobial agents. Probiotics are viable microorganisms which provide a health benefit to the host when administered in adequate amounts; studies show that probiotics have the potential to modify the oral microbiota and decrease the colony-forming unit (CFU) counts of the oral pathogens being investigated to prevent or treat oral disease, such as dental caries and the periodontal diseases. In addition, the identification of specific strains with probiotic activity is required for any oral infectious disease, in order to determine the exact dose, the time of treatment, and the ideal vehicle.
\end{abstract}

Keywords: probiotics, periodontal diseases, dental caries, oral health

\section{Introduction}

As we know tooth decay and oral health is one of the most common worries in the world [1], and with widespread public concern about the use of industrial drugs to reduce dental caries, natural base treatments are highly welcomed, but the question is: Can probiotics be used as a therapeutic agent? A few years before 1908, the theory is drawn up according to this theory; the Bulgarian people have a longer life; the reason of longer life was Bulgarian people used more fermented products. These products have increased the health of their digestive system [2]. This theory won the Nobel Prize in Physiology and Medicine (1908) [3]. Since then, many publications that have referred to this theory said using probiotic products can be factor in improving the health of the digestive system, reproductive organs, and oral hygiene $[4,5]$. Oral holes are environments with homeostasis conditions, which affect the nutritional conditions and individual health conditions and conditions of the environment $[3,4,6]$. Probiotics, as nonpathogenic microorganisms, can have beneficial health benefits at low levels in food. They have the ability to change this homeostasis environment $[3,7]$. Probiotic bacteria consist of two main groups of Lactobacillus and Bifidobacterium. The Lactobacillus, as a member of oral microbial flora, can play an important role in the microcosm balance of the oral cavity. Less information is available about the useful role of Bifidobacterium in oral cavity health $[8,9]$. 


\section{Oral health}

The mouth has a varied and heterogeneous microbial community. Oral health can be a state of being free from chronic mouth and tooth pain, such as oral and throat cancer, tooth loss, periodontal disease, and the other diseases that affect this tissue. The etiology of periodontal diseases and caries shows the prevalence of these both having microbial components. Host microbiota has important role in the individual's health. The theory from Nobel laureate Ilya Metchnikoff says "we fight microbe with microbe" and has attracted numerous followers [10].

\section{Probiotics background}

As we know, the presence of microorganisms in the body always had been a concern of a large group of scientists. Because the health of the oral and intestinal organs is depends on the balance of these microorganisms and their functioning [10]. For many years, scientists and doctors have been using antibiotics to improve the function of the oral cavity, lymph system, and intestinal organs and control the demographic of these microorganisms. However, the widespread use of antibiotics not only caused a lot of problems in the human body but also led to microorganisms exhibiting resistance and even in some cases caused new species in microorganisms. All these problems forced scientists and researchers to find new methods for controlling microorganisms in the body organs.

\section{Probiotic bacteria}

As it is mentioned in the introduction, probiotic bacteria consist of two main groups of Lactobacillus and Bifidobacterium. The best growth environments for these two groups are anaerobic or minimal oxygen conditions, for example, in saliva, vagina, vegetable juices, and dairy products. Probiotic bacteria were used in a variety of ways over time. For example, and prevent food corruption, Today, these bacteria are also used in industrial food products such as milk, wine and vegetables [11]. The name probiotic comes from the Greek word probosis, which means for life. This word was first used in 1965 by Lily and Stool to describe the secreted material by microorganisms to stimulate the growth of other microorganisms. In 1974, Parker introduced the word to describe microorganisms controlling the intestinal microbial population [12-14]. Today, probiotic bacteria refer to viable microorganisms that control the microbial population of the gut. They have lots of positive effects on the health of the host such as reduced constipation, decreased blood cholesterol, and improved lactose tolerance and calcium intake [14].

\section{Probiotic foods are functional foods}

Diets play an important role in health. These diets can play a leading role in reducing disease. Today, with increasing awareness of people about the beneficial effects of probiotic bacteria, consumption of functional foods is increasing. But what are these foods? Functional foods are such food that promotes health [14]. A wide range of foods are included, but the most important ones are oligosaccharides and probiotic foods [15].

What are the main criteria for selecting probiotic food as functional? Functional food must have three items: 
1. They have a different effect from a nutritional point.

2. They reduce the risk of pathological illnesses.

3. Consuming them benefits the community and the consumer [15].

Probiotic foods not only have the main characteristics that are mentioned but also have more benefits. These features include:
A. Useful effects on the host
B. High shelf life in the product
C. Ability to survive the intestines
D. Ability to produce antimicrobial agents
E. Stabilization of intestinal flora
F. Nonpathogenicity and non-toxicity [16]

\section{Which foods have the best tissue for the transfer of probiotic bacteria to the human digestive system?}

New food products are converted into probiotic foods by adding probiotic bacteria. These foods include a variety of different types such as cheese, ice cream, milk-based dessert, baby milk, and mayonnaise. In making these foods, the main thing is the texture of these foods. It can be said that among all foods, dairy products are known as the best option for the transmission of probiotic bacteria [17-20].

\section{What are the main mechanism probiotics in the body?}

Probiotics can function through several mechanisms. Probiotic bacteria through colonization in the intestinal environment, connect to each other, using the food in the body before it is taken by pathogenic microorganisms so by creating competition, it eliminates pathogens. Also, probiotics, unlike many harmful bacteria, are capable of producing acid to survive in the regulation of the local and systemic immune system [21].

\section{Probiotics and dental caries}

Dental caries is one of the most common oral diseases, even though it is preventable. There are different reasons for dental caries such as such as maternal characteristics, environment, child's individual factors and epigenetics, and sugar and sugar-rich diet [10]. A usual feature for caries-promoting bacteria is that they are acidogenic and aciduric. One of the most caries-promoting bacteria is Streptococcus mutans. For this reason lactobacilli and bifidobacteria are excellent acid producers, since we can use probiotics several times a day and they are safe for infants [22].

\section{Probiotics and periodontal disease}

Periodontal diseases include gingivitis and periodontitis. They are manifested by bleeding on probing, swelling, color alterations, pain, and tooth mobility in 
advanced stages. Scaling and root planning and deep pocket debridement are usual treatments [10]. Periodontal pathogens could be regulated by means of antagonistic interactions. According to the results of studies probiotics have been shown to reduce the number of the most frequently isolated pathogens such as Bacteroides sp., Actinomyces sp., Staphylococcus intermedius, and Candida albicans at optimal concentrations of $10^{8} \mathrm{cfu} / \mathrm{ml}[23]$.

\section{Probiotics and oral candida infections}

Another role of a probiotic is to restrain the chronic candida infections of the soft tissues in the mouth. Those that are isolated from oral cavity include C. albicans, C. glabrata, C. krusei, C. parapsilosis, and C. tropicalis. Many in vitro studies have shown that the strains of lactobacilli have inhibitory activity against oral candida, but the true value of probiotics in controlling oral candida is still an open question [10].

\section{Probiotics and halitosis}

One of the most common problems that people in the world suffer from is halitosis. This phrase is used in 1921 to describe the unpleasant odor of the mouth [23]. This complication has many causes such as bacterial coating of the tongue, systemic disorders, and different types of food [24]. At all levels, all physical and chemical treatments alone have not been able to completely control this pathology. All physical and chemical treatments alone have not been able to fully control this problem. Today, scientists believe that the use of probiotics as supportive therapies will play a role in controlling this problem. But how can these bacteria help?

1. Probiotics can act as antibiotics and inhibit gastrointestinal diseases, which can reduce the odor associated with these diseases.

2. Probiotics can reduce bacteria in terms of immunity.

These two methods are the main methods for reducing odor in the mouth by probiotics [25].

\section{Mechanism of probiotics in the oral cavity}

The ability to adhere to and colonize surfaces in the oral cavity is an essential requirement for an oral probiotic [9]. There are four main mechanisms for the effect of probiotic bacteria in the mouth. Probiotics compete with pathogens to stick to the mucosa and tooth and prevent the sticking of pathogenic bacteria [26]. Probiotic produce peroxide and bacteriocin as antibacterial agents against oral pathogens, so they remove from oral area [27]. The presence of probiotics can change the oral conditions such as reducing $\mathrm{pH}$ that can prevent the growth of bacteria producing tooth decay or change the protein structure of salivary gland [28]. Probiotics can have beneficial effects on dental health by stimulating non-specific immunity and regulating cellular and humoral immune responses [29]. 


\section{Probiotic strain in oral cavity}

According to the researches and their results, Lactobacilli and Bifidobacterium could play an important role in the microecological balance in the oral cavity. $B$. bifidum, B. longum, and B. infantis are the probiotic species of Bifidobacterium. Bifidobacterium is seen in deep caries in the oral cavity and plays an important role in the development of caries, but it has been shown that its probiotic species can reduce caries in people who do not have active caries. Acidophilus are the probiotic species of Lactobacillus. According to the researches, Lactobacillus is more associated with decayed dentin. It is at the point of development of the decayed lesion and is at the onset of the process that caries do not have a role. Consumption of products of probiotics does not predict the cause of decay growth. Firstly, the Lactobacillus rarely causes cavity formation. Secondly, all Lactobacillus species do not induce caries, and thirdly when carriers of dairy Lactobacillus are present, they can have a neutralizing effect on acid production by bacteria [30].

\section{Author details}

Razzagh Mahmoudi $^{1 *}$, Sara Moosazad ${ }^{2}$ and Katayoon Aghaei ${ }^{2}$

1 Medical Microbiology Research Center, Faculty of public Health Qazvin University of Medical Sciences, Qazvin, Iran

2 Department of Health and Food Safety, Faculty of public Health Qazvin University of Medical Sciences, Qazvin, Iran

*Address all correspondence to: r.mahmodi@yahoo.com

\section{IntechOpen}

(C) 2019 The Author(s). Licensee IntechOpen. This chapter is distributed under the terms of the Creative Commons Attribution License (http://creativecommons.org/licenses/ by/3.0), which permits unrestricted use, distribution, and reproduction in any medium, provided the original work is properly cited. (cc) BY 


\section{References}

[1] The role of probiotics in preventing dental caries in children. In:

International Congress on Nutrition, Growth and Development in Infants and Children; 2012

[2] Twetman S, Keller M. Probiotics for caries prevention and control. Advances in Dental Research. 2012; 24(2):98-102

[3] Seminario-Amez M, López-López J, Estrugo-Devesa A, Ayuso-Montero $\mathrm{R}$, Jané-Salas E. Probiotics and oral health: A systematic review. Medicina Oral, Patología Oral y Cirugía Bucal. 2017;22(3):e282

[4] Zarco M, Vess T, Ginsburg G. The oral microbiome in health and disease and the potential impact on personalized dental medicine. Oral Diseases. 2012;18(2):109-120

[5] Laleman I, Detailleur V, Slot DE, Slomka V, Quirynen M, Teughels W. Probiotics reduce mutans streptococci counts in humans: A systematic review and metaanalysis. Clinical Oral Investigations. 2014;18(6):1539-1552

[6] Hasslöf P, West C, Videhult FK, Brandelius C, Stecksén-Blicks C. Early intervention with probiotic Lactobacillus paracasei $\mathrm{F} 19$ has no long-term effect on caries experience. Caries Research. 2013;47(6):559-565

[7] Valizadeh S, Fakheri T, Mahmoudi R, Katiraee F, Gajarbeygi P. Evaluation of antioxidant, antibacterial, and antifungal properties of Satureja hortensis essential oil. Biotechnology and Health Sciences. 2014:1(3):e24733

[8] The role of probiotics in preventing dental caries in children. In: International Congress on Nutrition, Growth and Evolution in Infants and Children; Tabriz; 2012
[9] Meurman J, Stamatova I. Probiotics: Contributions to oral health. Oral

Diseases. 2007;13(5):443-451

[10] Dore MP, Goni E, Di Mario F. Is there a role for probiotics in helicobacter pylori therapy? Gastroenterology

Clinics. 2015;44(3):565-575

[11] Malcata FX, Tavares TG, Hernández-Mendoza A, Svensson UK, Håkansson J. Safety of food and beverages: Probiotics and prebiotics. Encyclopedia of Food Safety. 1 Jan 2014;3:427-440

[12] Everything I, But I. The anticipatory perspective-points and counterpoints. Utopia and Gospel; 2015. p. 376

[13] Cruz A, Cadena R, Castro W, Esmerino E, Rodrigues J, Gaze L, et al. Consumer perception of probiotic yogurt: Performance of check all that apply (CATA), projective mapping, sorting and intensity scale. Food Research International. 2013;54(1):601-610

[14] Jindal G, Pandey RK, Singh RK, Pandey N. Can early exposure to probiotics in children prevent dental caries? A current perspective. Journal of Oral Biology and Craniofacial Research. 2012;2(2):110-115

[15] Coman MM, Cecchini C, Verdenelli MC, Silvi S, Orpianesi C, Cresci A. Functional foods as carriers for SYNBIO ${ }^{\circledR}$, a probiotic bacteria combination. International Journal of Food Microbiology. 2012;157(3):346-352

[16] Farhat R. Suivi de la survie de "Geotrichum candidum" pendant la digestion in vitro du fromage type Camembert [thesis]. 2017

[17] Soccol CR, de Souza Vandenberghe LP, Spier MR, Medeiros AP, Yamaguishi CT, De Dea Lindner J, et al. The 
potential of probiotics: A review. Food Technology and Biotechnology. 2010;48(4):413-434

[18] Mahmoudi R, Zare P, Hasnzade P, Nosratpour S. Effect of Teucrium polium essential oil on the physicochemical and sensory properties of probiotic yoghurt. Journal of Food Processing and Preservation. 2014;38:880-888

[19] Mahmoudi R, Bajalanlou F, Ghajarbeygi P, Pakbin B. Chemical properties and sensory evaluation of probiotic yoghurt manufactured with aqueous extract of aloe vera. Journal of Biology and Today's World. 2016;5(11):197-202

[20] Mahmoudi R, Tajik H, Ehsani A, Farshid AA, Zare P. Effects of Mentha longifolia L. essential oil on viability and cellular ultrastructure of Lactobacillus casei during ripening of probiotic feta cheese. International Journal of Dairy Technology. 2012;66:70-77

[21] Hart A, Lammers K, Brigidi P, Vitali B, Rizzello F, Gionchetti P, et al. Modulation of human dendritic cell phenotype and function by probiotic bacteria. Gut. 2004;53(11):1602-1609

[22] Eva S. Abstract: Probiotics and dental caries. Microbial Ecology in Health and Disease. 2012;23(1):18582

[23] Sharma P, Thippeswamy H, Chandrasekar B, Thetakala RK. Oral halitosis and probiotics. TMU Journal of Dentistry. 2015;2(2):62-66

[24] Rösing CK, Loesche W. Halitosis: An overview of epidemiology, etiology and clinical management. Brazilian Oral Research. 2011;25(5):466-471

[25] Lalitha T. Probiotics and oral health. Journal of Oral Research and Review. 2011;3(1):20-26
[26] Comelli EM, Guggenheim B, Stingele F, Neeser JR. Selection of dairy bacterial strains as probiotics for oral health. European Journal of Oral Sciences. 2002;110(3):218-224

[27] Lewis S, Freedman A. The use of biotherapeutic agents in the prevention and treatment of gastrointestinal disease. Alimentary Pharmacology \& Therapeutics. 1998;12(9):807-822

[28] Haukioja A, Loimaranta V, Tenovuo J. Probiotic bacteria affect the composition of salivary pellicle and streptococcal adhesion in vitro. Oral Microbiology and Immunology. 2008;23(4):336-343

[29] Isolauri E, Sütas Y, Kankaanpää P, Arvilommi H, Salminen S. Probiotics: Effects on immunity. The American Journal of Clinical Nutrition. 2001;73(2):444s-450s

[30] Mortezavi SH, Akhlaghi N. The role of probiotic on oral health. Journal of Isfahan Dental School. 2011;7(2):187-199 



\title{
Metabolite Multiprobiotic Formulas for Microbial Health
}

\author{
Mikhail V. Lakhtin, Vladimir M. Lakhtin, \\ Vladimir A. Aleshkin and Stanislav S. Afanasiev
}

\begin{abstract}
On example of Lactobacillus and Bifidobacterium strains, approaches in creation of human multistrain probiotic metabolite mixtures for different goals were proposed. Human probiotic lectin systems (LS) (mucosal, others) reveal functions needed for organism. Advanced features of such systems include capability to recognize synthetic polymeric polyvalent glycoconjugates (GC)_imitators of natural ones (modified polysaccharides, glycoantigens of medical significance). Probiotic lectin systems function as imitators of multipro-/sym-/synbiotics in their resulting actions. They serve as carriers of the biotope glycoconjugate décor including glycoprebiotics, glycometabiotics, glycodrugs, and agents supporting décor organization and resistance. Probiotic lectin systems represent new perspective system agents to improve the health of mucosal microbiocenoses (MB) organized as communicative bodies to be corrected according to the principle "there is bodythere are diseases." They act as metabolomebiotics according to the principle "the network in the network." They deepen biotope resistance allowing quicker return to balance. They support prophylactic and therapeutic procedures directed to prolong aging and improve quality of life. Multistrain metabolite constructions can predict perspective cellular formulas of multipro-/synbiotics for prophylaxis, supporting and accompanying therapy. Approaches developed are universal. They are useful in the study of any Gram-positive and eukaryotic (yeasts and yeast-like fungi) monoand mixed cultures. The methodological principles proposed and described are of value for extended fields of clinical microbiology and medical bio-/nanotechnology.
\end{abstract}

Keywords: multistrain probiotics, probiotic lectins, glycoconjugates, microbiocenoses, antimicrobials

\section{Introduction}

Pro-/sym-/synbiotics are important objects of human microecology and medical biotechnology [1-4]. Microbes and human communicate each other by the way of recognition and binding glycoconjugates (GC) of varying pattern complexity by proteins (mainly adhesions and lectins) [5-9]. Lectin systems (LS) of symbiotic/ probiotic microorganisms (LSSM) recognizing GC represent new multifunctional factors [8-12]. LSSM are relatedly useful for human protein-/peptide-containing compounds and their complexes recognizing GC. LSSM reveal features of imitators of probiotics; members of new class of bacteriocin-like destructors of biofilms of yeast-like fungal and Gram-positive pathogens; systems cofunctioning together 
with enzymes of all known classes; and agents possessing antipathogenic synergism of different LS in antimicrobial combinations (between LS of Lactobacillus species and Bifidobacterium species, between genera Lactobacillus and Bifidobacterium, between LS of probiotic bacteria and lectins from medical plants, between LSSM and antibiotics) (see Table 2) $[8,9,13,14]$.

LS reveal significantly higher multifunctionality (antimicrobial, cytokine-like, others) and adaptive ability in surroundings in comparison to any component of LS. Applied prospects of LSSM in microbial associations of biotopes in the human body are of promised interest. LSSM and their reactive GC support balanced functioning in organism in respect to evolutionary created mucosal organ-like infrastructures of mutual interest for human and biotope microbiocenoses (MB) [12].

The purpose of the review is to evaluate our approaches in creation of probiotic metabolite compositions influencing and improving health of human biotope microbiocenoses. The data presented will be of interest for investigators in the fields of both medical microbiology and laboratory and industrial medical biotechnology.

\section{Methods}

Lactobacillus and Bifidobacterium strains were from the collection of microorganisms of the normal microflora of G. N. Gabrichevsky Institute for Epidemiology and Microbiology, and probiotics Bifidin and Acilact were products of our institute. Bacteria were grown in media containing casein hydrolysate and yeast autolysate. LSSM were extracted from the protein fractions $27-220 \mathrm{kD}$ using isoelectrofocusing (IEF) in a plate of polyacrylamide gel (PAG) in a gradient of $\mathrm{pH} 4-8$. Identification of proteins was performed by electroblotting on a hydrophobic membrane and staining with SYPRO blot stain (Bio-Rad Lab.). Nonstained proteins were evaluated by other spectrophotometric methods. The distribution of LSSM among proteins was determined by treatment of blots with biotinylated GC (GC-b) containing multiple residues of sugar(s) linked to the polyacrylamide (PA) linear core (like in external phenotypes of mucins and mucin-type glycans) (www.lectinity.com;

\begin{tabular}{|c|c|}
\hline 1. & $\alpha / \beta-\mathrm{D}-$ GalNAc-PA-b (animal mucins, $\mathrm{T}$ antigens) ${ }^{*}$ \\
\hline 2. & $\beta$-D-GalNAc-PA-b (animal mucins) \\
\hline 3. & $\beta$-D-GlcNAc-PA-b (insect chitins and chitosans) \\
\hline 4. & $\beta-\mathrm{D}-\mathrm{Gal}-\mathrm{PA}-\mathrm{b}$ (plant or animal galactans) \\
\hline 5. & $\beta$-D-Gal-3-sulfate-PA-b (acidic animal galactans) \\
\hline 6. & $\alpha-\mathrm{D}-\mathrm{Man}-\mathrm{PA}-\mathrm{b}$ (yeast mannans) \\
\hline 7. & $\alpha$-D-Man-6P-PA-b (yeast phosphomannans) \\
\hline 8. & $\alpha$-L-Fuc-PA-b (fucans from brown algae) \\
\hline 9. & $\alpha$-L-Rha-PA-b (Gram-negative rhamnans) \\
\hline 10. & MDP-PA-b (bacterial peptodoglycans) \\
\hline 11. & Adi-PA-b (A-blood group substance GalNAc $\beta 1-3 G a l \beta A 1-)$ \\
\hline 12. & Fs-PA-b (Forssman antigen GalNAc $\beta 1-3$ GalNAc $\beta A 1-)$ \\
\hline 13. & 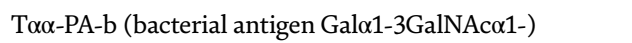 \\
\hline
\end{tabular}

*In brackets—natural substances which are imitated

Table 1.

A list of synthetic GC used. 
Table 1) followed by final treatment with streptavidin-peroxidase conjugate. The bound peroxidase on the blot was registered in the presence of a chemiluminescent substrate in regime of a real time in the system BioChemi System (UVP, CA). Antimicrobial activities and synergism of LSSM, antibiotics, and phytolectins were tested on solid agar media during the prolonged growth and survival of communicative fungal bodies (CFB) in the presence of disks of antimicrobials. Biosurfactants were tested and calculated using detection of sample drop activity against mineral oil film on water surface (the appearance of transparent circles). Amino acid compositions of samples were established using standard amino acid analyzer column chromatography. Oxidoreductase systems were detected on blots after IEF-PAG, resulting in kinetic protein stain disappearance (decolorization). Hydrolase systems were visually evaluated on blots after IEF-PAG (resulting in hydrolysis, splitting, and partial asymmetrical disappearance of protein bands). Maillard reaction products were partially evaluated as browning in culture supernatant according to optical density at $420 \mathrm{~nm}$.

\section{Results and discussion}

\subsection{Symbiotic lectins as system regulators and delivery agents}

LSSM function as metabolomebiotics regulating metabolome according to the principle "LSSM network-whole organism metabolome network or interactome" [15]. The network of LSSM is created in the following manner: lectin molecule of determined molecular weight (in the Laemmli system) is represented by LS including forms of varying charge and possessing a range of biological and physiological activities; such a minimal LS can be further transformed in a natural manner into extended network of complexes and supramolecular ensembles as a result of directional and sequential cascade binding of carbohydrates and GC. As a result of forming complexes and ensembles, lectin specificity of complexes and ensembles can be modified or changed during further development of recognition cascade network that will change the summary vector of specificity of LS. The latter will result in dynamic qualitative and quantitative changes of the local biotope surrounding. Thus, the final whole resulting network of LSSM (as metabolomebiotics) will regulate the whole metabolome and interactome of organism involving human glycome (carbohydrates and GC: glycoproteins, glycoenzymes, glycolipids, receptors, and others [16]). The metabolome possesses the ability to back direct and reversible effects of LSSM representing a part of hierarchic interactome. Multiple forms of adapted functioning LSSM microbiocenosis in the biotope will depend on the originality developed in a joint process of evolution involving host body local infrastructures for the distribution and disposition of microbiocenoses (organ-type constructions of both host and microbiocenosis interests are possible) [11, 12]. LSSM are ready to realize biologically active GC (as prebiotics, therapeutic agents, and metabiotics) in such symbiotic organs. The network of LSSM functions as noncellular simulators of symbiotics (probiotics) in the direct or indirect (through human higher hierarchic protection systems) predictable manners. For example, of communications between LSSM and own human protection systems, LSSM (as well as phytohemagglutinins from plants of medical significance) and artificial polymeric GC influenced peritoneal macrophage mobility in a coupled manner depending on doses of agents; LSSM were involved in modulation of cytokine production by human blood leukocytes $[9,17]$.

New useful properties of LSSM can be predicted and verified (cofunctioning to enzymes, adhesion, etc.), based on the fact that LSSM form a functional 
superfamily of symbiotic lectins (on example of probiotic lectins and lectins of nitrogen-fixing bacteria). In addition, LSSM are members of the new class of destructors of biofilms of yeast-like and Gram-positive pathogens that simplify antimicrobial choice of components among LSSM. Other possibilities to operate with LSSM include their potential participation in a set of hierarchic pathways of advanced human innate protective systems in biotopes for cross talks. Both types of communications allow LSSM to be a successful synergistic assistant against pathogens in biotopes together with other antimicrobials and antimicrobial physical stress factors. As a result, LSSM reveal prolonged (early and late) anti-Candida activities as cascade (coupled) actions possibly influencing microecological niches of pathogens within biotope [registered during coculturing in the first 3 days (early events; also involving probiotic-like leader strains of L. acidophilus and L. casei), 1-2 weeks, or 2-3 months (late events)] [18].

The used GC are characterized with known chemical structures simplifying interpretation and prognostics of results. Such GC reveal potential of metabiotics which may use LSSM as carriers $[8,12,19]$. As highly homogenous, synthetic GC better functionally imitate natural GC targets [bacterial proteoglycans, fungal (phosphor)mannans, others] important for antimicrobial/anti-infectious actions of LSSM. As a result, LSSM are very perspective in delivery and deposition of adequate specific GC which are locally releasing as therapeutics possessing anti-infectious, prebiotic, and/or communicative signal abilities and actions.

In biotopes LSSM participate in continuous (on-duty) support and periodical (biorhythmic) completion and exchange of normal GC décor of cells, tissues, and organs that must provide delaying or stopping further the development of the spot/ island/mosaic-landscape-originated and directed/metastasized abnormal processes as well as conserve any negative currently developmental events (initiation of appearance and survival of tumor-like cells as a result of innate intercellular communications involving lectin receptor-coupled cell surface receptor mosaics).

LSSM (natural combinative sets of LSSM-GC complexes) influence all yeast-like fungal phases of life by prolonging the degradation and lysis of pathogenic microbiocenosis massifs or biofilms in human biotopes (on examples of Candida species). In respect to CFB functioning as niches, lectins of lactobacilli (LL as preferentially mucins/mucus-recognizing) and lectins of bifidobacteria (BL as preferentially mannan-recognizing) synergistically act against internal and peripheral subniche territories, respectively. The late destructive and lytic events in CFB may also take place due to LSSM cooperative complex action as metabolomebiotics together with hydrolases involved in pathogen destruction network. Synergistic actions between LSSM and other antifungals increase resulting in final (early or late [also of apoptotic origin]) antipathogenic events as shown in Table 2 [20].

Endogenous LS antimicrobial actions (e.g., intestinal probiotic bifidobacterial and lactobacillar LS against intestinal yeast-like fungi) provide more directed, sensitive, and completed resulting effectiveness against pathogens (the primary absence and further late complete destruction of residual resistant colonies in external and internal regions of CFB of Candida albicans) compared to the action of phytolectin mixture from grasses of medical significance in the same conditions. In cases of antibiotic-resistant strains, relatively sensitive to LSSM C. albicans strain 547 (less potentially pathogenic compared to the strain 515, see below), the sorbed lactobacillar cationic LS revealed their synergistic ability to "regenerate" original anti-Candida effectiveness of antibiotic (on example of nystatin) in the internal region of CFB of yeast-like fungus (appearance of pathogen-free landscape connected to the border of the disk antibiotic). The phenomenon of synergistic reparation of the original ability of the sorbed antibiotic indicates prospects of additional mechanisms of LSSM combinative actions and partially 
describes how to increase resulting antifungal effectiveness during prolonged contact to pathogenic CFB at fungal late steps. In the case of more resistant (potentially "more pathogenic") fungal strains (like C. albicans strain 515), the sorbed

\begin{tabular}{|c|c|c|c|}
\hline Types of synergism & Lectins $^{*}$ & $\begin{array}{l}\text { Distant positions } \\
\text { (directions from left to } \\
\text { right) }\end{array}$ & $\begin{array}{l}\text { CBF as targets, affinity, } \\
\text { and significance }\end{array}$ \\
\hline \multicolumn{4}{|l|}{ Between PL } \\
\hline Between identical PL disks & $\begin{array}{l}\text { aBL and } \\
\mathrm{aBL}\end{array}$ & $\begin{array}{l}\text { p-aBL, c-aBL } \\
(p-a B L-c-a B L)\end{array}$ & C. albicans 991 \\
\hline $\begin{array}{l}\text { Intra-genus } \\
\text { (Lactobacillus) }\end{array}$ & $\begin{array}{l}\text { cLL and } \\
\text { aLL } \\
\text { aLL and } \\
\text { cLL }\end{array}$ & $\begin{array}{l}\text { From p-cLL to CR } \\
\text { (p-cLL-p-aLL) } \\
\text { From p-aLL to CR } \\
\text { (p-aLL-p-cLL) }\end{array}$ & $\begin{array}{l}\text { C. albicans } 515,547 \\
\text { C. albicans } 515,547\end{array}$ \\
\hline $\begin{array}{l}\text { Intra-genus } \\
\text { (Bifidobacterium) }\end{array}$ & $\begin{array}{l}\text { aLL and } \\
\mathrm{aBL}\end{array}$ & $\begin{array}{l}\text { p-aLL and c-aBL } \\
(\mathrm{p}-\mathrm{aLL}-\mathrm{c}-\mathrm{aBL})\end{array}$ & C. albicans strains \\
\hline $\begin{array}{l}\text { Intra-genus } \\
\text { (Bifidobacterium) }\end{array}$ & $\begin{array}{l}\mathrm{aBL} \text { and } \\
\mathrm{cBL}\end{array}$ & [PR aBL] and [CR aLL] & C. albicans strains \\
\hline $\begin{array}{l}\text { Inter-genera } \\
\text { (Lactobacillus and } \\
\text { Bifidobacterium) }\end{array}$ & $\begin{array}{l}\text { aBL and } \\
\text { aLL } \\
\text { aLL and } \\
\text { aBL }\end{array}$ & $\begin{array}{l}{[\mathrm{PR} a B L] \text { and }[\mathrm{CR} \mathrm{aLL}]} \\
(\mathrm{p}-\mathrm{aBL}-\mathrm{p}-\mathrm{aLL}) \\
{[\mathrm{PR} a L L] \text { and }[\mathrm{CR} \mathrm{aBL}]_{2}^{*}} \\
(\mathrm{p}-\mathrm{aLL}-\mathrm{p}-\mathrm{aBL})\end{array}$ & $\begin{array}{l}\text { C. albicans strains } \\
\text { S. aureus strains }\end{array}$ \\
\hline \multicolumn{4}{|l|}{ Between PL and phytolectins } \\
\hline $\begin{array}{l}\text { Between PL and grass lectins } \\
\text { (GL) }\end{array}$ & $\begin{array}{l}\text { aLL and } \\
\text { GL } \\
\text { cBL and } \\
\text { GL }\end{array}$ & $\begin{array}{l}\text { From aLL to CR } \\
\text { (p-MGBL-p-aLL) } \\
\text { From p-cBL to CR } \\
\text { (p-MGBL-p-cBL) }\end{array}$ & $\begin{array}{l}\text { C. albicans } 515 \\
\text { C. albicans } 515\end{array}$ \\
\hline \multicolumn{4}{|l|}{ Between PL and antimycotics } \\
\hline $\begin{array}{l}\text { Between PL and } \\
\text { amphotericin B }\end{array}$ & $\mathrm{aBL}$ & $\begin{array}{l}\text { p-Amphotericin B, c-aBL } \\
\text { (p-Amphotericin } \\
\text { B-c-aBL) }\end{array}$ & $\begin{array}{l}\text { C. albicans strains }>C \text {. } \\
\text { tropicalis strains }\end{array}$ \\
\hline Between PL and itraconazole & $\mathrm{aBL}$ & $\begin{array}{l}\text { c-Itraconazole, p-aBL } \\
\text { (p-Itraconazole-p-aBL) }\end{array}$ & C. albicans strains \\
\hline $\begin{array}{l}\text { Between PL and } \\
\text { ketoconazole }\end{array}$ & $\mathrm{aBL}$ & $\begin{array}{l}\text { p-Ketoconazole, c-aBL } \\
\text { (p-Ketoconazole-c-aBL) }\end{array}$ & C. albicans strains \\
\hline $\begin{array}{l}\text { Between PL and } \\
\text { nystatin }\end{array}$ & $\begin{array}{l}\mathrm{cLL} \\
\mathrm{cBL}\end{array}$ & $\begin{array}{l}\text { From p-cLL to CR } \\
\text { (p-cLL_c-nystatin) } \\
\text { From cBL to CR } \\
\text { (p-cBL-c-Nystatin) }\end{array}$ & $\begin{array}{l}\text { C. albicans } 515,547 \\
\text { C. albicans } 515,547\end{array}$ \\
\hline $\begin{array}{l}\text { Between GL and } \\
\text { nystatin }\end{array}$ & GL & $\begin{array}{l}\text { From p-MGBL to CR } \\
\text { (p-MGBL_c-nystatin) }\end{array}$ & C. albicans 515 \\
\hline \multicolumn{4}{|l|}{ Multiple synergism } \\
\hline Between BL and LL & $\begin{array}{l}\text { aBL, } \\
\text { aLL }\end{array}$ & $\begin{array}{l}\text { In triangle of CFB } \\
\text { landscape: } \\
\text { p-aBL }+c-a B L+p-a L L \\
(p-a B L-c-a B L ; \\
\text { p-aLL-c-aBL) }\end{array}$ & $\begin{array}{l}\text { C. albicans strains } \\
\text { (Not for C. tropicalis) }\end{array}$ \\
\hline \multicolumn{4}{|c|}{$\begin{array}{l}\text { Diffusion between disks placed on Sabouraud agar in Petri dishes (disk positions: } p \text {, peripheral; central; CR, } \\
\text { central region, between p-disk and the center; PR, peripheral region, between p-disk and the border of agar). Disks } \\
\text { included anionic (a) and cationic and (c) lactobacillar and bifidobacterial LSSM (aLL, cLL, aBL, cBL). MGBL as } \\
\text { the mixture of the grass lectins from the mill of plants of medical significance: Potentilla album and Stellaria media. } \\
\text { Lectins were used in subhemagglutinating doses (less } 1 \text { microgram/ml). Standard panel of disk antimycotics (HiMedia } \\
\text { Lab. Pvt. Ltd.) was used. CFB, communicative fungal bodies. }\end{array}$} \\
\hline
\end{tabular}

Table 2.

Antimicrobial synergism of LSSM and antibiotics. 
bifidobacterial cationic LS synergistically increased anti-Candida action of the grass phytolectin mixture.

Results indicate that LSSM may also participate in temporary separation and conservation of natural infectious biofilms to prevent early visual landscape development of diseases. The latter may be perspective as the assistant factor of improving quality of life (its prolongation, mucus and skin reparations, cosmetic significance, etc.) as it can be expected using symbiotics [21] .

On the whole, our experimental approach (observations of antagonistic relationships between LSSM and pathogens in prolonged stress conditions) and the data obtained are supported by the conception describing microecological stress events in organism as the normal but sensor natural reactions [22].

\subsection{The choice of strains and their consortia possessing potential for constructing new multistrain pro- and symbiotics}

Screening, choice, and selection of new or improved antimicrobial and other useful properties of symbiotic (probiotic) cultural properties of strains and consortia of human MB are important and strategic goals in prophylaxis and therapy of diseases, increasing resistance of organism and the acceleration of patient rehabilitation [1-4, 23]. Among GC investigated, glycans of mucin type (mucosal glycans) reveal special interest [24].

On the basis of own results, we proposed new algorithm of screening adequate probiotic-like microorganisms and their consortia possessing increased directed anti-infectious LS to construct new multipro-/sym-/synbiotics. The algorithm using LSSM (involving complexes to GC) among a panel of key factors in creating multiprobiotics (MP) included (a) the choice of synthetic GC-imitating bacterial proteoglycans and (phospho)mannans of yeast-like fungi; (b) identification of different LSSM (GC-type-dependent) among proteins of cultural fluids of probiotic strain or consortium of strains; (c) comparison of (GC-type)-dependent LS (evaluation of summary LS intensity, length of LS distribution in $\mathrm{pH}$-gradient tested, mosaic asymmetric configuration of distributed forms in LS, major forms as dominating in contribution to antimicrobial actions of LS, minor forms as expressing signal regulators of biorecognition in microbiocenoses, signals of communications to surrounding infrastructures, as well as additional participants of recognition of new types of biomarker GC); (d) identification of unique sets of components of LS significant for typing strains, species, or genera; (e) revealing and choice of combinative sets of potential antimicrobial forms of LS for further control and testing; and (f) control of antimicrobial activities initiated, supported, and/or influenced by LS-containing preparations in other (nondependent) methods.

The data which were useful for constructing any multiprobiotics (Acilact-like) is presented in Table 3.

In Table 3 the data needed for constructing formulas of any MP are presented on example of strain component compositions of Acilact (the well-known MP which served as a model). Algorithm for constructing formulas includes a few steps:

The first step: For formulas of any MP of category A (formulas as sum of wishful selected superiorities): the choice of all parameters of superiorities of MP (No. 4 as MP in code notes: positions 1.3, 1.4, 1.6, 2.7, 2.8, 2.13, 2.14, 2.15, and 4.3; major ingredient strain contributors are at the second position in the code sequences [from left to right] position in code).

The second step: For formulas of any MP of category B: accounting additional superiorities of MP [No. 4 as MP in code notes; selected minimal positions of parameters for No. 4 in sequence indicate maximal expression of the contrary (by implicity) parameters]. For example, in the case of No. 4 in codes 1.1 
Metabolite Multiprobiotic Formulas for Microbial Health

DOI: http://dx.doi.org/10.5772/intechopen.86449

\begin{tabular}{|c|c|c|}
\hline No. & Parameters of supernatants, ranging MP and its strains, proposals (P) & $\begin{array}{l}\text { Code ranging MP } \\
\text { and its strains }\end{array}$ \\
\hline 1 & Status of proteins & \\
\hline 1.0 & $\begin{array}{c}\text { Content of partially hydrolyzed protein } \\
\text { K3III24 }>\text { MP }>100 \text { ash }>\text { NK1 } \\
\text { P: K3III24 as the main source of active or signal oligopeptides }\end{array}$ & 3. 4.2.1. \\
\hline 1.1 & $\begin{array}{c}\text { Acidic proteins pI 4-5 } \\
\text { NK1 }>100 \text { ash }>\text { K3III24 }>\text { MP } \\
\text { P: NK1 as the main source of basis cytoagglutinating and adhesive agents } \\
\text { coupled to a spectrum of biological activities }\end{array}$ & 1.2.3. 4 . \\
\hline 1.2 & $\begin{array}{c}\text { Cationic proteins pI 7-8 } \\
\text { NK1 }>\text { K3III24 }>100 \text { ash }>\text { MP } \\
\text { P: Strains and their combinations as sources of lectins and lectin-like agents } \\
\text { coupled to exopolymeric substances of compounds }\end{array}$ & 1.3.2. 4 . \\
\hline 1.3 & $\begin{array}{c}\text { Oxidase-reductase systems pI 5-5.5 } \\
\text { MP }>100 \text { ash }>\text { K3III24 > NK1[absence] } \\
\text { P: NK1 without extracellular major oxidoreductase systems }\end{array}$ & 4. 2.3.1. \\
\hline 1.4 & $\begin{array}{c}\text { Hydrolase systems } \\
\text { MP }>\text { K3III24 }>100 \text { ash }>\text { NK1 } \\
\text { P: NK1 without extracellular major hydrolases (caseinases, peptidases, } \\
\text { others) }\end{array}$ & 4.3.2.1. \\
\hline 1.5 & $\begin{array}{c}\text { Level of aggregation upon storing concentrates } \\
\text { K3III24 > } 100 \text { ash > NK1 > MP[no aggregation] } \\
\text { P: Irreversibility for K3III24 (similar to red cell biofilm storing) }\end{array}$ & 3. 2.1. 4 . \\
\hline 1.6 & $\begin{array}{c}\text { Ability in membrane ultrafiltration } \\
\text { MP }>\text { NK1 }>100 \text { ash }>\text { K3III24 } \\
\text { P: Technological advantage of MP as mixture of strains (mixture of strains } \\
\text { is needed) }\end{array}$ & 4.1.2.3. \\
\hline 2 & Status of amino acids & \\
\hline 2.0 & $\begin{array}{c}\text { Production of amino acids } \\
\text { NK1 }>\text { K3III24 }>\text { MP }>100 \text { ash } \\
\text { P: Low antagonism between certain strains within MP can be under } \\
\text { consideration upon strain choice }\end{array}$ & 1.3. 4. 2 . \\
\hline 2.1 & $\begin{array}{c}\text { Tyr (sites for serine proteinases, fluorophores) } \\
\text { K3III24 }>100 \text { ash }>\text { MP }>\text { NK1 } \\
\text { P: Tyr can serve as criterion of utilization of fluorophores }\end{array}$ & 3.2. 4. 1 . \\
\hline 2.2 & $\begin{array}{l}\text { Phe (sites for serine proteinases, fluorophores) } \\
\text { NK1 }>\text { MP > K3III24 > } 100 \text { ash } \\
\text { P: Support of point 2, revealing mechanism for point } 2\end{array}$ & 1. 4. 3. 2 . \\
\hline 2.3 & $\begin{array}{c}\text { Fluorophores (Trp, Tyr) (excitation at } 254 \mathrm{~nm}) \\
100 \text { ash }>\text { K3III } 24>\text { NK1 }>\text { MP } \\
\text { P: Dominated contribution of Tyr and their derivatives }\end{array}$ & 2.3.1. 4 . \\
\hline 2.3.1 & $\begin{array}{c}\text { Fluorophores (excitation at } 365 \mathrm{~nm} \text { ) } \\
100 \text { ash }>\text { K3III24 }>\text { NK1 }>>\text { MP } \\
\text { P: Degradation/ utilization in MP (fluorophores cannot be used as targets) }\end{array}$ & 2314 \\
\hline 2.4 & $\begin{array}{c}\text { Gly (hydrophobic, anti-adhesion action) } \\
\text { NK1 }>\text { MP }>\text { K3III24 }>100 \text { ash } \\
\text { P: Gly as natural additive to improve signal activities and communications }\end{array}$ & 1. 4. 3. 2 . \\
\hline 2.5 & $\begin{array}{l}\text { Leu (hydrophobic, site for peptidases) } \\
\text { (Parameter is slightly dependent on strain origin) } \\
\text { K3III24 > } 100 \text { ash > MP, NK1 }\end{array}$ & 3. $2.1 / 4 * 4 / 1$ \\
\hline 2.6 & $\begin{array}{l}\text { Ile (hydrophobic, participation in synthesis of biologically active volatile } \\
\qquad \text { fatty acids) } \\
\qquad \text { K3III24 }>100 \text { ash }>\text { MP }>\text { NK1 }\end{array}$ & 3. 2. 4. 1 . \\
\hline
\end{tabular}




\begin{tabular}{|c|c|c|}
\hline No. & Parameters of supernatants, ranging MP and its strains, proposals $(\mathrm{P})$ & $\begin{array}{l}\text { Code ranging MP } \\
\text { and its strains }\end{array}$ \\
\hline 2.7 & $\begin{array}{c}\text { Ala (partially from peptidoglycans, site for exopeptidases) } \\
\text { MP > K3III24, } 100 \text { ash }>\text { NK1 } \\
\text { P: Antagonism between strains results in partial cell wall degradation in MP }\end{array}$ & 4. 2/3.3/2.1. \\
\hline 2.8 & $\begin{array}{l}\text { Ser (sites for hydrolase splitting and O-glycosylation) } \\
\qquad \begin{array}{l}\text { MP }>\text { K3III } 24>100 \text { ash }>\text { NK1 } \\
\text { P: Support of point } 1.4\end{array}\end{array}$ & 4.3.2.1. \\
\hline 2.9 & $\begin{array}{c}\text { Thr (site for O-glycosylation) } \\
\text { NK1 }>100 \text { ash }>\text { MP }>\text { K3III24 } \\
\text { P: Thr as criterion for evaluation of metabolism of cluster square positions } \\
\text { for recognition in proteins (in comparison to point 2.8) }\end{array}$ & 1.2. 4.3 . \\
\hline 2.10 & $\begin{array}{l}\text { Lys (from cationic poly/oligopeptides, site for serine } \\
\text { proteinases, participation in Maillard reaction) } \\
\qquad \begin{array}{l}\text { MP }>100 \text { ash }>\text { K3III } 24>\text { NK1 } \\
\text { P: Support of point } 1.4\end{array}\end{array}$ & 4.2.3.1. \\
\hline 2.11 & $\begin{array}{l}\text { Val (hydrophobic, participation in synthesis of biologically active volatile } \\
\qquad \text { fatty acids) } \\
\qquad \text { K3III24 }>100 \text { ash }>\text { NK1 }>\text { MP } \\
\text { P: Mostly important criterion concerning volatile fatty acids producing }\end{array}$ & 3.2.1. 4 . \\
\hline 2.12 & $\begin{array}{l}\text { Glu/Gln (also as sites for amidases) } \\
\text { NK1 > MP, K3III24 > } 100 \text { ash }\end{array}$ & 1. 4.3.2. \\
\hline 2.13 & $\begin{array}{l}\text { Asp/Asn (sites for amidases and N-glycosylation) } \\
\text { MP, } 100 \text { ash }>\text { NK1 }>\text { K3III } 24 \\
\text { P: Partial support of point } 1.4\end{array}$ & 4.2.1.3. \\
\hline 2.14 & $\begin{array}{l}\text { His (participation in auto-oxidation of protein, high affinity to metal } \\
\text { cations, activation of oxidases and heme) } \\
\text { MP }>\text { NK1 }>100 \text { ash }>\text { K3III24 } \\
\text { P: Potential for metal chelate affinity chromatography and immobilization } \\
\text { (for microassays) }\end{array}$ & 4.1.2.3. \\
\hline 2.15 & $\begin{array}{l}\text { Arg (from cationic poly[oligo] peptides, destruction } \\
\text { during pigments forming in Maillard reaction) } \\
\text { MP }>\text { NK1 }>\text { K3III } 24>100 \text { ash } \\
\text { P: One of the way of decolorization of MP }\end{array}$ & 4.1.3.2. \\
\hline 2.16 & $\begin{array}{c}\text { Met (antioxidant) } \\
\text { NK1 }>\text { MP }>\text { K3III24 > } 100 \text { ash }\end{array}$ & 1. 4.3.2. \\
\hline 2.17 & $\begin{array}{l}\text { Cys2 disulfide bonds (oxidation of SH-groups into Cys2) } \\
\text { K3III24 > NK1 }>\text { MP > } 100 \text { ash[not observed] }\end{array}$ & 3.1. 4. 2 . \\
\hline 2.18 & $\begin{array}{l}\text { Pro (Pro-bends in regular structures of proteins) } \\
\qquad 100 \text { ash }>\text { MP > K3III24 > NK1[traces] }\end{array}$ & 2. 4.3.1. \\
\hline 3 & Status of biosurfactants & \\
\hline 3.0 & $\begin{array}{c}\text { Associated biosurfactants in complexes }>27 \mathrm{kD} \\
\text { NK1 }>\text { MP }>>100 \text { ash }>\text { K3III24 } \\
\text { P: NK1 as the main source of movable permeable (detergent like) complex } \\
\text { effectors; support point } 4.3\end{array}$ & 1. 4.2.3. \\
\hline 3.1 & $\begin{array}{l}\text { Biosurfactants active against mineral oil } \\
\text { K3III24 }>\text { MP }>100 \text { ash }>\text { NK1 }\end{array}$ & 3. 4.2.1. \\
\hline 4 & Other parameters & \\
\hline 4.1 & $\begin{array}{c}\text { Emulsifiers } \\
100 \text { ash }>\text { NK1 }>\text { MP }>>\text { K3III24 [absence] } \\
\text { P: K3III24 needs combination to any other strain to increase cultural } \\
\text { components }(>27 \mathrm{kD}) \text { to be emulsified }\end{array}$ & 2.1. 4.3 . \\
\hline
\end{tabular}




\begin{tabular}{|c|c|c|}
\hline No. & Parameters of supernatants, ranging MP and its strains, proposals $(\mathrm{P})$ & $\begin{array}{l}\text { Code ranging MP } \\
\text { and its strains }\end{array}$ \\
\hline 4.2 & $\begin{array}{c}\text { Pigment products [optical density at } 420 \mathrm{~nm} \text { ] } \\
\text { K3III24 > NK1 > } 100 \text { ash }>\text { MP } \\
\text { P: K3III24 as the main potential source of neoglycoconjugates of } \\
\text { nonenzymatical origin; MP as maximally decolorized product needed } \\
\text { cofunctioning strain mixture; partial inverse correlation to point } 1.3\end{array}$ & 3.1.2. 4 . \\
\hline 4.3 & $\begin{array}{l}\text { Antimicrobial activity (toward a panel of diagnostic mainly Gram-negative } \\
\qquad \begin{array}{l}\text { bacteria) } \\
\text { MP }>\text { NK1 }>100 \text { ash }>\text { K3III24 }\end{array} \\
\text { P: Support point 3; potential of K3III24 to other targets (against Gram- } \\
\text { positive bacteria and fungi) }\end{array}$ & 4.1.2.3. \\
\hline \multicolumn{3}{|c|}{$\begin{array}{l}\text { "1, NK1 (Lactobacillus helveticus NK1); 2, } 100 \text { ash (L. helveticus } 100 \text { ash); 3, K3III24 (L. casei K3III24); } \\
\text { 4, multiprobiotic (MP) on example of variants of Acilact. }\end{array}$} \\
\hline
\end{tabular}

Table 3.

Strain code ranging for multiprobiotic construction on example of Acilact (the Lactobacillus multistrain probiotic).

(maximal resulting hydrolytic activities in respect to acidic proteins; increased level of antimicrobial peptides), 1.2 (maximal resulting hydrolytic activities in respect to cationic proteins; increased level of antimicrobial peptides including bacteriocin-like), 1.5 (the minimal level of aggregation upon storing concentrates), 2.3 (the minimal level of fluorophores exciting at $254 \mathrm{~nm}$; contribution of Tyr and Trp or their derivatives), 2.3.1 (the minimal level of fluorophores exciting at $365 \mathrm{~nm}$; contribution of Trp); and 4.2 (the minimal level of colored products); the major ingredient strain contributors are accounted as the third position in code.

The third step: The final formulas (formulas of category $\mathrm{C}$ ) include combinations of formulas A and B. Multifunctionality of parameters analyzed can be extended (as in cases of amino acids [25]).

Extended approach for constructing more adaptive mixtures of lactobacillar and bifidobacterial MP (on the basis of Acilact extended by accounting industrial bifidobacterial strains) is presented in Table 4.

As expected, taxonomically mixed probiotics (symbiotics) will possess increased survival in biotopes of human organism. The same principles and algorithm (as for formulas of Acilact variants described above) can be applied. Combinations of Acilact ingredient strains and ingredients of Bifidin (B. longum spp. adolescentis MS-42), Bioprotectin (B. bifidum No. 1), and other bifidobacterial probiotics produced in Russia are of priority interest (also due to the possibility of their usage as standard models).

Table 4 demonstrates algorithm of further passage from intra-genus cases (Lactobacillus) of Gram-positive MP to inter-genus cases of MP as combinations of probiotic lactobacilli and bifidobacteria of the human gut origin.

Selective sets of parameters (points in Table 4) indicate principle differences between lactobacilli and bifidobacteria (as blocks of lactobacillar and bifidobacterial strains in 7-mark code). Completing lactobacillar/bifidobacterial synergism is expected and predicted. Selected combinations of strains from both blocks can be used for creation of directed MP. Other more complex cases include unblocked lactobacillar and bifidobacterial sequences within the code (additional prognostic conclusions are possible). Code positions " 1 " and " 5 " (both strains produce high levels of cytoagglutinating LS) reveal adjacent/similar behavior that indicates high level of compatibility of the strains NK1 and MS42. 


\begin{tabular}{|c|c|c|}
\hline No. & Parameters of concentrate $(\mathrm{C})$, their ranging, proposals $(\mathrm{P})$ & $\begin{array}{l}\text { Code } \\
\text { ranging } \\
\text { strains } \\
\text { and MP }\end{array}$ \\
\hline 1 & $\begin{array}{l}\text { Antifreeze components }>27 \mathrm{kD} \text {, pI } 4-8 \\
\text { (against any type of crystal forming during IEF-PAG): } \\
\text { gall }>\text { bif1 }>\text { MS42 }>\text { NK1 }>\text { MP }>\text { K3III24, } 100 \text { ash } \\
\text { P: bifidobacterial C for stabilization of K3III24 and } 100 \text { ash }\end{array}$ & $\begin{array}{c}\text { 7. } 6.5 .1 .4 . \\
3 / 2^{*} .2 / 3 .\end{array}$ \\
\hline 2 & $\begin{array}{l}\text { Formation of organic crystals in the presence of components }>27 \mathrm{kD} \\
\text { (in conditions of } 7 \mathrm{M} \text { urea, } 5 \% \text { saccharose, } 8^{\circ} \mathrm{C} \text {, night, IEF in slab of PAG): } \\
\text { pI 4-6: 3III24, } 100 \text { ash }>\mathrm{MP}>\mathrm{NK} 1>\mathrm{MS}>\text { bif1 }>\text { gall }(\text { not) } \\
\text { pI 6-8: K3III24, } 100 \text { ash }>\mathrm{MP}>\mathrm{NK} 1>\text { gall }>\text { bif1 }>\text { MS42 } \\
\text { P: Potential approach to micro- and nanoassembling effectors }\end{array}$ & $\begin{array}{l}\text { 2/3.3/2. } 4 \text {. } \\
\text { 1.5.6.7. } \\
\text { 2/3.3/2. } 4 \text {. } \\
\text { 1.7.6.5. }\end{array}$ \\
\hline 3 & $\begin{array}{c}\text { Complex protein C }>27 \mathrm{kD} \text { : } \\
\text { pI 4-6: NK1 }>\text { MS42 }>\text { K3III24 }>\text { gall }>100 \text { ash }>\text { bif1 }>\text { MP } \\
\text { pI 6-8: NK1 }>\text { gall }>\text { K3III24 }>\text { MS42 }>100 \text { ash }>\text { MP }>\text { bif1 } \\
\text { P: Donors of cationic bacteriocin-like associates with exopolymeric compounds }\end{array}$ & $\begin{array}{l}\text { 1. 5. 3. } 7.2 . \\
\text { 6. } 4 . \\
\text { 1. } 7.3 .5 .2 . \\
\text { 4. } 6 .\end{array}$ \\
\hline 4 & $\begin{array}{c}\text { Adhesins as colorless transparent not water-soluble drops on } \\
\text { polystyrene (number of drops): } \\
\text { gall }>\text { MS42 }>\text { NK1 }>\text { bif } 1>\mathrm{MP}>\text { K3III } 24=100 \text { ash }(\text { not }) \\
\text { P: The size and numbers of drops indicate level of emulsification of } \mathrm{C} \text { compared to } \\
\text { original supernatant }\end{array}$ & $\begin{array}{c}\text { 7. 5. 1. } 6.4 \text {. } \\
\text { 2/3.3/2. }\end{array}$ \\
\hline 5 & $\begin{array}{c}\text { Associated biosurfactants: } \\
\text { bif1 }>\text { gall }>\text { K3III24 }>\text { MP }>\text { 100ash }>\text { MS42 }>\text { NK1 } \\
\text { P: C "NK1 + gall" and "NK1 + bif1" as synergistic antimicrobials }\end{array}$ & $\begin{array}{c}\text { 6. 7.3. 4. } 2 . \\
\text { 5. } 1 .\end{array}$ \\
\hline 6 & $\begin{array}{l}\text { LSSM as mucin-binding: } \\
\text { pI 4-5.5: gall }>\text { MP }>\text { NK1 }>\text { MS42 }>\text { bif1 }>\text { K3III24, } 100 \text { ash } \\
\text { pI 5.5-8: MS42 > bif1 }>\text { gall }>\text { NK1 }>\text { MP }>100 \text { ash, K3III24 } \\
\text { P: C for delivery into intestinal and urogenital mucosal cavities }\end{array}$ & $\begin{array}{l}\text { 7. } 4.1 .5 .6 \text {. } \\
\text { 2/3.3/2. } \\
\text { 5. } 6.7 .1 .4 \text {. } \\
\text { 2/3.3/2. }\end{array}$ \\
\hline 7 & $\begin{array}{l}\text { LSSM as mannan-binding: } \\
\text { pI 4-5.5: } 100 \text { ash, K3III24 }>\text { NK1 > MS42 > gall > MP > bif1 } \\
\text { pI 5.5-8: gall > bif1 > MS42 > NK1 > MP > } 100 \text { ash, K3III24 } \\
\text { P: Potential against eukaryotic (yeast and yeast-like), prokaryotic (staphylococci), } \\
\text { and HIV/HIV-related infections; delivery into cell and cell organelles }\end{array}$ & $\begin{array}{l}\text { 2/3.3/2.1. } \\
\text { 5. 7. } 4.6 \text {. } \\
\text { 7. 6. 5. } 1.4 \text {. } \\
\text { 2/3.3/2. }\end{array}$ \\
\hline
\end{tabular}

1, NK1 (L. helveticus NK1); 2, 100 ash (L. helveticus 100 ash); 3, K3III24 (L. casei K3III24); 4, MP (Acilact); 5, MS42 (B. adolescentis MS42); 6, bif1 (B. bifidum No. 1); 7, gall (B. gallinarum GB); C, concentrate $(>27 \mathrm{kD})$ of cultural fluid supernatant; IEF, isoelectrofocusing; PAG, polyacrylamide gel; $P$, prognostic proposals; 'Alternative position. Blocks of lactobacillar (boldface) and bifidobacterial (italic font) strains are shown.

Table 4.

Strain code ranging for multiprobiotic construction on example of new multiprobiotics including bifidobacteria and lactobacilli.

Further constructing other or extended multistrain symbiotics is depended on choice of important parameters of interest (to increase the number of comparable codes used in Tables 3 and 4). Important prospects in constructing taxonomically mixed symbiotic formulas are expected on the basis of identified LSSM sets of the strains as counted ingredients of multisymbiotic as well as evaluation of the relative contribution of LSSM types in resulting multifunctional activities of mixed product. For example, the general properties of LS of lactobacilli and bifidobacteria investigated by us are "recognition of mucin-type targets" more or less than "recognition of mannan-type targets" for LL or BL, respectively [8]. As a result, LSSMdependent synergism (which can be directed and predicted using extended panel of GC for LSSM selection and choice) of new taxonomically mixed symbiotics can be achieved. 
Universality of approach proposed in Table 4 means that the panel of comparative parameters of investigation is unlimited for selection. As advantages of this approach for creation of perspective formulas of multipro-/symbiotics, some properties of future combinative products can be predicted and verified.

Aforementioned codes (Tables 3 and 4 ) extend the potential of using traditional MP. Results open new possibilities for investigation of LSSM types among strains and constructed consortia to develop perspective GC-type-dependent LSSM combinations possessing needed actions toward human interactome. In terms of personalized medicine, individual LSSM applications are of reality. For example, LSSM could be applied as "a functional tissue biotope" or mucosal organ-specific agents and organizers of lectin-coupled reactions and activities [26, 27].

\subsection{Anaerobic synergistic preparations containing LSSM for support of human protective systems}

Due to high distribution in organism, oxidative stress (as the power destructive factor initiating diseases) needs the constant presence of the power protective antioxidant systems $[28,29]$. Some therapeutic proteins regulating cellular consumption of oxygen can be involved into development of tumor and other side pathologies in organism. We isolated system anaerobic (without oxidases initiating of oxygen and peroxide radicals) preparations of acidic/anionic and alkaline/cationic LSSM from cultures of symbiotic (probiotic) industrial strains of human bifidobacteria and lactobacilli as consortia that were successfully applied. Such preparations devoid the ability to induce destructive oxidative stress (crosslinking and inactivation of therapeutic proteins, etc.) in respect to surrounding infrastructures.

The used synthetic GC in our work were characterized with antioxidant properties in respect to LS as carriers of GC (prolongation of chemiluminescence of protective complexes was observed). Similar resulting protection of LSSM was also registered in the presence of neutral and cationic bifidobacterial and lactobacillar cultural exopolymeric compounds (EPC) of nonprotein origin (as observed on the blot after IEF-PAG). Acidic and alkaline anaerobic LS of bifidobacteria and lactobacilli revealed the following general antipathogenic actions: (a) own and overlapped/synergistic; (b) toward communicative bodies of microbial massifs and biofilms of the potentially pathogenic yeast-like fungi and Gram-positive bacteria. All four types of preparations of LSSM used were characterized by own mechanisms of antimicrobial actions in comparison to action of other antimicrobial systems (antibiotics, bacteriocins, phytolectins, subisotype products of isotypes C4B and C4A of the human complement component C4) [30, 31]. LS from human probiotic bacterial cultures revealed the ability to act as cascades in such reactions as initiation/changing or switching recognition of GC of different types (imitators of mannans, mucins, components of bacterial walls, Forssman antigens, Tn, blood group substance A) using the same original pool of lectin forms of taken multistrain probiotic. The presence of cations $\mathrm{Ru}^{2+}$ (ingredient of SYPRO involved in photosensibilization) strongly increased discreteness and number of forms of acidic lectins-potential carriers and deliveries of GC. Stability of obtained mosaic asymmetric landscape pictures of the systems LSSM-GC as multistrain probioticdepending and multistrain probiotic-supporting biotope balance of recognition and reversible retaining/depositing of GC (therapeutics, biomarkers, others) was observed. Combinations of anaerobic LS-containing proteins revealed themselves in respect to yeast-like and Gram-positive pathogenic targets as more selective in the choice of the adequate regional territory of massif of pathogen and limitation of early and late time (depending on localization of targeted region of communicative 
body of pathogen) for the mostly effective visible actions of LS, obtaining uniform pure landscapes of LSSM action on massif of Candida albicans (the absence or minimization of LSSM-resistant residual fungal colonies in the interacting intestine system "LS of human intestinal bifidobacteria and lactobacilli-human intestinal C. albicans"). Antimicrobial activities of LSSM and phytolectins (phytohemagglutinin from the kidney bean) could be realized not only directly but also through the influence (together with synthetic mannans and mucins) in respect to macrophage migration as well as through inducing production of cytokines by stimulated blood lymphocytes (on the example of tumor necrosis factor- $\alpha$ ). Results indicate prospects of anaerobic LSSM as assistant ingredients of the possible drug forms.

\subsection{Synbiotic minibioreactor using LSSM for screening GC}

During the last time, synbiotics and symbiotics (as synergistic sum of probiotics and prebiotics) are of increased investigator interest due to their antimicrobial and other useful reactions $[1,2]$. In this respect LSSM represent new class of antipathogenic proteins (possessing extended potential of application) which recognize different GC. LSSM represent multifunctional potential of relatively highly molecular mass polymeric metabolites of cultures of the human microbiota (microbiocenoses) and consortia (also multistrain probiotics) of human indigenous microorganisms. LSSM cofunction together with artificial and biologically active natural GC [32].

According to own results, we proposed suitable laboratory minisystem for screening prebiotic and therapeutical GP using LSSM and sterile heparinized insulin syringes of $1 \mathrm{ml}$ volume. The following results were obtained: (1) LSSM-containing fraction stimulated production of both the whole and adhesive mass of bifidobacteria, (2) $\mathrm{LiCl}$ (15 $\mathrm{mM}$ and higher) increased dose depending on the number of adhesive colonies, (3) bifidobacterial LSSM (within pI 4-4.5) were characterized with strong affinity to anionic synthetic GC (possessing exposed residues of sulfated galactosides or, in a less extent of affinity, exposed residues of mannose-6-phosphates), and (4) sulfated glycosaminoglycans together with cations $\mathrm{Li}^{+}$and LSSM as potential carriers of $\mathrm{Li}^{+}$participated in functioning bioreactor imitating synbiotope (multiplication of bifidobacterial colonies and their survival were observed).

Proposed synbiotic system is perspective for screening prebiotic GC (as it is known for prebiotic derivatives of chitin, chitosan, fucoidan, and glycopeptides $[33,34])$. Table 1 includes potential prebiotic sources such as chitin and $\alpha$-L-fucan which react to LSSM (LSSM may serve carriers of metabiotic GC; the list of GC can be unlimitedly extended).

\subsection{Membrane technological prospects of LSSM}

Progress in membrane and solid-phased technologies using LS-GC interactions includes the potential of their application in microassays, biochips (membrane bound glycoarrays or lectin arrays), and biosensors [35, 36].

The use of affine pore hydrophobic (uncharged) membranes predictably covered with mosaics of multifunctional sets of LSSM (additional significant purification of LSSM on membranes is reached) allows prolonged storing LSSM without decreasing samples in activities. The following prospects of LSSM-GC combinations may be of practical interest: (a) antifungal covers of prolonged action in combination with antibiotics and physical factors of stress [radiation (ultraviolet and ultrasonic), light (biorhythm "day-night"), temperature, $\mathrm{pH}$, oxygen, season changes (also biorhythmic), others] and (b) chemiluminescent systems cofunctioning in regime of real time for medical and industrial biotechnology and 
bionanotechnologies [our results include the following coupled systems: "low acidic LSSM, low acidic oxidoreductases of lactobacilli"; "alkaline bifidobacterial LS, alkaline bifidobacterial exopolymeric compounds"; "neutral lactobacillar/bifidobacterial LS, neutral lactobacillar/bifidobacterial biosurfactants"; "LS, strongly acidic (pI 3-4) serial phyto-oxidoreductases/phyto[glycosyl]oxidases"].

Membrane technologies using separated proteins, oligopeptides, and their complexes (especially) together with intrinsic or exogenic (SYPRO dye) fluorescence registered in live bioimagination are especially sensitive and perspective (protein band discreteness using fluorescence technique was better compared to the chemiluminescence technique). The latter allows identification stabile boundaries of the whole protein massifs for further establishment of LSSM and other biologically and physiologically active components among protein mosaics. Bioluminescence (fluorescent technique in combination with chemiluminescence technique) in optimal (depending on the object and the goal of study) conditions allows express-ranging cultural fluid groups of proteins and LS according to molecular mass (for additional standardization and typing of strains), evaluation of interstrain synergism and contribution of protease and oxidoreductase systems of mono- and multistrain probiotics (symbiotics) and other type consortia, and identification of mosaics of complexes containing fluorochromes in extended interval of $\mathrm{pI} / \mathrm{pH}$ (complexes and cell wall fragments as carriers of visible energy which is ready for energetic exchange with surrounding infrastructures as well as for monitoring directed supramolecular assembling and their reorganization).

Aforementioned data presented develop other possible important prognostic approaches and proposals. The choice of wished prognostic (LSSM-selected-type and GC-type interactions)-directed events in biotope can be determined and regulated by involving GC types needed (panels of natural and artificial GC used in biotope; extending the list of GC indicated in Table 1 is possible). The use of artificial polymeric GC with established chemical structures allows receiving adequate, understandable, and reliable results.

According to the multifunctional potential of artificial GC used, resulting events in biotope can be the following ones: antipathogenic actions (the use of GC-imitating pathogenic cell surface structures), prebiotic and symbiotic (synbiotic) actions (the use of GC-imitating prebiotic structures), increasing own human organism protective systems (the use of GC-interacting and GC-regulating macrophages and macrophage-like lymphocytes through their systemic receptor lectins), antitumor actions (potential using antigenic GC together with LSSM as antagonists and synergists in intercellular antitumor and anti-infectious communications [37]), and cytokine lectin/lectin-like cascades initiated/regulated with LSSM potentially influencing redistribution of cytokine network in organism.

\subsection{Prospects of LSSM for prophylaxis and therapy of infectious diseases}

Innate immunity plays an important role especially when antibody immunity is under development, suppression, or alteration. So the search of new natural antiinfectious agents is of actuality. In contrast to probiotic cells, LSSM (as systems of LL or LB) are not sensitive to the presence of antibiotics and chemotherapeutics as well as do not need special conditions for survival. LSSM function as metabolomebiotics according to the principle "the network in the network"; participation of major lectins in supporting physiologically significant glycodecor of biotope mucosal probiotic compartments, and minor lectins-in signal communications; support of such compartments (compensation of the absence of probiotic cells in MB upon therapy with antibiotics, delivery of fucosylated and galactosylated prebiotics of mutual supporting influence between populations of bifidobacteria and lactobacilli, 
cofunctioning to anti-infectious agents (antibiotics, metabiotics, GC) and cells of organism protective systems (macrophages and leukocytes).

We characterize LSSM (acidic, low acidic, cationic: aLL, laLL, cLL, aLB, and cLB) of domestic probiotics which recognize polymeric artificial GC mucin-like analogs of antigens and EPC (fungal and bacterial mannans, bifidobacterial $\alpha-\mathrm{L}$ Fuc-containing, sulfated and phosphorylated).

Antimicrobial directions of LSSM action were established [26, 31, 38].

\subsubsection{Anticandidosis activities}

- Against intestinal and urogenital Candida of epidemiologically significant species of group I (C. albicans and C. tropicalis: early action of aLB within the first 2 days; delayed action of cLL and LB within 1-2 months; synergism between acidic and cationic LSSM, cLB, and grass lectins, aLSSM/cLSSM, and some antimycotics)

- Against Candida of epidemiologically significant species of group II (C. glabrata: inhibition of virulent factors such as fungal IgA1 and IgG proteinases, EC 3.4.21.72 and EC 3.4.21., respectively [9])

- Against Candida of epidemiologically significant species of group III (C. krusei: delivery of potential effector GC on cell surface)

- Interruption of mycosymbiosis parasitism of Candida-Aspergillus: the drugs against candidosis as predictably affective against aspergillosis)

Activities of LSSM against staphylococci (on example of patients $S$. aureus isolates): aLL > aLB; aLL and aLB; LSSM activities accompanied with:

- Delayed degradation of microbial massifs

- Partial directed lysis of microbial massif

- Tearing away fragments of massif (by two mechanisms depending on lectin type)

- Synergism between aLL and LB in antistaphylococcal actions

LSSM possess potential of diagnostics and prognostics of biotope diseases [37]. Results support important principle approach that diseases of $\mathrm{MB}$ (as in the case of CBF according to the principle "there is the body-there are diseases") reflect own "biotope diseases" in organism [39]. LSSM can be used in phenotyping prognostics and diagnostics of infectious processes in organism; for prophylaxis and therapy of candidoses, staphylococcoses, mixed fungal-bacterial infections, mixed symbiotic mycoses; innate infections; immunodeficiency and infections against the background of immunodeficiency, upon antibiotics-/chemo-/radiotherapy. Such GC effectors as metabiotics, prebiotics, glycoantigens, and drugs of selective directed action are of availability.

It is of importance to consider the participation of LSSM in supporting biotope mucosal $\mathrm{MB}$ in conditions of oxidative stress (cofunctioning of laLL and probiotic oxidoreductase systems) [26]. Panel combinations of LB and LL are perspective in early evaluation (before the inflammation) of status of $\mathrm{MB}$ of functionally different biotopes of the vaginal tract. 
LSSM are similar (in specificities, systemic action) to communicative lectins of intercellular reception in innate immunity.

LSSM act as essential part of human protective supersystem (the supersystem with probiotic type action) [31]. Such supersystems contract disturbing the balance of the body's health processes; keep and maintain the integrity of biotope microbiocenoses like healthy consortia. There are supersystems with antimicrobial or antifungal action in organism.

\subsection{Potential of results for innovations}

Results obtained by us in a study of probiotics can be useful as a set of approaches in study of the following aspects of clinical microbiology and medical biotechnology (in brackets-significance and prospects of results for infectology) $[40,41]$.

\subsubsection{Metabolite technologies}

- Cultural metabolites 27-200 kD within pI 4-8 (separation of acidic and alkaline protein and nonprotein of taxonomically significant systems); phenotyping of strains in cationic region containing protected sets of proteins Subcytoagglutinating activities: initiatively coupled or non-coupled to lectin and cytoagglutinating activities (cytokine activities; synchronization of cultures for increasing vulnerability of pathogens; typing).

- Functional blotting analysis of cascade cultures in combinative nutrient media (NM) (as in the case of milk followed by transfer into "casein hydrolysate-yeast autolysate" media; monitoring lectins, enzymes, and exopolymeric compounds [EPC])

- Development of strain-supporting NM (comparison of blotted maps of components of cultures in identical conditions)

- The use of $\alpha$-S-, $\beta / \gamma$-, and kappa-caseinases (increase of effectiveness of NM, accumulation of physiologically active protein and nonprotein metabolites and their complexes)

- Systems of proteinases, EPC depolymerases, and/or peroxidase-like catalases in cultures (revealing strain-dependent producers of enzymes, proteins, and EPC; evaluation of cytolysis populations, oxidative stress, virulent factors, changes, and aging of cultures upon passages and storage)

- Lectin systems: major and minor, building and signal, cross talk and quorum sensing (standardization of cultures and analysis of communicative networks) *Evaluation of early and prolonged landscape synergism of recognizing components of cultures and antibiotics (individual choice and replacement of combinations of probiotics and antibiotics upon therapy of patient)

- Natural and recombinant systems oriented to recognition of polyvalent glycoconjugate targets of known structure (standardization of strains; monitoring and revealing signals of carbohydrate metabolism)

- Imitation by cultural metabolites in respect to strain or consortium effectiveness (standardization of strain multifunctionality) 
- The use of recognizing metabolites instead of cells or in combinations with cells for support of feeble living and antibiotic-sensitive cultures (also in cases of non-culturable microorganisms).

- Constructing balanced supporting MB of probiotic cell-metabolite consortia (constructing symbiotic consortia, balanced vaccines)

\subsubsection{Intercellular and cell-metabolite technologies}

- For Gram-positive bacteria (opportunistic and pathogenic)

- Sensor microbial systems of MB (revealing and using key antagonistic systems) Directed assembling of cytokine-cell gradients: reversible functional (1-2 days) or late irreversible conserved and partially inactivated (4-6 weeks), as in cases of biofilms containing erythrocytes-in microassay (evaluation of protection and degradation of human cells in the presence of pathogens)

- Biofilm forming as ranked quantitative and qualitative, early and delayed-in microassay (reactions of mono- and mixed biofilms)

- Species-dependent redistribution of antagonistic MB (prediction of mutual influence between species and strains of probiotics, opportunistic microbes, and antibiotics)

- Leader strains and species within MB (evaluation of temporary MB-destabilizing strains in coexistent antagonistic microbial populations)

- Destabilization and synchronization of MB by recognizing components of cultures for increasing future selective synergistic action of antimicrobials and stress factors (increase of early and late suppression of pathogens) Microecological interniche early and delayed landscape relationships in cases of solid-phased and suspension microbial massifs, for microanalysis (evaluation of opportunistic microbes and $\mathrm{MB}$ as communicative bodies opposed to mosaics of antimicrobials)

- Construction of active (involving probiotic leaders) and stabilizing (speciesdependent and resistant to antibiotics, probiotic-like supporting MB) consortia (using upon therapy)

- Strain-phenotyping dysbiotic MB using lectin systems (revealing early changes in patient $\mathrm{MB}$ in the presence of lectins of $\mathrm{MB}$, for development of new strategies of therapy)

- LS of probiotic consortia (directions of consortium formula actions can be predicted by constructing) as ingredients of functional food to support resistant functioning mucosal organs

\section{Conclusion}

The data presented consider aspects of constructing probiotic multistrain intra- and inter-genus Gram-positive bacterial metabolites on examples of bifidobacteria and lactobacilli of the human gut origin. Algorithms of creation 
of 4- and 7-code MP formulas are presented and argued. It is of importance to consider LSSM and their GC as a new perspective protective basis/scaffold factor influencing and supporting human interactome, involving biotope infrastructures, signaling, and anti-infectious actions as well as cofunctioning together with other protective human systems [17, 42]. Results support the use of pro-/symbiotic LS as assistant-coordinated metabolomic agents; carriers for delivery and releasing GC, metabiotics (including simulators of cell surface patterns of opportunistic microorganisms), prebiotics, therapeutics, and antigens (for cofunctioning to antibodies); and reserves for decoration elements that support stabile functioning landscapes of the human cell surfaces and mucosal tissues. Probiotic lectins (interacting with synthetic GC simulators) are important for screening, typing, and selection of useful strains and their consortia supporting organs. The proposed LSSM-containing preparations promise LSSM using a soft adaptive multidirected network synergistically acting together with other protectors (also in conditions of the absence of oxygen [involving oxidative stress and forming of covalently bound by-products] within biotope). Variants of multipro-/sym-/synbiotics constructed can be perspective for prophylaxis for individuals and contingents as well as for supporting treatments of patients (before and postoperative period, during chemotherapy, etc.). Approaches developed are useful in study of interniche relationships of extended set of Gram-positive and fungal microorganisms in mono- and mixed cultures. Procedures can be applied in different fields of clinical microbiology and medical biotechnology.

\section{Conflict of interest}

The authors declare the absence of conflict of interest.

\section{Author details}

Mikhail V. Lakhtin, Vladimir M. Lakhtin*, Vladimir A. Aleshkin

and Stanislav S. Afanasiev

G.N. Gabrichevsky Institute for Epidemiology and Microbiology, Moscow, Russia

*Address all correspondence to: lakhtinv@yandex.ru

IntechOpen

(C) 2019 The Author(s). Licensee IntechOpen. This chapter is distributed under the terms of the Creative Commons Attribution License (http://creativecommons.org/licenses/ by/3.0), which permits unrestricted use, distribution, and reproduction in any medium, provided the original work is properly cited. (cc) BY 


\section{References}

[1] Olveira G, Gonzalez-Molero I. An update on probiotics, prebiotics and symbiotics in clinical nutrition. Endocrinología y Nutrición. 2016;63(9):482-494. DOI: 10.1016/j. endonu.2016.07.006

[2] Floch MH. The role of prebiotics and probiotics in gastrointestinal disease. Gastroenterology Clinics of North America. 2018;47(1):179-191. DOI: 10.1016/j.gtc.2017.09.011

[3] Pandey KR, Naik SR, Vakil BV. Probiotics, prebiotics and synbiotics-A review. Journal of Food Science and Technology. 2015;52(12):7577-7587. DOI: $10.1007 /$ s13197-015-1921-1

[4] Pudlo NA, Urs K, Kumar SS, German JB, Mills DA, Martens EC. Symbiotic human gut bacteria with variable metabolic priorities for host mucosal glycans. mBio. 2015;6(6):e01282-e01215. DOI: $10.1128 / \mathrm{mBio} .01282-15$

[5] Toukach PV, Egorova KS. Carbohydrate structure database merged from bacterial, archaeal, plant and fungal parts. Nucleic Acids Research. 2016;44(Part D1):D1229-D1236. DOI: 10.1093/nar/gkv840

[6] Mehta AY, Cummings RD. GLAD: GLycan Array Dashboard, a Visual Analytics Tool for Glycan Microarrays. Bioinformatics. 1 Feb 2019. DOI: 10.1093/ bioinformatics/btz075 [Epub ahead of print]

[7] Marchetti R, Perez S, Arda A, Imberty A, Jimenez-Barbero J, Silipo A, et al. "Rules of engagement" of protein-glycoconjugate interactions: A molecular view achievable by using NMR spectroscopy and molecular modeling. ChemistryOpen. 2016;15(4):274-296. DOI: 10.1002/ open. 201600024
[8] Lakhtin M, Lakhtin V, Aleshkin A, Bajrakova A, Afanasiev S, Aleshkin V. Lectin systems imitating probiotics: Potential for biotechnology and medical microbiology. In: Rigobelo EC, editor. Probiotics 2012. New York: InTech; 2012. pp. 417-432

[9] Lakhtin MV, Lakhtin VM, Aleshkin VA, Afanasiev SS, Aleshkin AV. Lectins and Enzymes in Biology and Medicine. Moscow: Publishing House "Dynasty"; 2010. 496pp. ISBN: 978-5-98125-076-7. (in Russian)

[10] Lakhtin VM, Lakhtin MV, Bajrakova AL, Afanasiev SS. Candida albicans: New aspects of pathogenicity, interaction to antifungals, biofilms and preventive anti-Candida strategies-The overview of own works. In: Dietrich LA, Friedmann TS, editors. Candida albicans: Symptoms, Causes and Treatment Options. New York: Nova Science Publishers; 2013. pp. 145-152 [11] Lakhtin M, Lakhtin V, Afanasiev $\mathrm{S}$, Aleshkin V. Mucosal innate immunity involves system "Lectins of probiotics-Glycopolymers" against pathogens. In: Mendez-Vilas A, editor. Microbiology Book Series \#5: "The Battle against Microbial Pathogens: Basic Science, Technological Advances and Educational Programs". Vol. 2. Spain: Formatex Research Center; 2015. pp. 668-677. ISBN (13): 978-84-942134-7-2

[12] Lakhtin MV, Lakhtin VM, Afanasiev SS, Aleshkin VA. Mucosal open cavities as the organ of increased resistance and effectiveness. Journal of Advances in Biology and Biotechnology. 2016;10(3):1-10. DOI: 10.9734/jabb

[13] Lakhtin MV, Lakhtin VM, Afanasiev SS, Bajrakova AL. Lectins of probiotics in regulation of microecological niches of yeast-like fungi of human. Advances in 
Medical Mycology [Uspehi Meditsinskoy Mikologii]. 2017;17:168-171. DOI: 10.14427/amm.2017.xvii.02. (in Russian)

[14] Lakhtin MV, Lakhtin VM, Alyoshkin VA. Lectin and enzyme relationships in microbiology. International Journal of Molecular and Clinical Microbiology. 2011;1(1):9-14

[15] Lakhtin VM, Lakhtin MV, Afanasiev SS, Aleshkin VA. Symbiotic lectinsmetabolomebiotics and carriers of metabiotics. Gastroenterology of Saint-Petersburg [Gastroenterologiya Sankt-Peterburga]. 2016. No 3-4: M15. (in Russian)

[16] Cummings RD, Pierce JM. The challenge and promise of glycomics. Chemistry \& Biology. 2014;21(1):1-15. DOI: 10.1016/j.chembiol.2013.12.010

[17] Lakhtin MV, Lakhtin VM, Afanasiev SS, Aleshkin VA. $\alpha$-LFucan-binding lectin systems of human probiotic bacteria in evaluation of communications of probiotic compartment of human microbiocenoses. Medical Alphabet [Meditsinskiy Alfavit]. 2017;3(26):33-34. ISSN: 2078-5631. (in Russian)

[18] Lakhtin MV, Lakhtin VM, Afanasiev SS, Bajrakova AL, Aleshkin VA. Biofilm forming in human biotope microbiocenosis: The model for prognostic calculations of intermicrobial relationships. Bulletin of Eastern-Siberian Scientific Center of SB RAMS (Irkutsk, Russia). 2015;3:56-62. (in Russian)

[19] Sharma M, Shukla G. Metabiotics: One step ahead of probiotics; an insight into mechanisms involved in anticancerous effect in colorectal cancer. Frontiers in Microbiology. 2016;7:1940

[20] Lakhtin MV, Aleshkin VA, Lakhtin VM, Afanasiev SS, Bajrakova AL. Antipathogenic synergism of lectins possessing probiotic properties: Potential and prospects for medical biotechnology. In: Proceedings of the XII International scientific and practical conference "Cutting-edge science-2016". Biology. Sheffield: Science and Education Ltd. Volume 16. pp. 30-36. ISBN 978-9668736-05-6. (in Russian)

[21] Gracie DJ, Ford AC. Symbiotics in irritable bowel syndromeBetter than probiotics alone? Current Opinion in Clinical Nutrition and Metabolic Care. 2015;18(5):485-489. DOI: 10.1097/ MCO.0000000000000199

[22] Schwartzman JA, Ruby EG. Stress as a normal cue in the symbiotic environment: Specificities. Trends in Microbiology. 2016;24(5):414-424. DOI: 10.1016/j.tim.2016.02.012

[23] Krumbeck JA, Maldonado-Gomez MX, Martinez I, Frese SA, Burkey $\mathrm{TE}$, Rasineni $\mathrm{K}$, et al. In vivo selection to identify bacterial strains with enhanced ecological performance in synbiotic applications. Applied and Environmental Microbiology. 2015;81(7):2455-2465

[24] Tailford LE, Crost EH, Kavanaugh $\mathrm{D}$, Juge N. Mucin glycan for aging in the human gut microbiome. Frontiers in Genetics. 2015;6:81. DOI: 10.3389/ fgene.2015.00081

[25] Paßlack N, Doherr MG, Zentek J. Effects of free amino acids on cytokine secretion and proliferative activity of feline $T$ cells in an in vitro study using the cell line MYA-1. Cytotechnology. 2016;68(5):1949-1961. DOI: 10.1007/ s10616-016-0008-9

[26] Lakhtin MV, Lakhtin VM. Probiotic lectin systems - Prospects for biocontrol of mucosal organs. Advances in Medical Mycology: Moscow. All-Russian National Academy of Mycology. 2019;XX:24-29. (in Russian) 
[27] Petrova MI, Lievens E, Verhoeven TL, Macklaim JM, Gloor G, Schols D, et al. The lectin-like protein 1 in Lactobacillus rhamnosus GR-1 mediates tissue-specific adherence to vaginal epithelium and inhibits urogenital pathogens. Scientific Reports. 2016;6:37437. DOI: 10.1038/srep37437

[28] Manda G, Isvoranu G, Comanescu MV, Manea A, Debelec Butuner B, Korkmaz KS. The redox biology network in cancer pathophysiology and therapeutics. Redox Biology. 2015;5:347357. DOI: 10.1016/j.redox.2015.06.014

[29] Cobb CA, Cole MP. Oxidative and nitrative stress in neurodegeneration. Neurobiology of Disease. 2015;84:4-21. DOI: $10.1016 /$ j.nbd.2015.04.020

[30] Lakhtin MV, Lakhtin VM, Afanasiev SS, Aleshkin VA, Korsun VF, Afanasiev MS. Lectins in solutions and be sorbed, active and latent, system and network, fluorescent and chemiluminescent, in regulation of assembling and degradation, synergistic and symbiotic. The journal of scientific articles "Health and Education Millennium". 2014;16(3):64-68. ISSN 2226-7425. (in Russian)

[31] Lakhtin MV, Lakhtin VM. The human antifungal lectin basic supersystem. Advances in Medical Mycology: Moscow. All-Russian National Academy of Mycology. 2019;XX:30-35. (in Russian)

[32] Lakhtin MV, Lakhtin VM, Afanasiev SS, Bajrakova AL, Karaulov AV, Afanasiev MS, et al. Mobile synbiotope microbiocenosis against pathogens. Bulletin of Eastern-Siberian Scientific Center of SB RAMS (Irkutsk, Russia). 2016;3(Part2):168-173. (in Russian)

[33] Hayes M, Tiwari BK. Bioactive carbohydrates and peptides in foods: An overview of sources, downstream processing steps and associated bioactivities. International
Journal of Molecular Sciences. 2015;16(9):22485-22508. DOI: 10.3390/ijms160922485

[34] Corzo-Martinez M, Avila M, Moreno FJ, Requena T, Villamiel M. Effect of milk protein glycation and gastrointestinal digestion on the growth of bifidobacteria and lactic acid bacteria. International Journal of Food Microbiology. 2012;153(3):420-427. DOI: 10.1016/j.ijfoodmicro.2011.12.006

[35] Puvirajesinghe TM, Turnbull JE. Glycoarray technologies: Deciphering interactions from proteins to live cell responses. Microarrays (Basel). 2016;5(1):3. DOI: 10.3390/ microarrays5010003

[36] Belicky S, Katrlik J, Tkac J. Glycan and lectin biosensors. Essays in Biochemistry. 2016;60(1):37-47. DOI: 10.1042/EBC20150005

[37] Lakhtin MV, Lakhtin VM, Afanasiev SS, Bajrakova AL, Aleshkin VA, Afanasiev MS. Candida markers of diseases of urogenital biotopes: Reactivity to lectins of probiotics. Acta Biomedica Scientifica. 2018;3(1):4953. DOI: 10.29413/ABS.2018-3.1.7. (in Russian)

[38] Lakhtin MV, Lakhtin VM, Afanasiev SS, Bajrakova AL, Afanasiev MS, Aleshkin VA. Mucosal Candida species microecology, sensitivity to antifungals, antifungal strategies considering probiotic pressure. News of Science and Education. 2019;5(3):3-21. ISSN: 2312-2773.

(in Russian)

[39] Lakhtin MV, Lakhtin VM, Afanasiev SS, Aleshkin VA. Lectins of probiotics against diseases of microbiocenoses in human organism. Ural Scientific Vestnik [Uralskiy Nauchniy Vestnik]. 2017;2(9):35-45. ISSN: 1561-6908. (in Russian)

[40] Lakhtin MV, Lakhtin VM, Aleshkin VA, Afanasiev SS. System probiotic 
lectins for innovations. News of Science and Education. 2018;3(10):117-129. ISSN: 2312-2773. (in Russian)

[41] Lakhtin MV, Lakhtin VM, Afanasiev SS, Aleshkin VA. Microbiocenosis and strain probiotic lectin systems against infectious diseases and tumors: Potential of influence microbiocenoses through pro/synbiotics. The Problems of Scientific Idea (Dnepr, Ukraine) [Problemi Nauchnoy Misli (Dnepr, Ukraina)]. 2018;7(12):25-44. ISSN: 1561-6916. (in Russian)

[42] Chairatana P, Nolan EM. Defensins, lectins, mucins, and secretory immunoglobulin A: Microbe-binding biomolecules that contribute to mucosal immunity in the human gut. Critical Reviews in Biochemistry and Molecular Biology. 2017;52(1):45-56. DOI: 10.1080/10409238.2016.1243654 



\title{
Gut Microbiota and Obesity: Prebiotic and Probiotic Effects
}

\author{
Silvana Cisternas León, Paula Carrasco Vergara, \\ Alejandra Cruz Neira, Ricardo Muñoz Maldonado, \\ Carolina Díaz Araneda and Marcia Rivas Zuñiga
}

\begin{abstract}
Malnutrition through excessive food consumption is a worldwide pandemic. Changes in lifestyle, diet and physical activity have resulted in an exponential increase in the number of obese people around the world. Multiple factors influence the development of this disease, and recently it has been suggested that gut microbiota (GM) plays an important role in nutrient absorption and energy regulation of individuals, thus affecting their nutritional status. It has been proven that gut microbiota is different in individuals with a normal nutritional status compared to those who are obese. Therefore, to study bacterial populations that make up the microbiota and to understand how prebiotics and probiotics affect the increase of these bacteria has become a promising alternative to treat obesity. This chapter looks at defining the established relationship between probiotics, prebiotics and gut microbiota that develop in obese people and people of normal weight, with the aim of providing future dietary recommendations to treat this medical condition.
\end{abstract}

Keywords: gut microbiota, prebiotics, probiotics, obesity

\section{Introduction}

Currently, obesity is defined as a medical condition characterised by an energy imbalance as a consequence of energy intake bigger than energy expenditure [1]. The US Centers for Disease Control and Prevention (CDC) defines it as 'excessive weight that is considered unhealthy for a given height'. It was not until 1997 that the World Health Organization (WHO) described obesity as an excessive accumulation of body fat that can be harmful to people's health [2].

One of the criteria to diagnose obesity is through the calculation of body mass index (BMI); the result, according to the WHO, must be equal to or bigger than $30 \mathrm{~kg} / \mathrm{m}^{2}[2]$.

However, the Asian population including Korea, given their increased risk of developing comorbidities, such as cardiovascular diseases and type 2 diabetes, agreed to an overweight category with a BMI between 23 and $24.9 \mathrm{~kg} / \mathrm{m}^{2}$ and obesity with a BMI $>25 \mathrm{~kg} / \mathrm{m}^{2}$ (Table 1) [3].

Worldwide obesity is a public health problem, and despite all the strategies designed and implemented to reverse the situation, these have not been effective. According to the World Health Organization, globally, in 2016, more than 


\begin{tabular}{lcc}
\hline & WHO (BMI) & Asia-Pacific (BMI) \\
\hline Underweight & $<18.5$ & $<18.5$ \\
\hline Normal & $18.5-24.9$ & $18.5-22.9$ \\
\hline Overweight & $25-29.9$ & $23-24.9$ \\
\hline Obese & $\geq 30$ & $\geq 25$ \\
\hline
\end{tabular}

Table 1.

Comparison of the World Health Organization (WHO) and Asia-Pacific body mass index (BMI) classifications in COPD patients [3].

1900 million adults were overweight, over 650 million were obese, and 41 million children under the age of 5 were overweight. Fifty-seven percent of the world's population lives in countries where being overweight and obesity cause more deaths than being underweight. Furthermore, each year at least 2.8 million people die worldwide due to obesity or being overweight, irrespective of whether the country is economically developed or not $[1,2]$.

Various studies have shown that patients with illnesses related to the gastrointestinal tract, such as type 2 diabetes, obesity and cardiovascular diseases, among others, present dysbiosis or an imbalance within the gut microbiota (GM).

A hypothesis of the positive influence of microbiota on fat storage exists, and several studies carried out in mice have proven the role of certain fatty acids in the diet in the prevention of obesity, an effect mediated through changes in the composition of gut microbiota. Studies in humans have also shown a relationship between a decrease in Bacteroidetes in obese individuals and a greater proportion of these in the faecal microbiota in subjects who have undergone hypocaloric diets and who have managed to reduce their weight $[5,7]$.

An important role of the regulation of gut microbiota has been proven as the ingestion in the diet of prebiotics and probiotics that modulate the growth of diverse families of bacteria that could influence the nutritional status of individuals.

\section{Obesity as a multifactorial condition}

Obesity is a medical condition of multifactorial causes, ranging from the influence of the nearby environment on the acquisition of predisposing habits, such as the consumption of foods high in refined carbohydrates and saturated fats and a sedentary lifestyle. Genetic predispositions are also among the principle causes [5]. On the other hand, socioeconomic development, transport, urban planning, environmental, agricultural, educational, processing, distribution and marketing policies on food influence dietary habits and preferences, as well as people's level of physical activity [5, 6].

Research concludes that obesity occurs with greater prevalence in women, older people ( 25 years and above), those with a lower school level and those with a low socioeconomic income. Geographic location also has an influence, but it occurs in an opposite way in men and women. There is greater obesity in women living in rural areas, but in men rurality is a protective factor since obesity is more prevalent in those living in urban areas. This is most likely explained by the higher levels of physical activity of men living in rural areas [6]. In terms of lifestyles, obese people have lower levels of physical activity, a bigger consumption of salt and low levels of sleep [7].

Another bibliographical review relates meal times with the prevalence of obesity. This study, which is based on an analysis of the circadian rhythm, a biological function regulated by the anterior hypothalamus, reveals clinical observations 
and experiments on animals that relate the times of food intake to metabolism and body weight. It is proposed that eating at times when the body is prepared for rest increases body weight. At rest there are low levels of hormonal activity, a low body temperature and low activity of nutrient absorption which alters energy homeostasis and facilitates the accumulation of energy, increasing body weight $[5,8]$.

A factor recently studied as a cause of obesity is gut microbiota, defined as the communities of living microorganisms that colonise the intestines. It is known that the gut microbiota contributes significantly to the two main functions of the gastrointestinal tract: nutrition and defence.

\section{Human gut microbiota: role in people's health}

The human gut is colonised by an enormous quantity of communities of living microorganisms, mainly bacteria that form the GM. As well as participating in processes of digestion and absorption of nutrients, the homeostasis of GM has been linked to beneficial health effects [9].

In the womb, the intestine of the human foetus is sterile, and it is after birth when the newborn acquires its gut microbiota. From birth, several factors influence the composition and initial colonisation of the GM. Natural labour favours the rapid settlement of bacteria that come from the vaginal and faecal microbiota of the mother, associated with a low risk of suffering from diseases and some types of malnutrition through excessive food consumption in the future. On the other hand, children born through caesarean section have a slower colonisation of bacteria, mainly from the hospital environment and healthcare professionals who are in contact with the child. It must be considered that the time taken to establish the GM is a risk factor for the colonisation of Clostridium. Despite the fact that GM is established from birth, its colonisation continues to vary, given that there are diverse factors that influence its composition: nutrition, exclusively or predominantly breastfeeding, age, geographic location and intake of supplements and medicines $[9,10]$.

In the first years of life, when nutrition is acquired through breastfeeding or formula milk, GM is mostly populated by bifidobacteria. This is highly adapted to processing oligosaccharides in milk. Later, reaching adulthood, the GM is made up of two main families of bacteria: Firmicutes and Bacteroidetes. Firmicutes are the family found in greater proportion, including more than 200 genders, and the most important are Mycoplasma, Bacillus and Clostridium. Once these are established in adulthood, they remain stable in the individual (Figure 1) [11-14].

Various studies support the fact that variations in people's health status are directly related to functions of the GM, highlighting its effect on the immune response, nutrition and metabolism [15].

The immune tissues of the gastrointestinal tract make up the most complex and largest proportion of the body's immune system, which is why alterations of GM are caused by disequilibrium of the immune system, such as the development of allergies and autoimmune diseases [16].

There is a complex interaction between the microbiota, the intestinal epithelium and the gastrointestinal immune system, with many metabolites and microbial components that have a direct influence on the host immunity. The production of metabolites from nutrients or the modification of the metabolites produced by the host has a direct effect on the immune cells and on the integrity and permeability of the intestinal epithelium. The enteric immune system is constantly evaluating and responding to the gut microbiota [17].

Nutritional and metabolic functions of GM involve the synthesis of certain vitamins such as $\mathrm{K}, \mathrm{B} 12$, biotin, folic acid and pantothenic acid, as well as the 


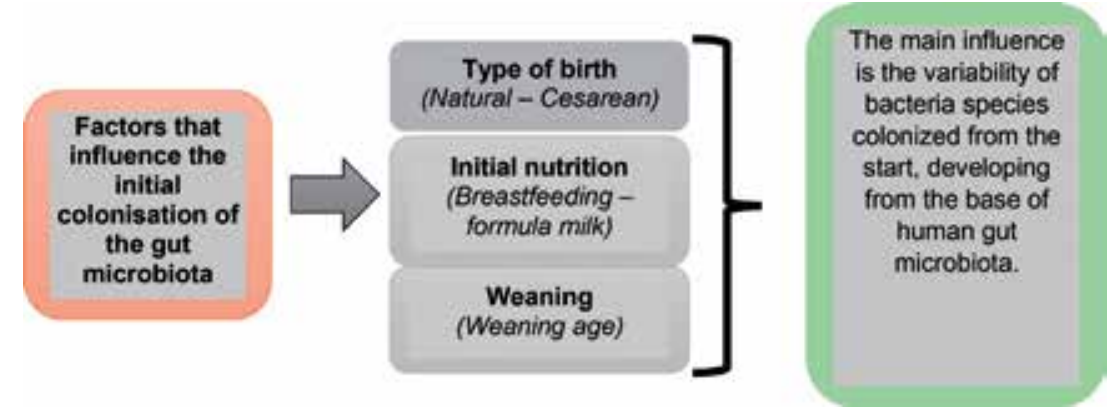

Figure 1.

Factors that influence the initial colonisation of gut microbiota.

fermentation of non-digestible carbohydrates, polysaccharides and oligosaccharides. It makes up an important source of energy for bacterial proliferation and produces short-chain fatty acids that the host can absorb, favouring the recovery and absorption of ions such as calcium, iron and magnesium [18].

As well as the principal functions of GM, recent studies have associated it with the development of obesity and chronic diseases. In order to avoid such conditions, it has been proposed that the role of prebiotics and probiotics in the maintenance of the nutritional status and prevention of diseases should be studied [4].

Undoubtedly, microorganisms present in the guts are fundamental throughout life as they have a direct relationship with health and illness. It is vital to take special care in the factors that make up the initial GM as it is responsible for the general status of future health of individuals.

\section{Microbiota and its role in obesity and chronic diseases}

As already described, the gut microbiota is made up of a diversity of pathogens which highlights the presence of Gram-negative or Gram-positive bacteria. The equilibrium of this ecosystem provides us great health benefits, in the absorption and digestion of nutrients, as well as influencing immune function [4-18].

In recent years, the prevalence of non-transmittable chronic diseases has increased, which has led different researchers to address the different risk factors related to the appearance of those that have been mentioned and the direct risk between microbiota and diseases [18].

Studies linked to the establishment of microbiota with chronic diseases have described that this stability of original microbiota is affected by diverse factors among which the macro- or micronutrients and dietary patterns are mentioned [18].

When the balance of microbiota is altered by a factor, whether it is the use of antibiotics, stress or diet with an increased consumption of fats, carbohydrates and fibre, it will have an effect on health. It has also been mentioned that abundance or scarcity of food, environmental pollution, chronic stress and food such as dairy products, sugars, coffee, tea and alcohol, among others, affects the intestinal mucous membrane and, consequently, changes the stability and mode of action of the microbiota [19].

All these factors cause an alteration in microbiota where the equilibrium of two large families of bacteria is affected: Bacteroidetes and Firmicutes. In a study carried out on the composition of the microbiota of obese mice, it was shown that they had increased concentrations of Firmicutes by more than $50 \%$, while those of Bacteroidetes decreased correlatively [20]. 
In order to demonstrate that the microbiota changes through time, a study was carried out where old teeth found in skeletons in different periods of history were analysed. It was found that microbial changes are linked to human evolution from the hunter-gatherer period to the industrial revolution, due to the increased consumption of processed foods. These conclusions support the idea that diet and the type of food alter human microbiota [18].

Turnbaugh et al. carried out studies on 'humanised' or sterile mice models to which human faecal matter was transplanted and the microbiota was analysed once they were fed with a Western diet rich in fats and sugars. They found a presence of greater adiposity and a reduced proportion of Bacteroidetes than Firmicutes in the faecal microbiota of these mice [19].

There is a direct relationship between microbiota and energy uptake and consequently a relationship with the onset of obesity. This has been supported by a study in obese children, which showed a microbiota rich in Enterobacteriaceae, low in Bacteroidetes and increased in Firmicutes. When the children were subjected to diets with low carbohydrate and fat content, the composition of the microbiota changed [18].

Other studies carried out in mice reflect the relationship between energy balance, diet and microbiota. The transplantation of the obese microbiota results in an increase of adiposity in the recipients, which shows that microbiota affects nutrient acquisition, energy storage and consequently the development of obesity [18, 22] .

Jumpertz et al. carried out studies on the GM of obese and slim patients. They were given caloric diets, and their stools were analysed by measuring calories ingested and those eliminated in the faeces using a bomb calorimeter. This study concluded that there are changes in the GM where there are increases in energy storage, a decrease in the Bacteroidetes and an increase in the Firmicutes bacteria. All these changes could explain the variation of the uptake of energy in individuals and therefore a relationship with the predisposition to obtain metabolic disorders [18].

According to the above, the instability of the GM or changes in the original GM affects the metabolism of the whole organism. Recent studies have shown that the increase of bile acids in the intestine when comparing sterile rats with normal rats would show that the GM is not only related with obesity but also with a diverse range of metabolic diseases [21].

When transplanting GM into obese mice, the new term obesogenic microbiota was determined, associated with an increase in hepatic glucose production and promotion of triglyceride deposits. These studies show that there is an increase in TNF pro-inflammatory cytokines which can cause insulin resistance. This can be correlated with the appearance of DM-OB, since its presence has been proven to be directly related to the presence of elevated pro-inflammatory factors [22].

Toll-type receptors are receptors that recognise important patterns within immunity and inflammation processes; they are present in diabetic obese patients with metabolic syndrome. In publications made in the Latin American report, they show the role of GM with regard to the regulation of these diseases, since the mice deficient in Toll-like receptor 5 (TLR5), which recognises microbial patterns, show hyperphagia, become obese and develop characteristics indicative of metabolic syndrome. This is also proven when GM from these mice was transplanted into germ-free mice with the TLR5 gene-the receptor mice developed characteristics similar to the metabolic syndrome. In summary, Larsen et al. demonstrated that GM from diabetic patients produced a significant reduction in Firmicutes and Clostridia [22, 23].

When administering antibiotics to these types of obese patients, many Firmicutes were eliminated, which resulted in improved insulin and glucose intolerance.

The exact mechanisms by which GM contributes to the development of obesity have not been fully elucidated, but it has been suggested that the main ways would 
include increased lipoprotein lipase (LPL) activity, increased intestinal permeability and lipogenesis [20]. Faecal microbiota transplantation studies in both healthy individuals and rats to obese receptors have shown the favourable action of the GM of the emitters towards the obese individuals, reducing the levels of glycemia, preventing the expansion of fat and regulating inflammatory processes. Studies also suggest that the reverse mechanism, that is, transplantation of intestinal microbiota from obese to healthy individuals, can transmit the development of obesity, assigning GM as a predisposing factor for obesity [17].

Thanks to many randomised studies that have been carried out, it will be possible to identify the microbiota properties that are contributing to the obesity epidemic, diabetes and metabolic diseases. This will in turn allow scientists to extract information and characterise diseases with the aim to prevent or cure them [21].

\section{Role of prebiotics and probiotics in maintaining nutritional status}

Probiotics have been defined by the United Nations' Food and Agriculture Organization (FAO) and the WHO as 'living microorganisms that provide their host with health benefits when consumed in appropriate quantities' [4].

Prebiotics were defined by Gibson and colleagues in 2004 as 'ingredients that when selectively fermented, give rise to specific changes in gut microbiota composition and/or activity, which leads to many health benefits with regard to, for example, the wellbeing of individuals' [24].

According to the preceding analysis, it has been recently established that the microbiotics that colonise the human intestine can play an important role in causing obesity and developing other metabolic and immunological illnesses within their host. This statement is based on recent metagenomic studies that have determined that there are differences between obese individuals and those of a normal weight in terms of gut microbiota. These differences are associated with the presence of a microbial population in obese individuals, which has a greater capacity to recuperate dietary energy and/or favour the onset of chronic low-grade inflammation [25]

Some studies conducted on obese individuals in relation to their prebiotic consumption - capable of selectively stimulating a limited number of gut microbiota genres/species which results in health benefits-have demonstrated results that can be categorised by an increasing trend in satiation. This effect has been observed with inulin fibre [24].

The mechanisms implicated in satiation following the consumption of oligofructose and inulin have been associated with intestinal fermentation-induced hydrogen formation, which in turn has been correlated with a postprandial increase in plasma levels of peptides GLP-1 and PYY, which are involved in energy homeostasis through supressing the sensation of hunger (Figure 2) [24].

Studies carried out involving the use of probiotics to control body fat accumulation show promising results, but it is also necessary to carry out further, well-designed studies which incorporate randomised, double-blind trials with a placebo control, in order to demonstrate the efficacy of specific probiotic strains when preventing or treating the overweight and obese. In this sense, it is important to highlight that the results obtained in the trials would be specific to the strains analysed, meaning it is not possible to extrapolate the results or action mechanisms to a species or genre as a whole $[4,24]$.

Consequently, much remains to be done in this field. However, when putting everything in perspective, modulating the composition of gut microbiota using probiotics could be considered as a new avenue through which we can treat the overweight and obese [24]. 

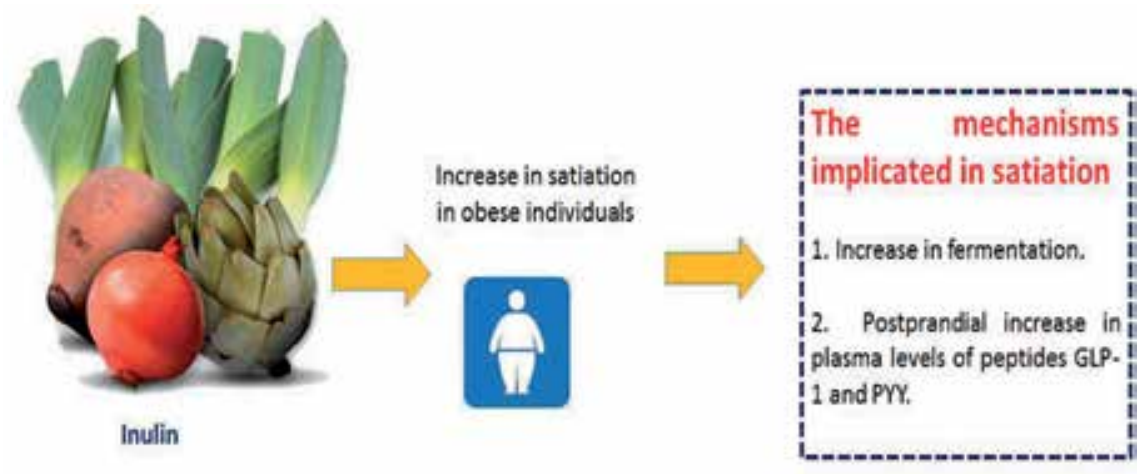

Figure 2.

Mechanisms implicated in the satiety of obese individuals related to inulin consumption.

On the other hand, prebiotics promote the absorption of minerals such as calcium, magnesium, zinc and iron due to their ability to bind to them. This thereby prevents their absorption into the small intestine to reach the colon, where they are released and subsequently absorbed. Better calcium absorption is linked to prebiotic fermentation caused by gut microbiota, which produces short-chain fatty acids and lowers luminal $\mathrm{pH}$, increasing the bioavailability and passive absorption of calcium through colonocytes. It has also been proven that calcium bioavailability is improved when released through hydrolysis of a compound called 'calcium phytate', which occurs due to action of bacterial phytases present in the beneficial microbiota. It is also improved when calcium becomes more soluble as a result of an increase in the volume of water in the colon, caused by the osmotic effect of prebiotics. This increase in calcium absorption is beneficial for bone health as it increases bone mass and delays the onset of osteoporosis. This is important when considering growth periods, during which peak bone mass is reached in postmenopausal women and in elderly people [25].

Prebiotics stimulate iron absorption into the colon, by increasing the soluble fraction in the cells. Zinc is necessary for the development and maturation of the skeleton, and prebiotics stimulate zinc bioavailability. Therefore, mineral is supplemented through the diet. Furthermore, prebiotics are attributed to another set of properties related to particular systemic disorders. Prebiotic carbohydrates (GOS, FOS, inulin) reduce blood pressure, as well as blood levels of glucose, cholesterol, triglycerides and phospholipids, as well as triglyceride and fatty acid synthesis in the liver, minimising the risk of developing diabetes, obesity and atherosclerosis $[25,26]$.

\section{Influence of probiotics in the development of obesity}

The development of obesity is not caused by one specific factor. On the contrary, it is the result of an interaction of genetic, environmental, social, lifestyle factors, etc., which transforms it into a multifactorial disorder, which explains how quickly it has become more prevalent throughout all age groups in developed countries and shows that traditional theories are not adequate to explain the complex phenomenon of gaining body weight [27].

In recent decades and as a result of advances in science, research for 'nontraditional' etiological factors involved in an individual's excessive weight gain has begun [28]. One of these new factors is highlighted in a study on the role of probiotics and their influence on gut microbiota. It should be noted that even now few studies have been carried out on humans to elucidate the effect of these microorganisms on body 
weight, and existing studies still show contradictory results; the available literature arises from findings found in animals (rats) [4].

However, several ways in which probiotics may influence adiposity and weight gain have been identified. These range from extracting calories from nutrients, generating specific metabolites, to modulating the behaviour of the brain-intestine axis [27].

These hypotheses arise from research suggesting that obese individuals have a different composition of gut microbiota to subjects of a normal weight. For example, in people with obesity, they have observed a decrease in members of phylum Bacteroidetes (Prevotella and Bacteroides genera) and an increase in members of phylum Firmicutes (Clostridium, Enterococcus, Lactobacillus). It has been suggested that the aforementioned microorganisms have a greater capacity to extract energy from the undigestible waste products of nutrients that pass through the large intestine. These alterations are normalised with both phyla, when the subjects lose weight (increase of Bacteroidetes and decrease of Firmicutes) [29]. It has been observed that obese and inactive people have greater adiposity and insulin resistance but also less diversity and microbial composition (Figure 3) [4].

A study conducted at Laval University in Canada evaluated the effect of Lactobacillus rhamnosus probiotic (LRP) supplementation on weight reduction, appetite control and eating behaviour in a group of obese men and women. The results showed that, in the group of women, the consumption of this microorganism provides beneficial effects on mood and behaviour linked to dietary intake, compared to the group of men and those who received the placebo. This opens up a series of possibilities for health professionals with regard to the implementation of successful obesity programmes, especially considering that many individuals experience great difficulties when trying to sustain their weight loss. This is mainly due to poor appetite control and not taking the necessary action to lead a healthy lifestyle. Based on the findings of this research, it has been suggested that some probiotic strains could be included as environmental factors with regard to body weight loss and maintenance [27].

Corroborating these findings, a multicentre, randomised, double-blind study conducted on 29 men and 14 women, using the microorganism Lactobacillus gasseri and administered through a probiotic yogurt for 12 weeks, demonstrated, in the individuals analysed, a $4.6 \%$ decrease in areas of abdominal and subcutaneous fat, as well as a decrease in BMI, waist and hip circumference [4].

Nevertheless, and contrary to these results, several investigations using a similar model maintain that administering yogurt with other species of probiotics such as

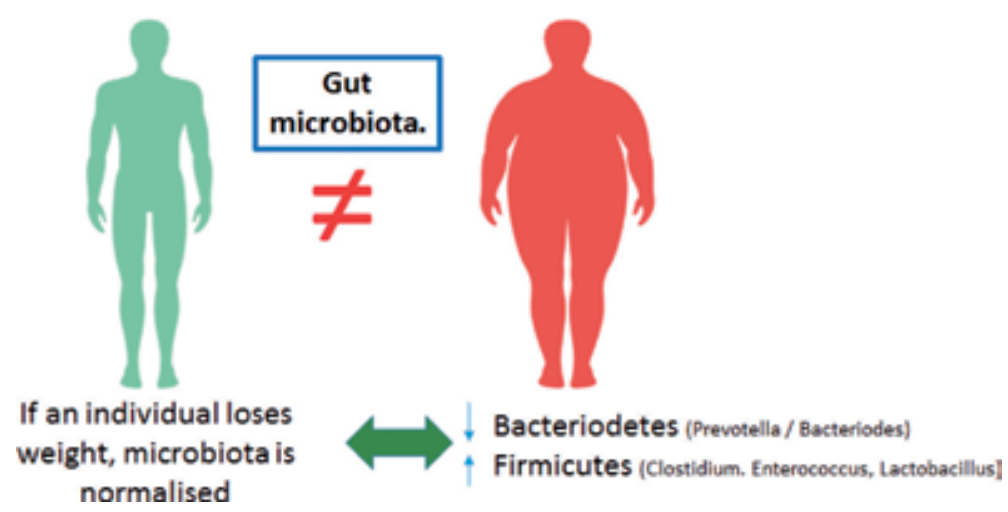

Figure 3.

Gut microbiota imbalance between healthy and obese individuals. 
Bacillus lactis $\mathrm{Bb} 12$ and Lactobacillus acidophilus La5 has no effect on body weight, BMI and serum lipid levels. This is also the case with Streptococcus thermophilus in fermented milk for 8 weeks [4].

As previously mentioned, the impact of consuming probiotics in relation to obesity and a variety of parameters has been widely documented. This is, thanks to studies on rats, used when administering different strains of the Lactobacillus and Bifidobacterium genera; various hypotheses have emerged from these investigations. More specifically, one of these arose from observing axenic mice (without gut microbiota). Despite consuming 30\% more food than conventional animals of the same age and weight, they have $42 \%$ less total body fat. However, once the microbiota from conventional mice was transplanted into the digestive tract of the axenic mice, these latter experienced a $57 \%$ increase in total body fat. The mechanism associated with this increase is linked to the increased activity of the enzyme lipoprotein lipase, which inhibits the fasting-induced adipocyte factor (FIAF) hormone due to the effect of the gut microbiota. This explains why axenic mice do not show weight gain even when consuming a high-calorie diet. Various studies carried out on rats show that the 'antiobesity' effect is determined by differences between microbial species and strains [20].

There is not much research on the effect of probiotics and their relationship with obesity; however, the findings that are available indicate that the changes caused by gut microbiota could be useful as another strategy in the current quest to combat obesity. However, it is necessary to continue researching in this area, with more emphasis on investigations on humans and populations with a representative number of subjects so that results can be valid and extrapolated.

\section{Discussion}

Currently, obesity is a major public health problem worldwide. There is no specific cause that determines the development of this disease; on the contrary, it is the result of numerous factors that interact, including genetic, environmental, food, lifestyles, etc. [27]; however, the study of intestinal microbiota and its implication in obesity has aroused curiosity among scientists. The current information obtained comes mainly from the work done in rats and, exceptionally, in humans [17].

Although much of the research indicates that there are differences in the composition of the intestinal microbiota of obese and normal subjects, there is still controversy about it [4].

As indicated in this chapter, the development of these intestinal bacterial communities depends to a large extent on the host and can be modified by exogenous and endogenous influences. Ghosh et al. in 2011 talked about the direct relationship between food patterns and the microbiota composition [18].

In 2013, Devaraj et al. established the existing association in the imbalance of the microbiota where the composition of this is affected producing an increase of the Firmicutes genus and a decrease of the Bacteroidetes; this instability would affect the metabolism of the human being and as a consequence the appearance of various metabolic diseases among which obesity stands out [21]. In the same way, several publications continue confirming this situation, for example, the study of Jameel Barkat of the year 2018 relates the role of the microbiota in the regulation of energy balance, food absorption and its relationship with the appearance of various diseases: diabetes, metabolic syndrome and obesity, among others [30]. A study was conducted in 36 adults analysing the faecal bacterial composition, finding a decrease in Firmicutes and Clostridia in diabetic patients compared to the control group. This same research reaffirms that among the factors that alter the stability 
and composition of the microbiota are the changes in the diet (high-fat diets) that impact on the relationship between Firmicutes and Bacteroidetes [31].

In order to demonstrate the aforementioned, it is convenient to point out two investigations carried out in 2015; Kasai et al. [32] conducted a study in Japanese population where they observed that bacterial diversity was significantly higher in obese subjects than in nonobese subjects. In the first group, there was a decrease of the Bacteroidetes species and increase of Firmicutes [31]. Angelakis et al. showed in a study performed in thin and obese subjects that the Firmicutes and Actinobacteria genera were the most predominant of the duodenal microbiota; however, in subjects with obesity, a higher proportion of anaerobic and lower proportions of aerobic genus were observed [33].

On the other hand, there are other authors such as Murugesan et al. that indicate in a study carried out in 190 Mexican children between 9 and 11 years old no significant differences between the different bacterial species of microbiota in the different evaluated subjects [34]. The same happens in Hu et al. In 2015, when 134 Korean adolescents from 13 to 16 years old were evaluated, no significant differences were found between the Bacteroidetes, Firmicutes and Proteobacteria populations [35].

It is widely recognised in the scientific community that diets with high-fat content favour the development of resistance to leptin, hyperphagia and therefore obesity. A study points out that the inclusion in the diet of the oligofructose prebiotic prevents the development of resistance to leptin and hyperphagia in rats; from this it is concluded that oligofructose reduces the energy of ingestion, and therefore it is suggested that it has the potential for the obesity treatment [36].

On the other hand, the use of probiotics is associated with multiple health benefits, which are highly endorsed by the scientific community. So far, the data that associate a specific type of microorganisms with human obesity are not conclusive, since they do not say whether it is the microbiota that plays a cause-effect function of obesity or whether it is the intestinal microbiota that is modulated in response to obesogenic diets and other factors related to the pathogenesis of this condition [28-30, 37].

Studies aimed at modulating the gut microbiota to prevent or control the obesity of the host, including the use of probiotics, show positive results [25, 30].

With the reviewed bibliographic evidence, it is crucial to highlight the importance of including the gut microbiota as one of the factors involved in the management of obesity; however, more conclusive information must be analysed about it evaluating what happens even in other specific groups such as the child population.

\section{Conclusions}

As has been discussed in this chapter, multiple factors influence the development of obesity, including diet, a sedentary lifestyle, selection and an inadequate intake of nutrients such as simple carbohydrates and saturated fats. It has also been observed that obese individuals and those of a normal weight have different compositions of gut microbiota, with some bacterial families more predominate than others, which in turn modulates an individual's energy balance in some way and promotes the development of obesity. It has been established that a dietary supply of prebiotics and probiotics, for which there is scientific evidence demonstrating their benefits, could serve as an additional tool to curb the rising trend of obesity in the population.

However, more studies using randomised, double-blind, controlled trials are necessary to demonstrate the efficacy of prebiotics and probiotics for the prevention or treatment of overweight and obesity. 
Gut Microbiota and Obesity: Prebiotic and Probiotic Effects

DOI: http://dx.doi.org/10.5772/intechopen.86672

\section{Acknowledgements}

This work team is made up by academics from the Nutrition and Dietetics Department at the Technological University of Chile, INACAP, Concepción Talcahuano.

\section{Conflict of interest}

The work team declares that it has no conflict of interest of any kind.

\section{Author details}

Silvana Cisternas León*, Paula Carrasco Vergara, Alejandra Cruz Neira, Ricardo Muñoz Maldonado, Carolina Díaz Araneda and Marcia Rivas Zuñiga Escuela de Salud, Universidad Tecnológica de Chile, INACAP, Sede Concepción, Chile

*Address all correspondence to: silvana.cisternas@inacapmail.cl

\section{IntechOpen}

(C) 2019 The Author(s). Licensee IntechOpen. This chapter is distributed under the terms of the Creative Commons Attribution License (http://creativecommons.org/licenses/ by/3.0), which permits unrestricted use, distribution, and reproduction in any medium, provided the original work is properly cited. (cc) BY 


\section{References}

[1] Fernando MB, Santiago MB. La desconcertante epidemia de obesidad. Revista Chilena de Nutricion. 2015;42(1):96-102. Disponible en: https://scielo.conicyt.cl/scielo. php?script=sci_arttext \&pid=S071775182015000100013\&lng=es [citado: October 01 2015]. DOI: 10.4067/ S0717-75182015000100013

[2] WHO. Obesidad y sobrepeso [Internet]. 2018. Available from: http://www.who.int/es/ news-room/fact-sheets/detail/ obesity-and-overweight

[3] Lim JU et al. Comparison of world health organization and Asia-Pacific body mass index classifications in COPD patients. International Journal of Chronic Obstructive Pulmonary Disease. 2017;12:2465

[4] Prados-Bo A, Gómez-Martínez S, Nova E, Marcos A. El papel de los probióticos en el manejo de la obesidad. Nutrición Hospitalaria. 2015;31:10-18

[5] Escobar C, Ángeles-Castellanos M, Espitia Bautista EN, Buijs RM. Food during the night is a factor leading to obesity. Revista Mexicana de Trastornos Alimentarios. 2016;7(1):78-83

[6] Maira PM, Solar AP. Encuesta Nacional de Salud, ENS 2016-2017: Un aporte a la planificación sanitaria y políticas públicas en Chile. Margozzini y Passi. 2018;43(1):30-34

[7] Petermann F, Durán E, Labraña AM, Martínez MA, Leiva AM, GarridoMéndez A, et al. Factores asociados al desarrollo de obesidad en Chile: Resultados de la Encuesta Nacional de Salud 2009-2010. Revista Médica de Chile. 2017;145(6):716-722. Available from: http://www.scielo.cl/scielo. php?script=sci_arttext $\&$ pid $=$ S0034$98872017000600716 \& \operatorname{lng}=$ en $\& \mathrm{nrm}=$ is o\&tlng=en
[8] Rodrigo C, Rut F, Patricio P. Circadian rhythms, eating patterns, and sleep: A focus on obesity. Revista Chilena de Nutricion. 2018;45(3):285-292. Disponible en: https://scielo.conicyt.cl/scielo. php?script $=$ sci_arttext \&pid=S071775182018000400285\&lng=es [citado October 162018$]$. DOI: $10.4067 /$ s0717-75182018000400285

[9] Icaza-Chávez ME. Microbiota intestinal en la salud y la enfermedad. Revista de Gastroenterología de México. 2013;78(4):240-248. DOI: $10.1016 / \mathrm{j}$. rgmx.2013.04.004

[10] Holguín LD, García AM, Lemus K, Ramos A, Sierra GJ, Jiménez M. Microbiota intestinal y sus generalidades en el organismo del ser humano Intestinal microbiota and its generalities in the organism of the human being. Microbiota Biociencias. 2017;1(2):23-31

[11] Castañeda GC. Microbiota intestinal y salud infantil. Revista Cubana de Pediatría. 2017;90(1). Disponible en: http://www.revpediatria.sld.cu/index. $\mathrm{php} / \mathrm{ped} /$ article/view/320) [citado October 8 2018]

[12] Koenig JE, Spor A, Scalfone N, et al. Succession of microbial consortia in the developing infant gut microbiome. Proceedings of the National Academy of Sciences of the United States of America. 2013;108(Suppl 1):4578-4585

[13] Rajilic-Stojanovic M, Heilig HG, Molenaar D, et al. Development and application of the human intestinal tract chip, a phylogenetic microarray: Analysis of universally conserved phylotypes in the abundant microbiota of young and elderly adults. Environmental Microbiology. 2009;11:1736-1751

[14] Suarez Diéguez T, Galván M, López-Rodríguez G, Olivo D, Olvera 
Nájera M. El efecto de la dieta sobre la modulación de la microbiota en el desarrollo de la obesidad. Revista de Salud Pública y Nutrición. 2018;17(1):31-39

[15] Chan YK, Estaki M, Gibson DL. Clinical consequences of diet-induced dysbiosis. Annals of Nutrition \& Metabolism. 2013;63 (Suppl. 2):28-40

[16] Ley RE, Peterson DA, Gordon JI. Ecological and evolutionary forces shaping microbial diversity in the human intestine. Cell. 2006;124:837-848

[17] Castaner O, Goday A, Park YM, Lee SH, Magkos F, Shiow SATE, et al. The gut microbiome profile in obesity: A systematic review. International Journal of Endocrinology. 2018;(1):1-9

[18] Ghosh S, Dai C, Brown K, Rajendiran E, Makarenko S, Baker J, et al. Colonic microbiota alters host susceptibility to infectious colitis by modulating inflammation, redox status, and ion transporter gene expression. American Journal of Physiology. Gastrointestinal and Liver Physiology. 2011;301(1):G39-G49. Available from: http://www.physiology.org/doi/10.1152/ ajpgi.00509.2010

[19] Turnbaugh PJ, Hamady M, Yatsunenko T, Cantarel BL, Duncan A, Ley RE, et al. A core gut microbiome in obese and lean twins. Nature. 2009;457:480-484

[20] Gotteland M. El papel de la microbiota intestinal en el desarrollo de la obesidad y de la diabetes de tipo- 2 . Revista Chilena Endocrinol Diabetes. 2013;6(4):155-162

[21] Devaraj S, Hemarajata P, Versalovic J, Dra Lau L. La microbiota intestinal humana y el metabolismo corporal: Implicaciones con la obesidad y la diabete. Acta Bioquím Clín Latinoam. 2013;47(2):421-434
[22] Ariza-Andraca R, García-Ronquillo M. Cirugía y cirujanos El microbioma humano. Su papel en la salud y en algunas enfermedades. 2016;84:31-35. Available from: www.amc.org.mx

[23] Musso G, Gambino R, Cassader $\mathrm{M}$. Interactions between gut microbiota and host metabolism predisposing to obesity and diabetes. Annual Review of Medicine. 2011;62:361-380

[24] Corzo N, Alonso JL, Azpiroz F, Calvo MA, Cirici M, Leis R, et al. Prebióticos; Concepto, propiedades y efectos beneficiosos. Nutrición Hospitalaria. 2015;31:99-118

[25] Rodríguez JM, Sobrino OJ, Marcos A, Collado MC, Pérez-Martínez G, Martínez-Cuesta MC, et al. ¿Existe Una Relación Entre La Microbiota Intestinal, El Consumo De Probióticos Y La Modulación Del Peso Corporal? Nutrición Hospitalaria. 2013;28(Suppl. 1):3-12

[26] Pamela M, Jerusa B, Martín G. La microbiota intestinal: Un nuevo actor en el desarrollo de la obesidad. Revista Médica de Chile. 2010;138(8):1020-1027. Disponible en: https://scielo.conicyt.cl/scielo. php? script $=$ sci_arttext $\&$ pid $=$ S003498872010000800013\&lng=es [citado: October 08 2018]

[27] Gérard P. Gut microbiota and obesity. Cellular and Molecular Life Sciences. 2016;73(1):147-162

[28] Sanchez M, Darimont C, Panahi S, Drapeau V, Marette A, Taylor $\mathrm{VH}$, et al. Effects of a diet-based weight-reducing program with probiotic supplementation on satiety efficiency, eating behaviour traits, and psychosocial behaviours in obese individuals. Nutrients. 2017;9(3):1-17

[29] Martínez-Cuesta MC, Peláez C, Requena T. Probioticos En la Salud humana. Grupo de Biología Funcional de Bacterias Lácticas. 2012 
[30] Lone JB, Koh WY, Parray HA, Paek WK, Lim J, Rather IA, et al. Gut microbiome: Microflora association with obesity and obesity-related comorbidities. Microbial Pathogenesis. 2018;124:266-271

[31] Ley RE, Turnbaugh PJ, Klein S, Gordon JI. Microbial ecology: Human gut microbes associated with obesity. Nature. 2006;444:1022-1023. DOI: 10.1038/4441022a.nuevo

[32] Kasai C, Sugimoto K, Moritani I, et al. Comparison of the gut microbiota composition between obese and non-obese individuals in a Japanese population, as analyzed by terminal restriction fragment length polymorphism and next-generation sequencing. BMC Gastroenterology. 2015;15(1):100. DOI: 10.1186/ s12876-015-0330-2

[33] Angelakis E, Armougom F, Carrière $\mathrm{F}$, et al. A metagenomic investigation of the duodenal microbiota reveals links with obesity. PLoS ONE. 2015;10(9):e0137784. DOI: 10.1371/ journal.pone.0137784

[34] Murugesan S, Ulloa-Martínez M, Martínez-Rojano H, et al. Study of the diversity and short-chain fatty acids production by the bacterial community in overweight and obese Mexican children. European Journal of Clinical Microbiology \& Infectious Diseases. 2015;34(7):1337-1346. DOI: 10.1007/ s10096-015-2355-4

[35] Hu HJ, Park SG, Jang HB, Choi MG, Park KH, Kang JH, et al. Obesity alters the microbial community profile in Korean adolescents. PLoS ONE. 2015;10(7):e0134333

[36] Abreu-Abreu AT. Prebióticos, probióticos y simbióticos. Revista de Gastroenterología de México. 2012;77:26-28
[37] Baothman OA, Zamzami MA, Taher I, Abubaker J, Abu-Farha M. The role of gut microbiota in the development of obesity and diabetes. Lipids in Health and Disease. 2016;15(1):108 



\section{Edited by Razzagh Mahmoudi}

One of the most prevalent and important health problems in the world is periodontal and plaque-related diseases for which antibiotic drugs with their associated side effects are used as treatment. With increasing resistance to antibiotics and a desire from the general public for "natural" therapies, there is a need to minimize antibiotic use and develop new treatments for oral diseases without antimicrobial agents. Probiotics are viable microorganisms that provide a health benefit to the host when administered in adequate amounts; studies show that probiotics have the potential to modify the oral microbiota and decrease the colony-forming unit counts of the oral pathogens being investigated to prevent or treat oral diseases, such as dental caries and the periodontal

diseases. In addition, the identification of specific strains with probiotic activity is required for any oral infectious disease to determine the exact dose, the time of treatment, and the ideal vehicle. 